\title{
Evaluation Design Recommendations for the Certified Community Behavioral Health Clinic Demonstration Program
}

Joshua Breslau, J. Scott Ashwood, Courtney Ann Kase, Harold Alan Pincus, Susan L. Lovejoy 
For more information on this publication, visit www.rand.org/t/rr1439

Library of Congress Cataloging-in-Publication Data is available for this publication.

ISBN: 978-0-8330-9564-0

Published by the RAND Corporation, Santa Monica, Calif.

(C) Copyright 2016 RAND Corporation

RAND $^{\circledR}$ is a registered trademark.

\section{Limited Print and Electronic Distribution Rights}

This document and trademark(s) contained herein are protected by law. This representation of RAND intellectual property is provided for noncommercial use only. Unauthorized posting of this publication online is prohibited. Permission is given to duplicate this document for personal use only, as long as it is unaltered and complete. Permission is required from RAND to reproduce, or reuse in another form, any of its research documents for commercial use. For information on reprint and linking permissions, please visit www.rand.org/pubs/permissions.html.

The RAND Corporation is a research organization that develops solutions to public policy challenges to help make communities throughout the world safer and more secure, healthier and more prosperous. RAND is nonprofit, nonpartisan, and committed to the public interest.

RAND's publications do not necessarily reflect the opinions of its research clients and sponsors.

Support RAND

Make a tax-deductible charitable contribution at www.rand.org/giving/contribute

www.rand.org 
Section 223 of the Protecting Access to Medicare Act of 2014 (Public Law 113-93) authorized a demonstration program aimed at improving the accessibility and quality of community-based behavioral health care through creation of an innovative clinic model, known as a Certified Community Behavioral Health Clinic. The Office of the Assistant Secretary for Planning and Evaluation (ASPE), in collaboration with the Substance Abuse and Mental Health Services Administration and the Centers for Medicare and Medicaid Services, will conduct an evaluation of the demonstration.

ASPE contracted with RAND to provide information on the availability of data sources pertinent to the evaluation of the Certified Community Behavioral Health Clinic demonstration, input on the research questions to be addressed in the evaluation, and suggested study designs to address the research questions. This evaluation design report includes those findings, suggested research questions and study designs, and cost and burden estimates for various evaluation options.

This work was sponsored by ASPE under contract HHSP23320095649WC, for which Christie Peters serves as project officer. The research was conducted in RAND Health, a division of the RAND Corporation. A profile of RAND Health, abstracts of its publications, and ordering information can be found at www.rand.org/health. 


\section{Contents}

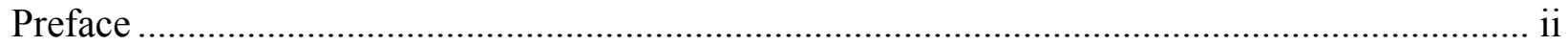

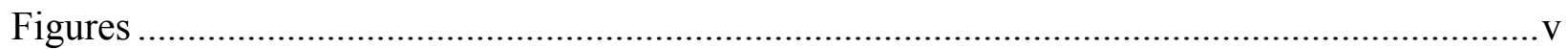

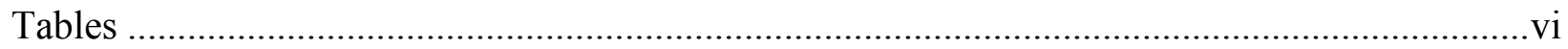

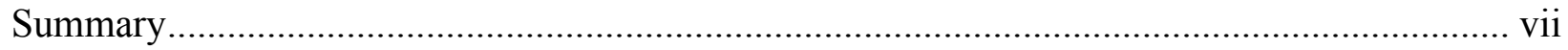

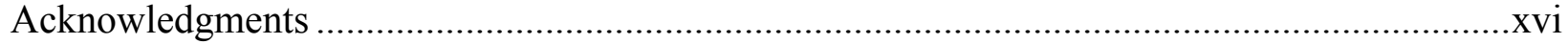

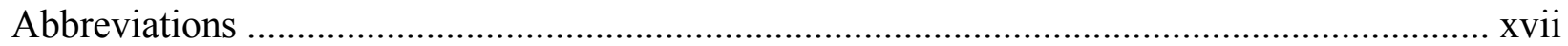

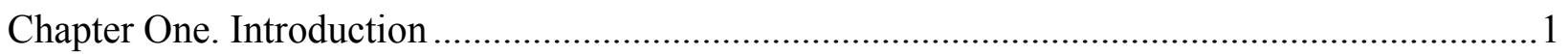

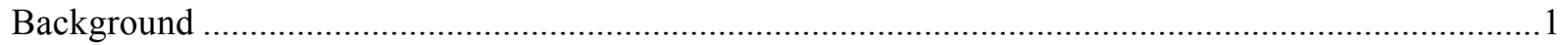

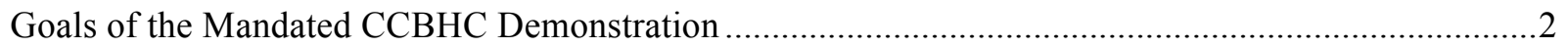

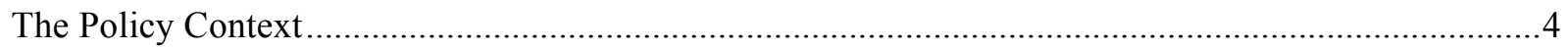

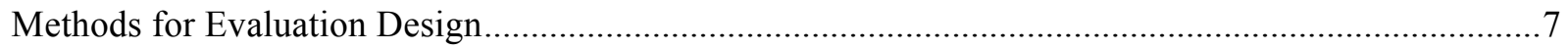

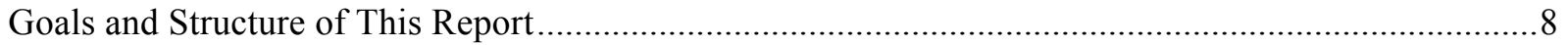

Chapter Two. Evaluation Research Questions ..................................................................... 9

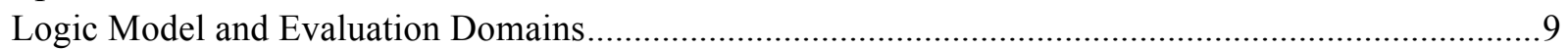

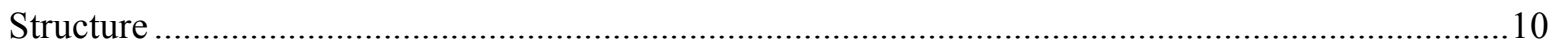

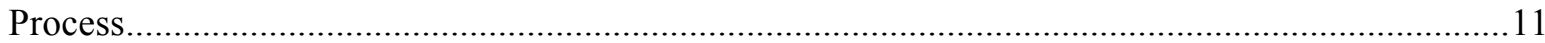

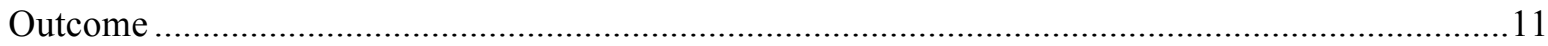

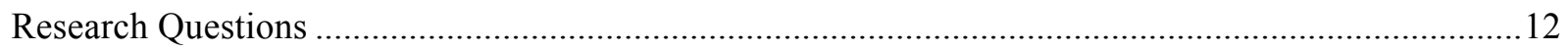

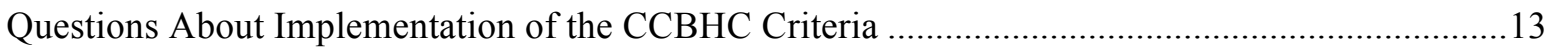

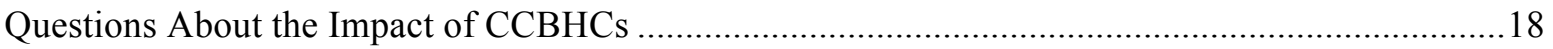

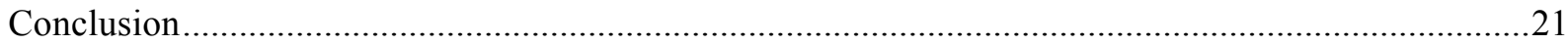

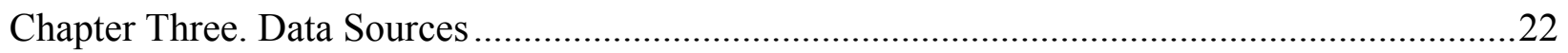

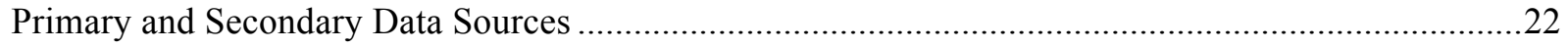

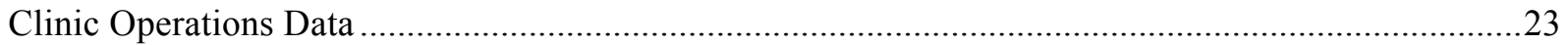

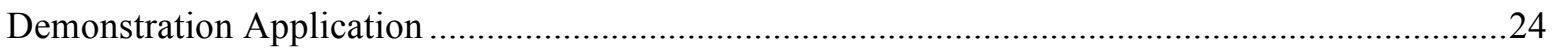

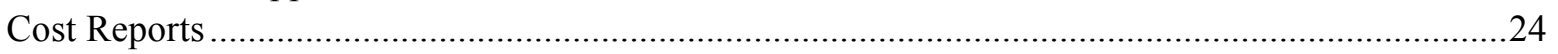

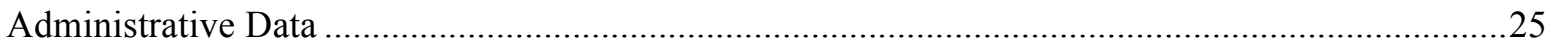

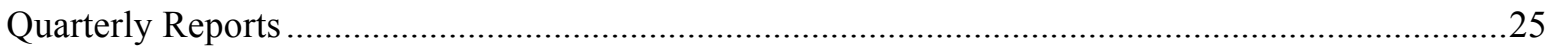

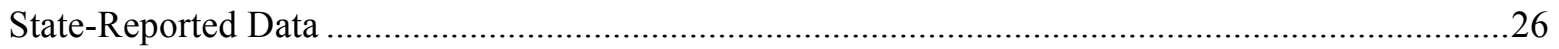

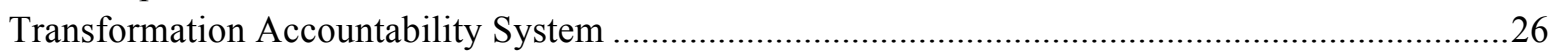

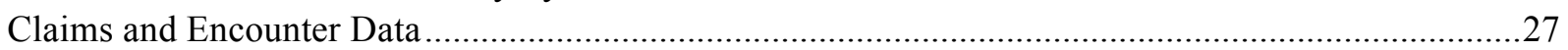

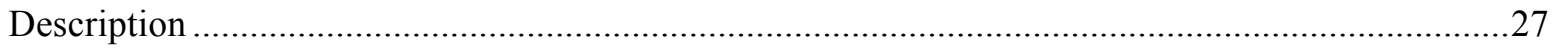

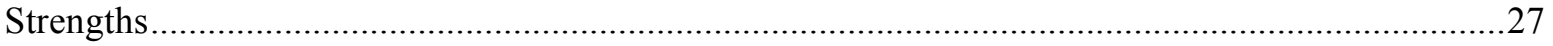

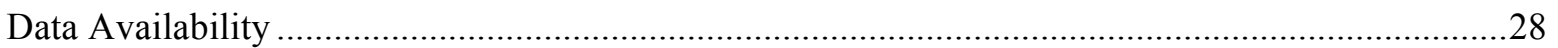

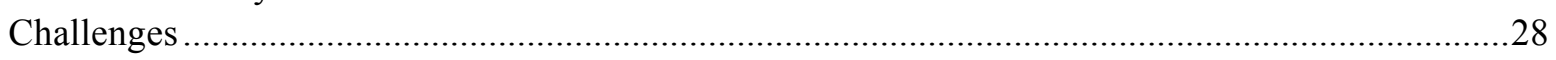

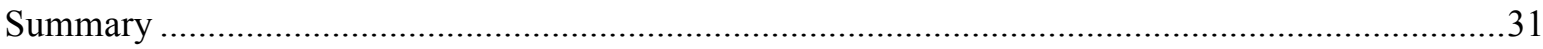

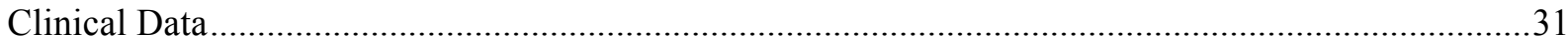

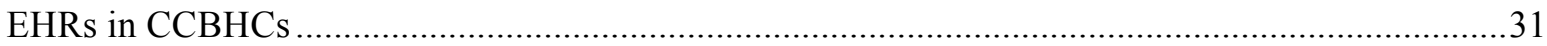

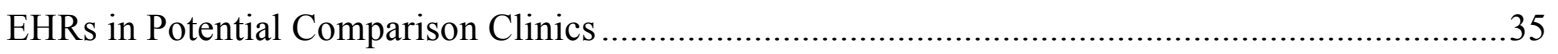

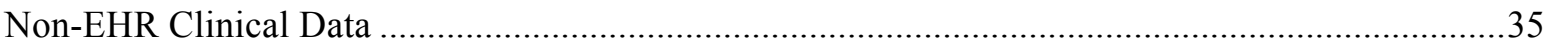

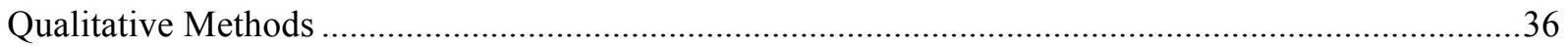




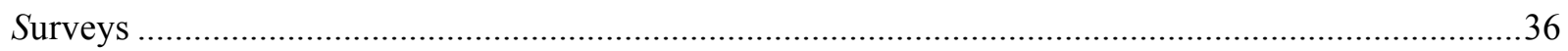

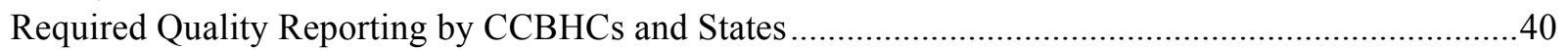

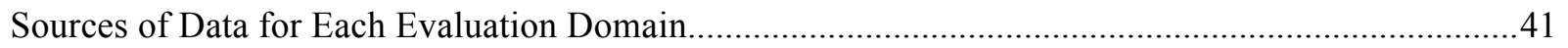

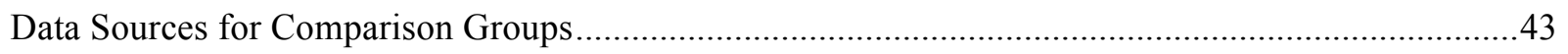

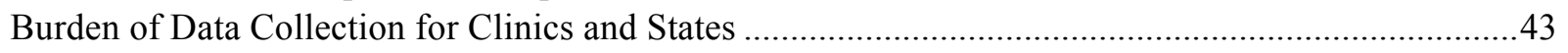

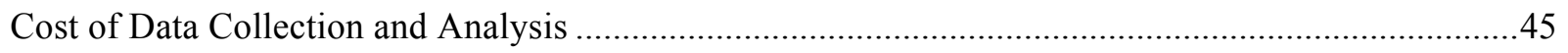

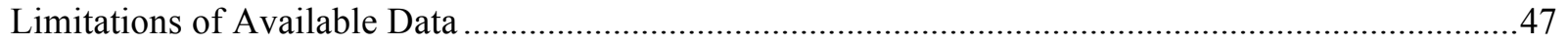

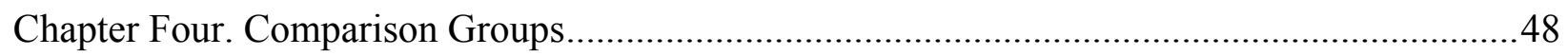

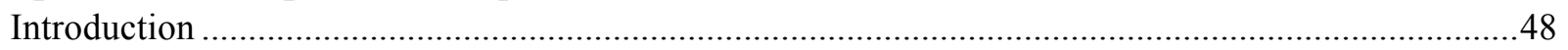

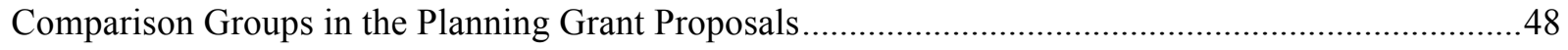

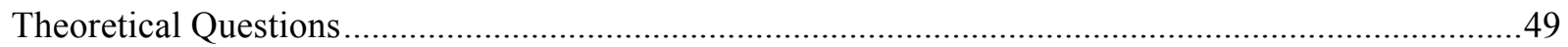

What Is The Right Level Of Analysis For Assessing The Impact Of CCBHCs? ............................49

With What Type of Clinical Setting Should CCBHCs Be Compared? .............................................50

What Is The Best Analytic Model For Assessing The Impact Of CCBHCs? ...................................51

How Can The Two Payment Mechanisms, PPS-1 and PPS-2, Be Compared With Each Other? ......51

How Can The Scope Of Services, Including Nonmedical Supportive Services Provided By CCBHCs, Be Compared With That Provided In Other Clinics?.................................................52

Can Existing Data Collected By States On Mental Health And Substance Use Disorder Services Be

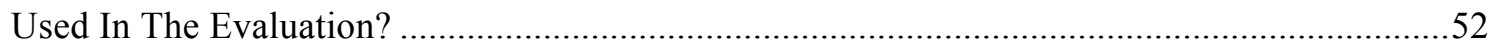

What Data Sources Can Be Used To Compare CCBHCs With Community-Based Mental

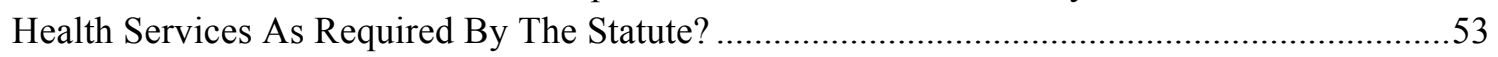

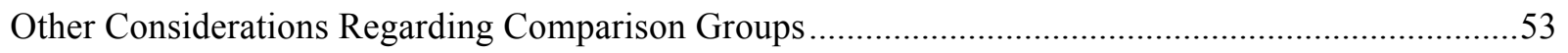

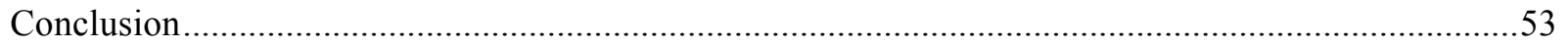

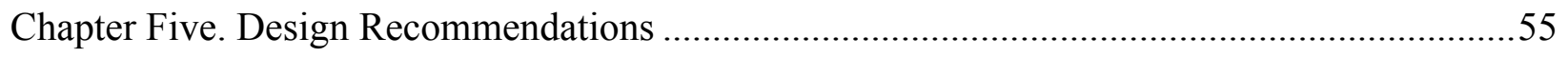

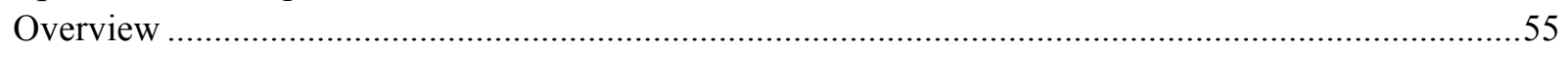

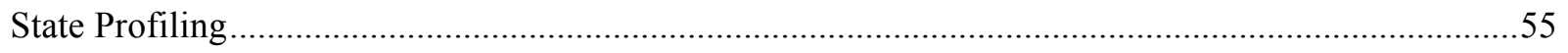

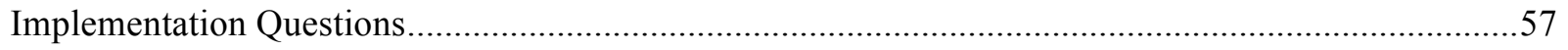

Description of CCBHC Implementation Using Existing Data ..................................................60

Description of CCBHC Implementation Using Supplemental Data..............................................61

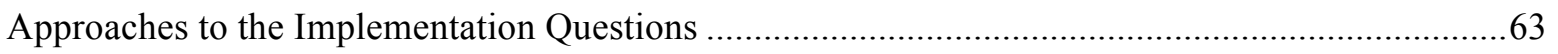

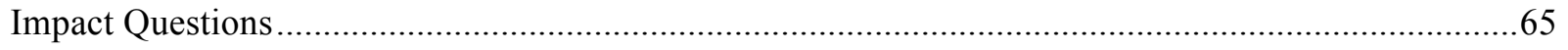

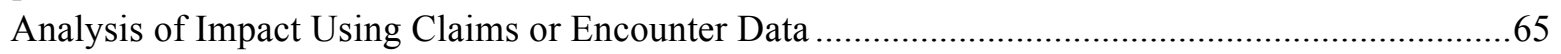

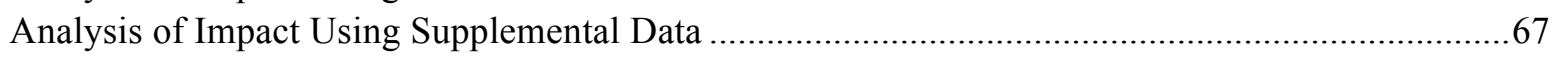

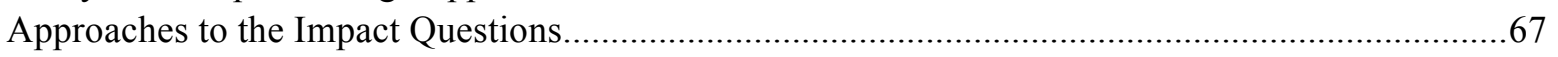

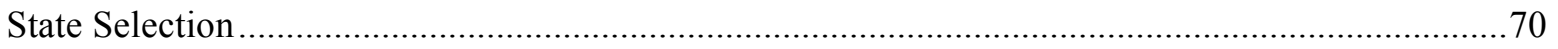

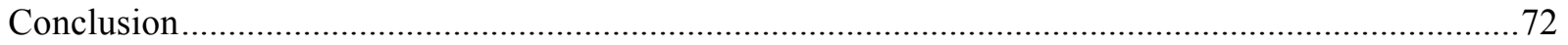

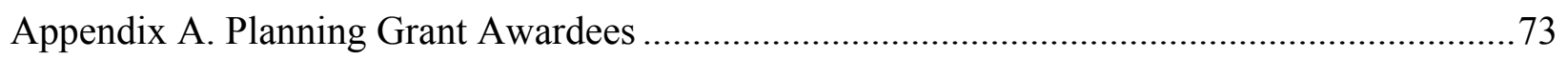

Appendix B. Required Quality Measures............................................................................. 74

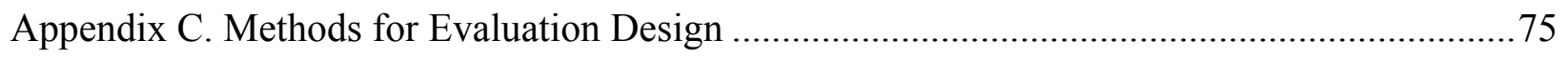

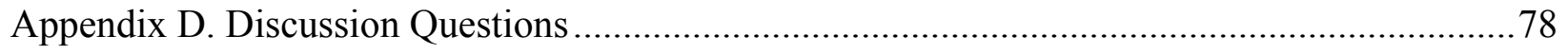

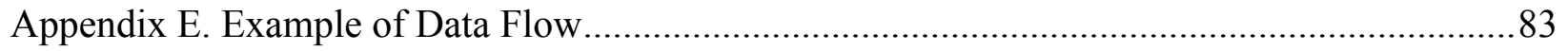

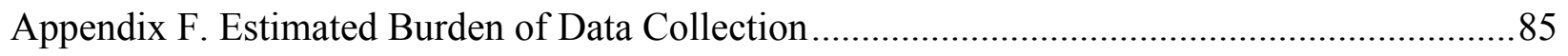

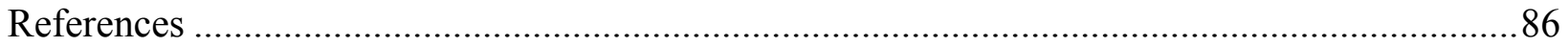




\section{Figures}

Figure S.1. CCBHC Logic Model ................................................................................ viii

Figure 1.1. CCHBC Planning and Implementation Timeline .....................................................2

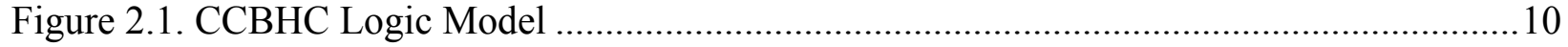

Figure E.1. Flow of Medicaid Encounter Data in a Single State with FFS

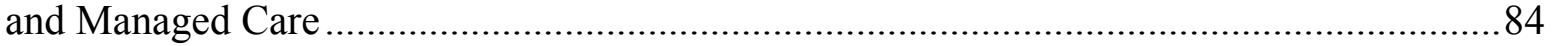




\section{Tables}

Table S.1. Evaluation Data Sources, by Domain ...................................................................

Table S.2. Coverage of Implementation Questions by Core and Supplemental

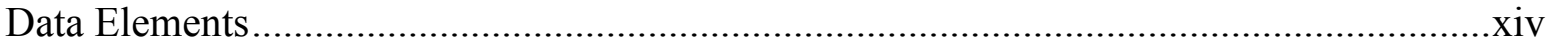

Table S.3. Sources of Data for Addressing Impact Research Questions......................................xv

Table 1.1. Planning Grant States' Participation in Medicaid Expansion and

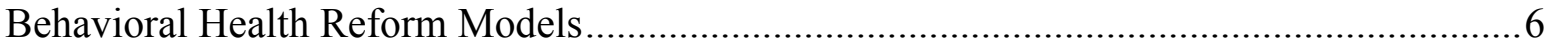

Table 3.1. Existing Data Sources for Evaluation, by Domain.....................................................23

Table 3.2. Medicaid Managed Care Penetration Rate, by State, 2015, as Percentages..................30

Table 3.3. EHR Adoption from the State Mental Health Agency Profiling System, 2015 ............32

Table 3.4. Agreements Allowing EHR Patient-Level Data-Sharing from State Mental

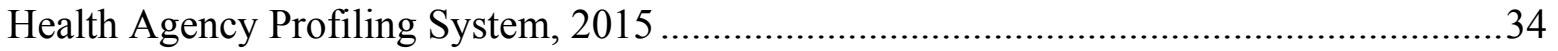

Table 3.5. Grantee State Administration of the MHSIP Adult Consumer Surveys from

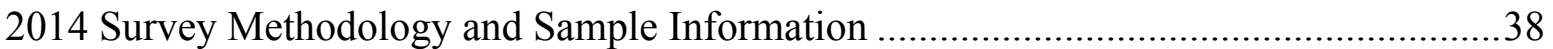

Table 3.6. Required Quality Measures and Potential Supplemental Measure Content Areas for CCBHC- and State-Level Reporting ..............................................................41

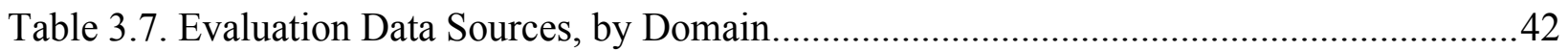

Table 3.8. Potential Data Collection Burden for CCBHCs and Comparison Clinics for Evaluation Data Source Options..............................................................................45

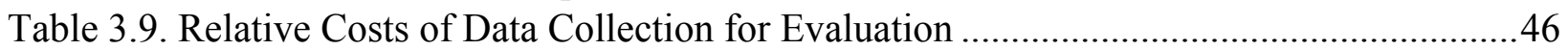

Table 4.1. State-Suggested Comparison Group Selection Methods..............................................49

Table 5.1. Sources of Data for Addressing Implementation Research Questions..........................57

Table 5.2. Coverage of Implementation Questions by Core and Supplemental

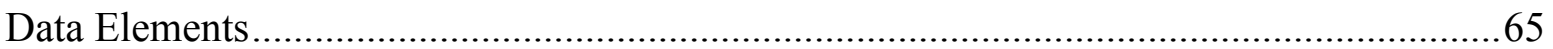

Table 5.3. Sources of Data for Addressing Impact Research Questions ......................................68

Table A.1. States Awarded Planning Grants and Grant Amounts, in Dollars................................73

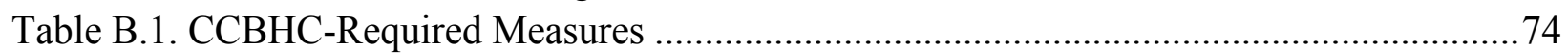

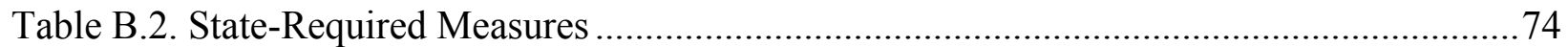

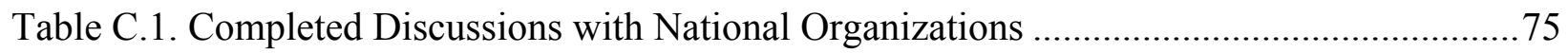

Table C.2. Completed Discussions with State Officials..............................................................76

Table F.1. Estimated Burden Hours for Potential New Data Collection.........................................85 


\section{Summary}

This report aims to provide information and recommendations regarding the evaluation design of the Certified Community Behavioral Health Clinic (CCBHC) demonstration. Mandated by Congress in Section 223 of the Protecting Access to Medicare Act of 2014 (Public Law 113-93), the CCBHC is a new model of specialty behavioral health clinic, designed to provide comprehensive and integrated care for adults with mental health or substance use disorders and children with serious emotional distress. Certification criteria for the CCBHCs have been specified by the Substance Abuse and Mental Health Services Administration covering six core areas: staffing; accessibility; care coordination; scope of services; quality and other reporting; and organizational authority, governance, and accreditation. In addition, services provided to Medicaid enrollees in CCBHCs will be reimbursed through one of two alternative prospective payment systems. At present, 24 states have been awarded grants to begin the planning process for implementing CCBHCs. Of these states, eight will be selected to participate in the demonstration project beginning in January 2017. Results from the evaluation will inform mandated reports to Congress over the two-year demonstration period and the three years following the end of the demonstration.

To inform this report, the RAND team conducted a series of key informant interviews with representatives from national advocacy organizations and state mental health officials and reviewed the planning grant applications. The interviews covered the priority research questions and the specific data sources available for evaluation purposes. Two important lessons for the evaluation design emerged from these interviews. First, enormous disparity exists across states in the availability of data that could potentially inform the CCBHC evaluation, including variability in Medicaid claim data, other human services utilization data, and health and social functioning outcomes data. This variability across states will present challenges and opportunities to the evaluation, but the specific data sources available at the state level will be known only after the demonstration states have been selected. Second, the CCBHCs are being implemented at a time when multiple service delivery innovations that target the same or overlapping patient populations are being tested. Other models being tested share some of the same goals as the CCBHCs, such as improving integration between mental health and substance use treatment and integration of behavioral health and general medical care. The evaluation of the CCBHC demonstration project will be more relevant to this complex policy context to the extent that it can provide evidence of the program's performance relative to other innovative service delivery models.

\section{Logic Model and Evaluation Domains}

The evaluation design is guided by a logic model of the CCBHC that has six linked domains ordered according to Donabedian's structure-process-outcome model for assessing quality of care (Donabedian, 1980, 1982, 1988) (Figure S.1). The CCBHC structures are the model 
components explicitly required by the legislation. These model structures are intended to directly improve access to a broader scope of evidence-based behavioral health care services and enhance the quality of services provided in specialty behavioral health clinics. If successful, these direct effects are expected to have positive downstream impacts on utilization of health care, including inpatient stays and emergency department (ED) utilization, the health and social functioning of consumers treated in CCBHCs, and costs of care to Medicaid and the clinics.

Figure S.1 CCBHC Logic Model

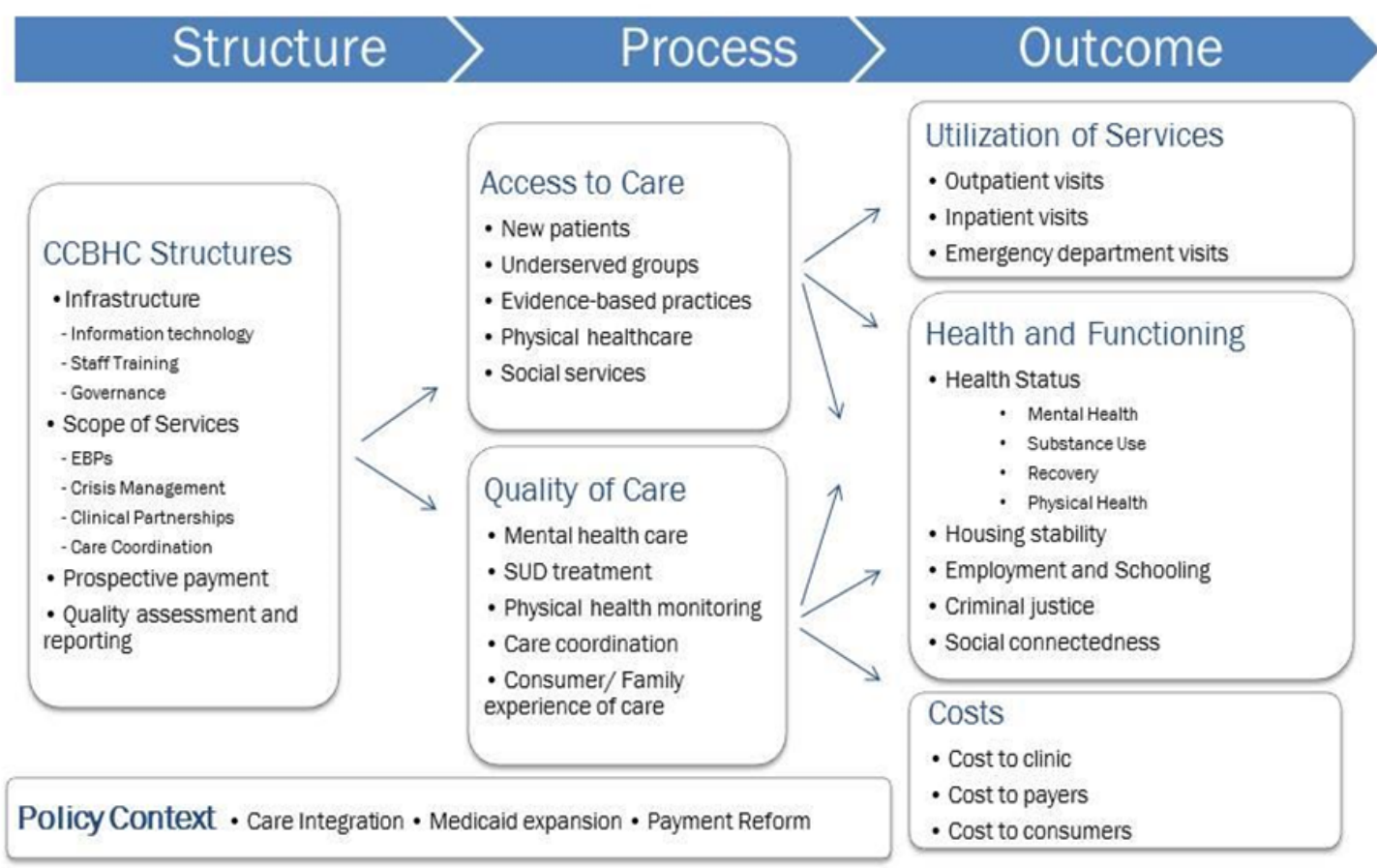

SOURCE: Authors' analysis.

\section{Research Questions}

The logic model can guide identification of the research questions for the evaluation, which can be divided into two types: implementation questions and impact questions. Implementation questions will address the ways in which the model is realized in practice, including barriers to implementation that might affect outcomes, with a particular emphasis on those aspects of structure meant to have a direct effect on access to and quality of care. Examples of implementation questions include the following:

- What types of behavioral health services, including care management and coordination, do CCBHCs offer?

- How do CCBHCs establish and maintain formal and informal relationships with other providers?

- How do CCBHCs respond to prospective payment systems? 
- How do states establish and maintain prospective payment rates?

- How do CCBHCs attempt to improve access to care?

- How do clinics collect, report, and use information to improve quality of care?

- How do states collect, report, and use information on quality of care?

Impact questions will address the effect that the CCBHC model has on processes and outcomes of care, relative to existing delivery models. Examples of impact questions include the following:

- Relative to comparison groups, do CCBHCs expand access to behavioral health care?

- Relative to comparison groups, do CCBHCs improve the quality of behavioral health care?

- Relative to comparison groups, do CCBHCs improve patterns of total health care utilization?

- Relative to comparison groups, do CCBHCs improve consumers' health and functioning outcomes?

- Relative to comparison groups, do CCBHCs impact federal and state costs for behavioral health services?

\section{Data Sources}

Three major sources of data to address the research questions were identified. First, information on the implementation of the CCBHC model will be generated as part of the functioning of the program, i.e., without imposing any additional data collection burden on the CCBHCs. These sources include documentation of compliance with the certification criteria as part of the application process for the demonstration, required quality measure reporting from the $\mathrm{CCBHCs}$ and the states, and cost reports. Second, the evaluation can collect additional data on implementation of the $\mathrm{CCBHC}$ model using a range of methods, including quarterly reports (QRs) from CCBHCs, surveys of providers, or qualitative studies of selected CCBHCs. These sources can be used to elaborate the description of how the CCBHCs were implemented, providing important details on change over time and strategies for overcoming implementation barriers. Third, data from Medicaid claims or encounters covered by managed care payments can be analyzed to address the evaluation's impact questions. The availability and suitability of these data are likely to vary dramatically across states, but they provide a uniquely valuable source of information and are a requirement for state participation in the demonstration. They are particularly valuable because they provide information on comparison groups and CCBHCs. In addition to claims or encounter data, some states have other data sources on consumer outcomes or service utilization that can be useful to the evaluation, although the existence of such data sets will not be known until the demonstration states are selected.

Table S.1 summarizes our conclusions regarding the availability of data for each evaluation domain. As shown in the table, all of the evaluation domains are at least in part covered by the four major sources of existing data: the certification process conducted by states (as reported in the applications for the demonstration or obtained directly from states), clinical data derived 
from electronic health records (EHRs) (including the required quality measures and Mental Health Statistics Improvement Program [MHSIP] surveys), claims and encounter records, and cost reports. These sources have the potential to provide a robust description of CCBHC implementation in the demonstration states. However, these data sources are highly variable in format and detailed content across states and across providers and payers within states. Some states already have sophisticated, integrated data systems that can create uniform, detailed, and reliable data on clinic performance, but most states are not yet at that point. In addition, state data systems are in flux, with new capabilities being added frequently. The quality and timing of data also vary depending on whether a consumer is covered under Medicaid fee-for-service, a managed care organization (MCO), or some combination of the two. Fee-for-service claims have the advantage of being more complete and accessible, because they are publicly adjudicated, but MCO encounter data can be available more quickly and better suited to analysis of quality of care, which MCOs are already likely to be assessing. The evaluation design will need to take these variations into account in assessing the potential use of data sources in each demonstration state.

Gaps in the reporting requirements with respect to structure could be filled through strategically targeted new data collection efforts, which would most likely include additional structured reporting of operational data by CCBHCs, surveys of providers, and qualitative investigations of specific operational issues. Additional electronic health record-based quality measures could be requested from CCBHCs, provided that the additional reporting burden is minimal, and additional quality measures could be specified when the evaluation has access to the claims or encounter data. Data collection and reporting systems put in place for the reporting required by the demonstration could be expanded to include additional instruments to minimize costs and burden. 
Table S.1. Evaluation Data Sources, by Domain

\begin{tabular}{|c|c|c|c|c|c|c|}
\hline Data Source & Structure & Access & Quality & Utilization & Costs & $\begin{array}{l}\text { Health and } \\
\text { Functioning }\end{array}$ \\
\hline $\begin{array}{l}\text { Existing clinic } \\
\text { operations data }\end{array}$ & $\begin{array}{l}\text { Demonstration } \\
\text { application }\end{array}$ & - & $\begin{array}{l}\text { Demonstration } \\
\text { application }\end{array}$ & CRs & CRs & $\begin{array}{c}\text { Transformation } \\
\text { Accountability } \\
\text { System, } \\
\text { National } \\
\text { Outcome } \\
\text { Measures }\end{array}$ \\
\hline $\begin{array}{l}\text { New clinic } \\
\text { operations data }\end{array}$ & QRs & QRs & - & - & QRs & - \\
\hline $\begin{array}{l}\text { Existing claims and } \\
\text { encounter data }\end{array}$ & - & $\begin{array}{l}\text { Required } \\
\text { measures }\end{array}$ & $\begin{array}{l}\text { Required } \\
\text { measures }\end{array}$ & $\begin{array}{l}\text { Required } \\
\text { measures }\end{array}$ & $\begin{array}{l}\text { Required } \\
\text { measures }\end{array}$ & - \\
\hline $\begin{array}{l}\text { New } \\
\text { claims/encounter } \\
\text { data }\end{array}$ & - & $\begin{array}{l}\text { Additional } \\
\text { measures }\end{array}$ & $\begin{array}{l}\text { Additional } \\
\text { measures }\end{array}$ & $\begin{array}{l}\text { Additional } \\
\text { measures }\end{array}$ & $\begin{array}{l}\text { Additional } \\
\text { measures }\end{array}$ & - \\
\hline $\begin{array}{l}\text { Existing clinical } \\
\text { data }\end{array}$ & - & $\begin{array}{c}\text { EHRs/ } \\
\text { quality } \\
\text { measure }^{a}\end{array}$ & $\begin{array}{c}\text { EHRs/ } \\
\text { quality } \\
\text { measures }\end{array}$ & $\begin{array}{c}\text { EHRs/ } \\
\text { quality } \\
\text { measure }^{b}\end{array}$ & - & $\begin{array}{c}\text { EHRs/ } \\
\text { quality } \\
\text { measure }^{c}\end{array}$ \\
\hline New clinical data & - & $\begin{array}{l}\text { EHRs/ } \\
\text { additional } \\
\text { measures }\end{array}$ & $\begin{array}{l}\text { EHRs/ } \\
\text { additional } \\
\text { measures }\end{array}$ & $\begin{array}{c}\text { EHRs/ } \\
\text { additional } \\
\text { measures }\end{array}$ & - & $\begin{array}{l}\text { EHRs/ } \\
\text { additional } \\
\text { measures }\end{array}$ \\
\hline Existing surveys & - & $\begin{array}{c}\text { MHSIP } \\
\text { Consumer } \\
\text { and Family }\end{array}$ & $\begin{array}{c}\text { MHSIP } \\
\text { Consumer } \\
\text { and Family }\end{array}$ & - & - & $\begin{array}{l}\text { MHSIP, quality } \\
\text { measure }^{d}\end{array}$ \\
\hline New surveys & $\begin{array}{l}\text { Provider and } \\
\text { clinic survey }\end{array}$ & $\begin{array}{l}\text { Provider and } \\
\text { clinic survey }\end{array}$ & $\begin{array}{l}\text { Provider and } \\
\text { clinic survey }\end{array}$ & - & - & - \\
\hline $\begin{array}{l}\text { New qualitative } \\
\text { data }\end{array}$ & $\begin{array}{l}\text { Interviews, } \\
\text { site visits }\end{array}$ & Site visits & $\begin{array}{l}\text { Consumer } \\
\text { focus groups }\end{array}$ & - & Site visits & - \\
\hline
\end{tabular}

SOURCE: Authors' analysis.

NOTE: $C R=$ cost report

${ }^{a}$ Each clinic must report a measure of timely access to care.

${ }^{\mathrm{b}}$ Each clinic must report a measure of hospital readmissions.

${ }^{c}$ Each clinic must report a measure of depression remission.

${ }^{d}$ Each state must report one measure of housing status for $\mathrm{CCBHC}$ clients.

\section{Data Sources for Comparison Groups}

Collection of data for comparison purposes presents additional challenges. To assess the impact of the CCBHC model, the services received by consumers in a CCBHC should be compared with services that similar consumers received in other clinical settings. Clinical data and claims and encounter data are likely to be available for comparison purposes for the evaluation, provided that an appropriate comparison group can be identified in the relevant data 
set. For EHR-based measures, this requires that comparison clinics be found with EHRs that can produce measures to the same specifications, likely adding substantial burden to the evaluation. For claims and encounter data, this requires that states or MCOs have place-of-service codes or provider identifiers that will allow them to reliably attribute consumers to specific clinics. In fact, several states are using their planning grants to put such systems in place.

Collection of operational and survey data from comparison sites presents more serious challenges. Some states already might have systematic reporting by CMHCs that could be used to provide data comparable to that collected for CCBHCs, but those systems are even more variable across states than the claims and encounter data systems. Some clinics in some states already might be reporting similar data to SAMHSA because they are participating in another federal program. Existing consumer survey data, which exist in the majority of states, offer another potential source of comparison data, but sampling methods vary across states and might not provide appropriate controls without specific adjustments for that purpose. There is no alternative to investigating these potential data sources on a state-by-state basis. New data collection efforts at comparison clinics are feasible, but likely to be costly.

\section{Burden of Data Collection}

Assessing the burden posed by data collection is a critical component of evaluation design and a requirement of the Office of Management and Budget in certain circumstances. The evaluator must weigh the benefit of new data collection by CCBHCs, and potential comparison sites, against the burden on clinic staff and the resulting quality of the data. If providing data beyond the demonstration requirements is very burdensome on participating clinic staff, then they are less likely to put in the effort needed to ensure complete or valid data. This is especially a concern for comparison sites because they do not face the same incentives to produce even the data required of participating sites by the demonstration.

The largest burden would likely result from a request for EHR-based measures from CCBHCs or comparison clinics if they are not currently reporting those measures. The burden of additional EHR-based quality measures would depend on the CCBHCs' ability to specify them within their systems. In some cases, reporting on an additional measure could be a relatively simple change to make, but the same measure might not be easily reported in other cases. Likewise, collecting the data from comparison clinics will depend on the EHR systems in those clinics, which can be less sophisticated technologically than the CCBHCs'. Additional burden would be imposed on CCBHCs should the evaluation require quarterly reports, a consumer survey other than the MHSIP, a provider survey, provider interviews, or site visits. Ideally, the

evaluator would collect analogous information from comparison sites, but doing so might require some type of incentives offered by the state or the evaluator.

\section{Limitations of Available Data}

Our exploration of data sources also identified two important gaps that can limit the evaluation in significant ways. First, while the PAMA intends to have population-level impacts on access to behavioral health care, data to support population-based measures of access are 
lacking. It might be possible to link data from clinic records to population data from the census on the areas that the CCBHCs are designed to serve. However, the population of untreated seriously mentally ill adults is likely to be poorly tracked in the census data and highly mobile across catchment areas. Second, data on use of nonmedical social services also are lacking. Many consumers can also receive services, such as temporary housing, which are funded through state or local services. Lack of more comprehensive data on service use is concerning because of the possibility of shifting care between providers. For instance, consumers who are receiving services from locally funded providers can instead opt to receive those services from a CCBHC, where they will be funded through Medicaid. In the absence of data on the locally funded services, this shift in payer will appear to be an increase in utilization.

\section{Selection of Comparison Groups}

Addressing the impact questions will require the selection of comparison groups from within each of the demonstration states, against which the performance of the CCBHCs can be assessed. The evaluation will have a number of options in selecting appropriate groups, such as whether to select comparisons at the clinic level or the individual consumer level. Constraints of the available data and the nature of the mental health systems in the demonstration states will need to be investigated to inform these decisions. Comparison groups should be selected so that the findings can be interpreted with respect to well-understood existing models of care. The states awarded a CCBHC planning grant already have specified potential comparison groups in their grant applications and are working on refining these plans during the planning grant period. In developing a detailed strategy for addressing the impact questions, the evaluation will need to assess and refine these analytic recommendations from the states. The evaluation can elect to focus on a subset of states to address particular impact questions, based on the assessment of the value of the available data.

\section{Design Recommendations}

Based on the findings in this report, we recommend that the evaluation of the $\mathrm{CCBHC}$ demonstration project have three components. First, the evaluation should compile profiles of the mental health systems in each of the demonstration states. The state profiles will include information on the current delivery models, which might serve as informative comparison groups, and the data sources available in the state that could be used for the evaluation. Second, the implementation questions can be addressed through a mix of existing data sources and supplemental data collection efforts (Table S.2). The existing data can be summarized systematically across states to provide a basic description of how the CCBHC model was implemented. However, supplemental data collection can add considerable depth to those descriptions. The particular selection of supplemental data collection efforts will be guided in part by the state profiles. The specific methods used will depend on the budget for the evaluation and the need to minimize the burden of the evaluation on the CCBHCs. 
Table S.2. Coverage of Implementation Questions by Core and Supplemental Data Elements

\begin{tabular}{|c|c|c|}
\hline Research Question & Core Data Element & Supplemental Data Element \\
\hline $\begin{array}{l}\text { What types of behavioral health services, } \\
\text { including care management and } \\
\text { coordination, do CCBHCs offer? }\end{array}$ & $\begin{array}{l}\text { Description of services } \\
\text { and staffing }\end{array}$ & $\begin{array}{l}\text { Challenges of providing services; } \\
\text { factors influencing selection of } \\
\text { services; change in services } \\
\text { over time. }\end{array}$ \\
\hline $\begin{array}{l}\text { How do CCBHCs establish and maintain } \\
\text { formal and informal relationships with other } \\
\text { providers? }\end{array}$ & $\begin{array}{l}\text { Description of relationships } \\
\text { with designated collaborating } \\
\text { organizations }\end{array}$ & $\begin{array}{l}\text { Relationships with network of } \\
\text { community providers; data-sharing } \\
\text { agreements; referral tracking }\end{array}$ \\
\hline $\begin{array}{l}\text { How do CCBHCs respond to } \\
\text { prospective payment systems? }\end{array}$ & $\begin{array}{l}\text { Submitted claim or encounter } \\
\text { data and CRs }\end{array}$ & $\begin{array}{l}\text { Administrators' and clinicians' } \\
\text { perspectives; accounts of } \\
\text { operational impact }\end{array}$ \\
\hline $\begin{array}{l}\text { How do states establish and maintain } \\
\text { prospective payment rates? }\end{array}$ & $\begin{array}{l}\text { Analyses supporting } \\
\text { rate-setting and revision }\end{array}$ & Policymakers' perspectives \\
\hline $\begin{array}{l}\text { How do CCBHCs attempt to improve } \\
\text { access to care? }\end{array}$ & $\begin{array}{l}\text { Policies as described } \\
\text { in the certification process; } \\
\text { timeliness of care as } \\
\text { described in quality } \\
\text { measures }\end{array}$ & $\begin{array}{l}\text { Outreach efforts; clinical } \\
\text { processes for tracking access; } \\
\text { barriers to increasing access }\end{array}$ \\
\hline $\begin{array}{l}\text { How do clinics collect, report, and use } \\
\text { information to improve quality of care? }\end{array}$ & $\begin{array}{l}\text { Extent of reporting of required } \\
\text { measures }\end{array}$ & $\begin{array}{l}\text { Use of data to improve quality; } \\
\text { monitoring of quality beyond } \\
\text { required measures }\end{array}$ \\
\hline $\begin{array}{l}\text { How do states collect, state-specific } \\
\text { report, and use information on } \\
\text { quality of care? }\end{array}$ & $\begin{array}{l}\text { Extent of reporting of required } \\
\text { measures }\end{array}$ & $\begin{array}{l}\text { Use of data to improve quality; } \\
\text { monitoring of quality beyond } \\
\text { required measures }\end{array}$ \\
\hline
\end{tabular}

SOURCE: Authors' analysis.

Third, the impact questions can be addressed primarily through analysis of the claims and encounter data, with additional information drawn from cost reports or, potentially, other state specific data sets (Table S.3). The specific comparisons drawn to examine the impact of the model and the statistical approach taken to the analysis will depend in part on the state profiles. 
Table S.3. Sources of Data for Addressing Impact Research Questions

\begin{tabular}{|c|c|c|c|}
\hline Impact Question & $\begin{array}{l}\text { Claims/ } \\
\text { Encounters }\end{array}$ & CR & $\begin{array}{l}\text { Other } \\
\text { State } \\
\text { Data }\end{array}$ \\
\hline $\begin{array}{l}\text { Relative to comparison groups, do CCBHCs expand } \\
\text { access to behavioral health care? }\end{array}$ & $\checkmark$ & - & $\checkmark$ \\
\hline $\begin{array}{l}\text { Relative to comparison groups, do CCBHCs improve } \\
\text { the quality of behavioral health care? }\end{array}$ & $\checkmark$ & - & $\checkmark$ \\
\hline $\begin{array}{l}\text { Relative to comparison groups, do CCBHCs improve } \\
\text { patterns of total health care utilization? }\end{array}$ & $\checkmark$ & - & - \\
\hline $\begin{array}{l}\text { Relative to comparison groups, do CCBHCs improve } \\
\text { consumers' health and functioning outcomes? }\end{array}$ & - & - & $\checkmark$ \\
\hline $\begin{array}{l}\text { Relative to comparison groups, do CCBHCs affect the } \\
\text { costs of care from the state and federal perspectives to } \\
\text { clinics and consumers? }\end{array}$ & $\checkmark$ & $\checkmark$ & - \\
\hline
\end{tabular}

SOURCE: Authors' analysis.

The proposed design guidelines are flexible, allowing for considerable tailoring of the methods to the evaluation budget while focusing on a set of core components that will provide information for reports to Congress. The evaluation can be efficient, making maximum use of existing data to reduce costs, timely, and relevant to the complex contemporary policy context. However, some new data collection efforts will be required to explore important issues affecting implementation of the model over time. Results of the evaluation will provide a strong basis for the mandated reports to Congress and the ultimate recommendations to continue, discontinue or modify the model. 


\section{Acknowledgments}

We thank Emily Jones and Judy Dey, project officers for this task, from the Office of Disability, Aging and Long-Term Care Policy within the Office of the Assistant Secretary for Planning and Evaluation for their valuable guidance and feedback throughout the project. We also are grateful to Carrie Farmer and Justin Timbie of RAND for their careful reviews and constructive comments that served to strengthen this report. 


\section{Abbreviations}

ACA Patient Protection and Affordable Care Act

$\mathrm{ACO}$

accountable care organization

ASPE

Office of the Assistant Secretary for Planning and Evaluation

$\mathrm{CCBHC}$

Certified Community Behavioral Health Clinic

$\mathrm{CMHC}$

community mental health center

CMHS

Center for Mental Health Services

CMS

Centers for Medicare and Medicaid Services

CR

cost report

DASA

Department of Substance Abuse

$\mathrm{DCO}$

designated collaborating organization

DD

difference in differences

$\mathrm{DMH}$

department of mental health

DSA

department of substance abuse prevention

EBP

evidence-based practice

ED

emergency department

EHR

electronic health record

FFS

fee-for-service

FQHC

Federally Qualified Health Center

HHS

U.S. Department of Health and Human Services

HIE

health information exchange

MAX

Medicaid Analytic Extract

$\mathrm{MCO}$

managed care organization

MHSIP

Mental Health Statistics Improvement Program

MMIS

Medicaid Management Information System

NOM

National Outcome Measure

NQF

National Quality Forum

$\mathrm{ONC}$

Office of the National Coordinator of Health Information Technology 


$\begin{array}{ll}\text { PAMA } & \text { Protecting Access to Medicare Act of } 2014 \\ \text { PPS } & \text { prospective payment system } \\ \text { PPS-1 } & \text { prospective payment system-1 } \\ \text { PPS-2 } & \text { prospective payment system-2 } \\ \text { QR } & \text { quarterly report } \\ \text { RQM } & \text { required quality measure } \\ \text { SAMHSA } & \text { Substance Abuse and Mental Health Services Administration } \\ \text { SED } & \text { serious emotional disturbance } \\ \text { SMHA } & \text { state mental health agency } \\ \text { SMI } & \text { serious mental illness } \\ \text { SQM } & \text { supplemental quality measure } \\ \text { SUD } & \text { substance use disorder } \\ \text { TEDS } & \text { Treatment Episodes Data Set } \\ \text { TRAC } & \text { Transformation Accountability System } \\ \text { URS } & \text { Uniform Reporting System }\end{array}$




\section{Chapter One. Introduction}

\section{Background}

Section 223 of the Protecting Access to Medicare Act of 2014 (PAMA) (Public Law 113-93) mandates a demonstration aimed at testing the ability of an innovative clinic model, known as a Certified Community Behavioral Health Clinic (CCBHC), to improve the accessibility and quality of community-based behavioral health care. The $\mathrm{CCBHC}$ will be distinctive as a clinic model defined by a common federal standard, a broad scope of services, required monitoring of quality-of-care measures, and a cost-based prospective payment system (PPS). Twenty-four states were awarded one-year planning grants in October 2015 by the Substance Abuse and Mental Health Services Administration (SAMHSA) to support infrastructure development and preparation of applications for the demonstration project. ${ }^{1}$ Out of the 24 states awarded planning grants, eight will be selected for the two-year demonstration near the end of 2016. CCBHCs in those states have the flexibility for launching the demonstration in the first six months of 2017.

An evaluation of the CCBHCs will provide critical information to Congress and other policymakers regarding the future of the program. RAND was contracted to support the Office of the Assistant Secretary for Planning and Evaluation (ASPE) in the design of the CCBHC evaluation by investigating priority evaluation research questions, data sources to address those questions, and potential evaluation designs. For this purpose, the RAND team conducted a series of key informant discussions with officials in federal government agencies with oversight over the $\mathrm{CCBHC}$ demonstration project, representatives of national organizations active in mental health policy, and officials in state governments who have received CCBHC planning grants. This report describes the results of those discussions and presents our recommended guidelines for the design of the CCBHC evaluation.

Figure 1.1 shows a detailed timeline for the planning grants, demonstration, and required reporting to Congress. The states selected for the demonstration are expected to begin implementation within the first six months of 2017, and the demonstration will last for two years in each state. The first annual report to Congress will be due no later than one year after the first state is selected, likely the end of 2016. The annual reports will continue to be submitted to Congress after the end of the demonstration, with the final report submitted by December 31 , 2021 , as required by statute. This evaluation time frame will be required in order to incorporate data on Medicaid claims and encounters that typically become available only after a considerable time lag for processing.

\footnotetext{
${ }^{1}$ Planning grant proposals included budgets of up to $\$ 2$ million, as was stated in the Request for Proposals, but awards ranged from $\$ 728,054$ to $\$ 982,373$ (see Appendix A).
} 
Figure 1.1 CCHBC Planning and Implementation Timeline

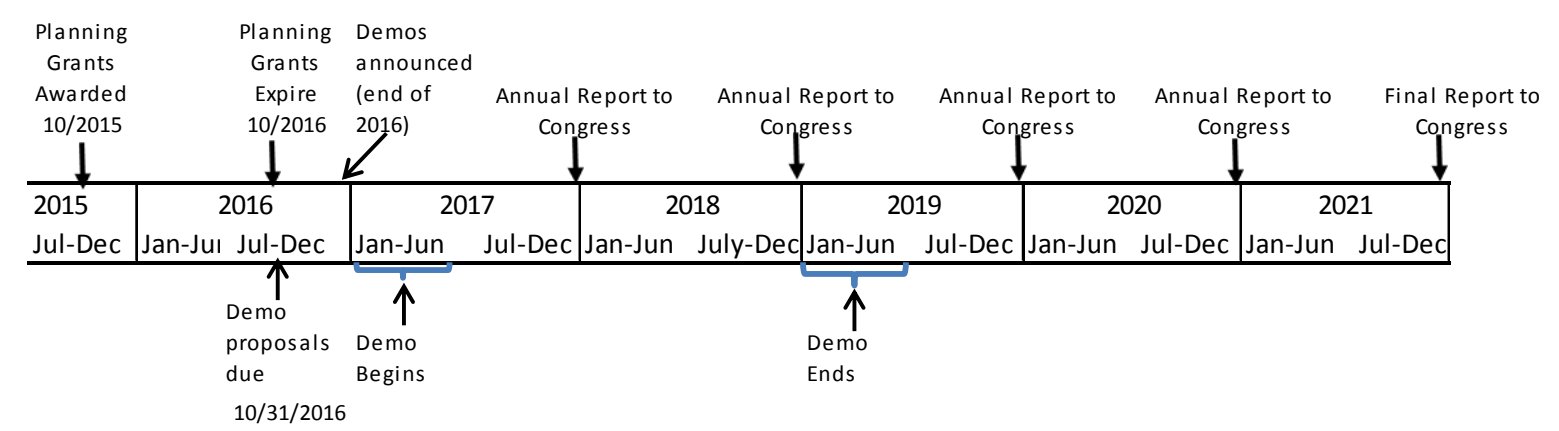

SOURCE: Authors' analysis.

\section{Goals of the Mandated CCBHC Demonstration}

The legislation enabling the CCBHC demonstration (PAMA, Section 223) was motivated by a desire to increase access to high-quality coordinated behavioral health services, particularly for adults with serious mental illness (SMI), children with serious emotional disturbance (SED), and those with long-term and serious substance use disorders (SUDs). CCBHCs are meant to provide community-based mental health and substance use services, advance integration of behavioral health and physical health care, and consistently utilize evidence-based practices (EBPs) (SAMHSA, 2015a). The statute specifies six categories of criteria for certifying CCBHCs, including staffing, availability and accessibility of services, care coordination, scope of services, quality reporting, and organizational authority. Within each of these categories, SAMHSA established explicit criteria for certification (SAMHSA, 2015a), and states were given the authority to certify CCBHC sites utilizing these standards. A broad overview of the criteria follows:

- Staffing: Must have credentialed, certified, and licensed professionals with training in person-centered, family-centered, trauma-informed, culturally competent, and recoveryoriented care.

- Access: Must have accessibility and availability at times and places convenient to consumers; prompt intake and engagement in services; consumer choice in treatment planning and services; clearly established relationships with local emergency departments (EDs) to facilitate care coordination; use of peer, recovery, and clinical supports in the community; and increased access through telehealth or telemedicine and mobile in-home supports.

- Care coordination: Must have communication and collaboration between CCBHC staff and medical or other service providers in the community to address consumer needs and preferences through partnerships or formal contracts with Federally Qualified Health Centers (FQHCs), inpatient psychiatric facilities, other community or regional services or providers, the Department of Veterans Affairs facilities, inpatient acute care hospitals, and hospital outpatient clinics. A health information technology system that has the 
capability to capture consumer demographics, diagnoses, and medication lists and provides clinical decision support and electronic prescribing is also required.

- Scope of services: Must provide directly or through referrals or formal relationships with other providers a broad array of services, including crisis mental health services; screening, assessment, and diagnosis; must have patient-centered treatment planning; outpatient mental health and substance use services; outpatient clinic primary care screening and monitoring of key health indicators; targeted case management; psychiatric rehabilitation services; peer support and counseling services and family supports; and intensive mental health services for service members, reservists, and veterans.

- Quality and other reporting: Must have the collection, annual reporting and tracking of encounter, outcome, and quality data on consumer characteristics; access to services; use of services; screening, prevention, and treatment; care coordination; other processes of care; costs; and consumer outcomes. CCBHCs are required to report 12 measures, and states are required to report nine, primarily claims-based, measures. A complete list of required measures is provided in Appendix B.

- Organizational authority, governance, and accreditation: Must maintain data-driven continuous quality improvement plans; have an annual financial audit; adhere to applicable state accreditation, certification, and/or licensing agreements; and have boards or governing bodies representative of the individuals being served.

The legislation also aims to align Medicaid reimbursement with the cost of providing services through a cost-based PPS. States participating in the demonstration will be able to choose between one of two PPS models, both designed to incentivize high-quality care while allowing providers the flexibility to provide the diverse array of medical and supportive services needed by the target population. The first, prospective payment system-1 (PPS-1), pays a preset amount for each day that a Medicaid beneficiary visits a CCBHC for care. The second, prospective payment system-2 (PPS-20), pays a preset amount for each month in which a Medicaid beneficiary has at least one visit at a CCBHC. There are several additional features to the payment system required for PPS-2 but optional for PPS-1, including adjusted payments for patient characteristics, outlier payments for high-cost patients, and a quality bonus payment to clinics meeting performance standards on a set of quality measures. The quality measures and the potential for a bonus payment are meant to encourage the provision of quality care and prevent skimping on care under the new prospective payment model. Finally, the statute authorizes the Centers for Medicare and Medicaid Services (CMS) to pay the states participating in the demonstration an enhanced federal match for CCBHC services provided to Medicaid beneficiaries. $^{2}$

The selection of states for the demonstration will be based on the goals established in PAMA (below), and the legislation requires that the states selected represent a diverse selection of geographic areas, including rural and underserved areas.

\footnotetext{
2 The match rate for CCBHC services is either the Enhanced Federal Medical Assistance Percentage/Children's Health Insurance Program rate or, for newly eligible Medicaid beneficiaries, the current Federal Medical Assistance Percentage for that population_-which currently is 100 percent and moves down to 90 percent by 2020.
} 


\section{Criteria for Selecting Demonstration States}

- Provide the most complete scope of services as described in the previously noted criteria for certification to individuals eligible for medical assistance under the state Medicaid program

- Improve availability of, access to, and participation in services described in the previously noted criteria for certification to individuals eligible for medical assistance under the state Medicaid program

- Improve availability of, access to, and participation in assisted outpatient mental health treatment in the state

- Demonstrate the potential to expand available mental health services in a demonstration area and increase the quality of such services without increasing net federal spending.

PAMA requires the Secretary of Health and Human Services to submit annual reports that assess the performance of the CCBHCs on access to community-based mental health services under the Medicaid program; the quality and scope of services delivered; and the impact on federal and state costs across mental health services delivered in inpatient, emergency, and ambulatory settings. Additionally, the legislation requires that access to care in areas of a state targeted by participating CCBHCs be compared with access in other parts of the state. Furthermore, the quality and scope of services must be compared with nonparticipating community mental health centers (CMHCs) within the state or in states not participating in the demonstration.

\section{The Policy Context}

This new model for care and payment for behavioral health is being introduced amid rapid change in major structural features of the mental health system, such as Medicaid expansion and mental health parity, and concurrent with state and federal implementation of a range of innovations in integrated behavioral health delivery and payment, such as health homes, accountable care organizations (ACOs), and primary care and behavioral health integration models. For several reasons, it is critical that the evaluation take into account both the structural changes in the system and the new models of care. First, to identify the effects of CCBHCs, the evaluation will need to understand the context in each state included in the demonstration. Second, it will be important for policymakers to understand the relative value of the CCBHC model compared to other models of care. Next, we briefly discuss each of these trends.

The Patient Protection and Affordable Care Act (ACA) (Public Law 111-148, 2010) provides for federally subsidized expanded Medicaid enrollment and strengthens requirements that insurance plans cover mental health care and substance abuse treatment as two of the ten required essential health benefits (Buck, 2011; Mechanic, 2012; Beronio, Glied, and Frank, 2014). In addition, the ACA encourages implementation of integrated models of care for 
behavioral health, such as health homes, as well as changes in the payment mechanisms, such as bundled or episodic payments (Mechanic, 2012). Medicaid enrollment has expanded as states have responded to the incentives in the ACA. Thirty-two states and the District of Columbia have expanded Medicaid, and additional states are considering expansion (Henry J. Kaiser Family Foundation, 2016). This has led to an increase of 14.9 million in total Medicaid enrollment nationwide (CMS, 2016). In addition to increased enrollment, Medicaid now covers more behavioral health care services as a result of the parity requirements of the ACA and the earlier Mental Health Parity and Addiction Equity Act (Public Law 110-343, 2008). Because health plans are no longer allowed to deny coverage based on preexisting conditions, including mental health and SUDs, more people with these conditions are able to find coverage (Mechanic, 2012; Beronio, Glied, and Frank, 2014). Collectively, these changes could have a significant impact for people with mental health disorders, with an estimated 3.7 million with severe mental illnesses gaining access to care (Mechanic, 2012). Increased coverage is expected to lead to increased utilization of mental health treatment services and improved outcomes (Busch et al., 2013; Beronio, Glied, and Frank, 2014; Mark et al., 2015).

The expansion of Medicaid coverage for SUDs and the requirement of parity in benefits for newly eligible beneficiaries are likely to change the way that treatment is delivered and paid for (Buck, 2011). Major changes expected include the consolidation, professionalization, and integration of providers - replacing a decentralized system relying on small specialty providers with a system in which treatment is provided through centralized, certified specialists and integrated with mental and physical health providers (Buck, 2011). Payment for many substance use services will shift from grant funding to Medicaid fee-for-service (FFS). These changes likely will have an impact on utilization, spending, and outcomes for SUDs.

In addition to expanding coverage, the ACA has encouraged implementation of patientcentered models of care and integration of physical and behavioral health care for individuals with mental health and SUDs (Alakeson, Frank, and Katz, 2010; Buck, 2011; Bao, Casalino, and Pincus, 2013; Mechanic, 2012). There are other innovative integrated care and payment models currently in use. The ACA encourages states to offer health home options in their Medicaid plans for management of serious chronic conditions, including SMI, through federal matching funds. The health home model allows reimbursement for providers who manage care and use health information technology to coordinate care among medical and nonmedical community service providers. Health homes are often based in CMHCs. Nineteen states have approved Medicaid health homes, although not all of these are designed for people with mental health or substance abuse disorders (Mechanic, 2012; CMS, 2014). ACOs are another potential vehicle for integrating behavioral and physical health care, and an increasing number of states are encouraging integration through Medicaid ACO models (Center for Health Care Strategies, 2015). Currently, there are four methods to encourage integration, which include requiring ACOs to pay for behavioral health services, utilizing behavioral health quality metrics, requiring the inclusion of behavioral health providers, and offering support for integration through datasharing (Center for Health Care Strategies, 2015).

Experimentation also is under way to improve the coordination of care for Medicare and Medicaid enrollees (dual eligibles). For example, there currently are 13 states participating in the 
Center for Medicare and Medicaid Innovation's Financial Alignment Initiative, which seeks to better integrate primary, acute, behavioral health and long-term services and supports and tests two new payment models to encourage coordination (Centers for Medicare and Medicaid Innovation, 2016).

Table 1.1 illustrates participation in these initiatives and models among the $24 \mathrm{CCBHC}$ planning grant states. Nearly every state is affected by these changes, and some state and CMHCs are participating in multiple initiatives.

\section{Table 1.1. Planning Grant States' Participation in Medicaid Expansion and Behavioral} Health Reform Models

\begin{tabular}{|c|c|c|c|c|}
\hline State & $\begin{array}{c}\text { Medicaid } \\
\text { Expansion (a) }\end{array}$ & $\begin{array}{l}\text { Health Home State } \\
\text { Plans That Include } \\
\text { Behavioral Health } \\
\text { Conditions (b) }\end{array}$ & $\begin{array}{l}\text { Medicaid ACOs } \\
\text { with Behavioral } \\
\text { Health Providers } \\
\text { (c) }\end{array}$ & $\begin{array}{l}\text { CMS Financial } \\
\text { Alignment Initiative } \\
\text { (d) }\end{array}$ \\
\hline Alaska & $x$ & - & - & - \\
\hline California & $x$ & - & - & $x$ \\
\hline Colorado & $x$ & - & - & - \\
\hline Connecticut & $x$ & - & - & - \\
\hline Illinois & $x$ & - & $x$ & $x$ \\
\hline Indiana & $x$ & - & - & - \\
\hline lowa & $x$ & $x$ & - & - \\
\hline Kentucky & $x$ & - & - & - \\
\hline Maryland & $x$ & $x$ & - & - \\
\hline Massachusetts & $x$ & - & - & $x$ \\
\hline Michigan & $x$ & - & - & $x$ \\
\hline Minnesota & $x$ & - & $x$ & $x$ \\
\hline Missouri & - & $x$ & - & - \\
\hline Nevada & $x$ & - & - & - \\
\hline New Jersey & $x$ & - & - & - \\
\hline New Mexico & $x$ & - & - & - \\
\hline New York & $x$ & $x$ & - & $x$ \\
\hline North Carolina & - & - & - & - \\
\hline Oklahoma & - & - & - & - \\
\hline Oregon & $x$ & $x$ & $x$ & - \\
\hline
\end{tabular}




\begin{tabular}{lcccc}
\hline & $\begin{array}{c}\text { Mealth Home State } \\
\text { Plans That Include } \\
\text { Behavioral Health } \\
\text { Conditions (b) }\end{array}$ & $\begin{array}{c}\text { Medicaid ACOs } \\
\text { with Behavioral } \\
\text { Health Providers } \\
\text { (c) }\end{array}$ & $\begin{array}{c}\text { CMS Financial } \\
\text { Alignment Initiative } \\
\text { (d) }\end{array}$ \\
\hline Pennsylvania & $\mathrm{X}$ & - & - & - \\
Rhode Island & $\mathrm{X}$ & $\mathrm{X}$ & - & $\mathrm{X}$ \\
Texas & - & - & - & $\mathrm{X}$ \\
Virginia & - & - & - & $\mathrm{X}$ \\
\hline
\end{tabular}

SOURCES: (a) Henry J. Kaiser Family Foundation, 2016; (b) CMS, 2014; (c) Centers for Health Care Strategies, 2015; (d) Centers for Medicare and Medicaid Innovation, 2016.

Finally, individual states might have important initiatives under way that impact delivery and payment for behavioral health services. For example, New York's Delivery System Reform Incentive Payment Program, a Medicaid Section 1115 waiver demonstration, offers incentives to provider groups (Performing Provider Systems) to improve care and reduce costs for Medicaid patients and the uninsured.

Understanding that CCBHCs will be operating not in isolation but rather in a very complex and rapidly changing environment is critical to the selection of research questions, comparison groups, and analytic methods.

\section{Methods for Evaluation Design}

To develop options for the evaluation design, we relied primarily on key informant interviews with representatives from nine national organizations and representatives from Medicaid and mental health officials from nine states. Supplemental data were collected from a review of existing data sets and relevant literature, and the proposals submitted by states for the CCBHC planning grants. We used information gathered from these sources to better understand the availability of data for the evaluation and develop the research questions. Our evaluation design recommendations were informed by RAND expertise in evaluation methodology. For additional detail on methods, see Appendix C. Discussion items are included in Appendix D.

Key informant interviews:

- Discussions with national organizations. Organizations were selected for specific expertise in policy analysis and knowledge of data usage in public mental health settings. Discussions focused on the current state of health information technology, claims and encounter data timeliness, quality reporting, the proposed scope of services for CCBHCs, and other topics as relevant.

- Discussions with state Medicaid and mental health officials. Information from past key informant discussions and the planning grant proposals were used to identify states for interviews regarding their specific procedures for collecting and analyzing data on public mental health services for possible CCBHC evaluation use. 
Supplemental sources of information:

- Review of existing data sets and literature. Available information on states' and community providers' current infrastructure and systems was gathered to help inform current capacity to participate in CCBHC demonstration and evaluation data collection.

- Review of planning grant proposals. The proposals that states submitted to SAMHSA for a CCBHC planning grant include descriptions of the data sources that the states aim to use to meet the reporting requirements of the $\mathrm{CCBHC}$ demonstration, as well as preliminary plans for collecting data on a comparison group for the evaluation. These proposals are useful because they describe existing systems of quality reporting, state plans for collecting data on CCBHCs, and state plans for selecting comparison groups for the $\mathrm{CCBHC}$ evaluation. However, they are limited because the information presented was not verified and they were prepared for the purpose of obtaining grant funding.

\section{Goals and Structure of This Report}

This report describes the research questions, data sources, and potential research designs that might be employed to evaluate the $\mathrm{CCBHC}$ demonstration project, with the ultimate aim of providing evidence to Congress, other policymakers, and stakeholders on its impact and value.

The remainder of the report is divided into four chapters. Chapter Two presents a logic model for the CCBHC, a heuristic showing hypothesized causal links between the intervention and its targeted outcomes. The logic model introduces the five key evaluation domains. We then set out the major research questions for each of the five domains. Two types of questions are presented: implementation questions concerning how the CCBHC model was implemented in practice and impact questions concerning the impact of the model, which can require comparisons with a control group to answer. Chapter Three reviews the data sources that could be used in the evaluation to address the research questions. The discussion includes consideration of the time frame in which the data are likely to become available, the feasibility of collecting them and the associated burden for states and clinics, and the cost of the data to the evaluation. Chapter Four addresses the issue of comparison groups in greater detail. We compare and contrast a range of options, including those proposed by the states in their initial applications for the planning grants. Chapter Five draws on the preceding chapters to discuss a range of options for the design of the evaluation. 


\section{Chapter Two. Evaluation Research Questions}

This chapter identifies and discusses the research questions that an evaluation of the CCBHC demonstration could and should address. These questions are rooted in two equally important sources: the goals of the CCBHC demonstration as specified in legislation and the broader contemporary context of mental health policy. The legislation establishes some clear goals for the program and explicitly mandates that reports to Congress provide evidence regarding the demonstration's effect on access, quality, and cost. However, it is also important to recognize that $\mathrm{CCBHCs}$ are being implemented during a period of rapid change in the mental health system and the health care system as a whole. In order to be relevant to the overall policy discussion, the evaluation should assess the impact of CCBHCs not only with respect to traditional mental health services models but also with respect to newer delivery system models currently being tested across the country.

The research questions are motivated by the logic model presented in Figure 2.1. The logic model shows how the structures of the CCBHC stated in the PAMA are designed to impact processes and outcomes of care. The research questions can be divided into two types: implementation questions concerned with how the CCBHCs put the model into practice and impact questions concerned with the effects of the model on consumers and the health care system. The implementation questions are descriptive and can be addressed using information obtained directly from the CCBHCs or from the state agencies responsible for administering the program. The aim of the implementation questions is to provide a detailed account of how the CCBHCs operate, the challenges that clinics and states face in the implementation process, and potential resolutions of those challenges. The impact questions are analytically more complex because they require comparison of data on processes and outcomes in the CCBHCs with similar data on well-defined comparison groups. More-detailed discussions of the available data sources and potential comparison groups are presented in Chapters Three and Four, respectively.

\section{Logic Model and Evaluation Domains}

The logic model has six linked domains according to Donabedian's structure-processoutcome model for assessing quality of care (Donabedian, 1980, 1982, 1988) (Figure 2.1). The structural component of the model is composed of the distinctive features of the CCBHC as described in the legislation. These structures are intended to directly influence processes of care, characterized by two domains: access to care and quality of care. Improvements in these processes of care influence outcomes of care, represented by three domains: utilization of health care, consumer health status and functioning, and costs of care. Throughout, we emphasize that this model should be understood not in a vacuum but in the context of the complex ongoing changes in the broader health care system discussed in Chapter One.

We discuss each of these domains in greater detail below. 
Figure 2.1 CCBHC Logic Model

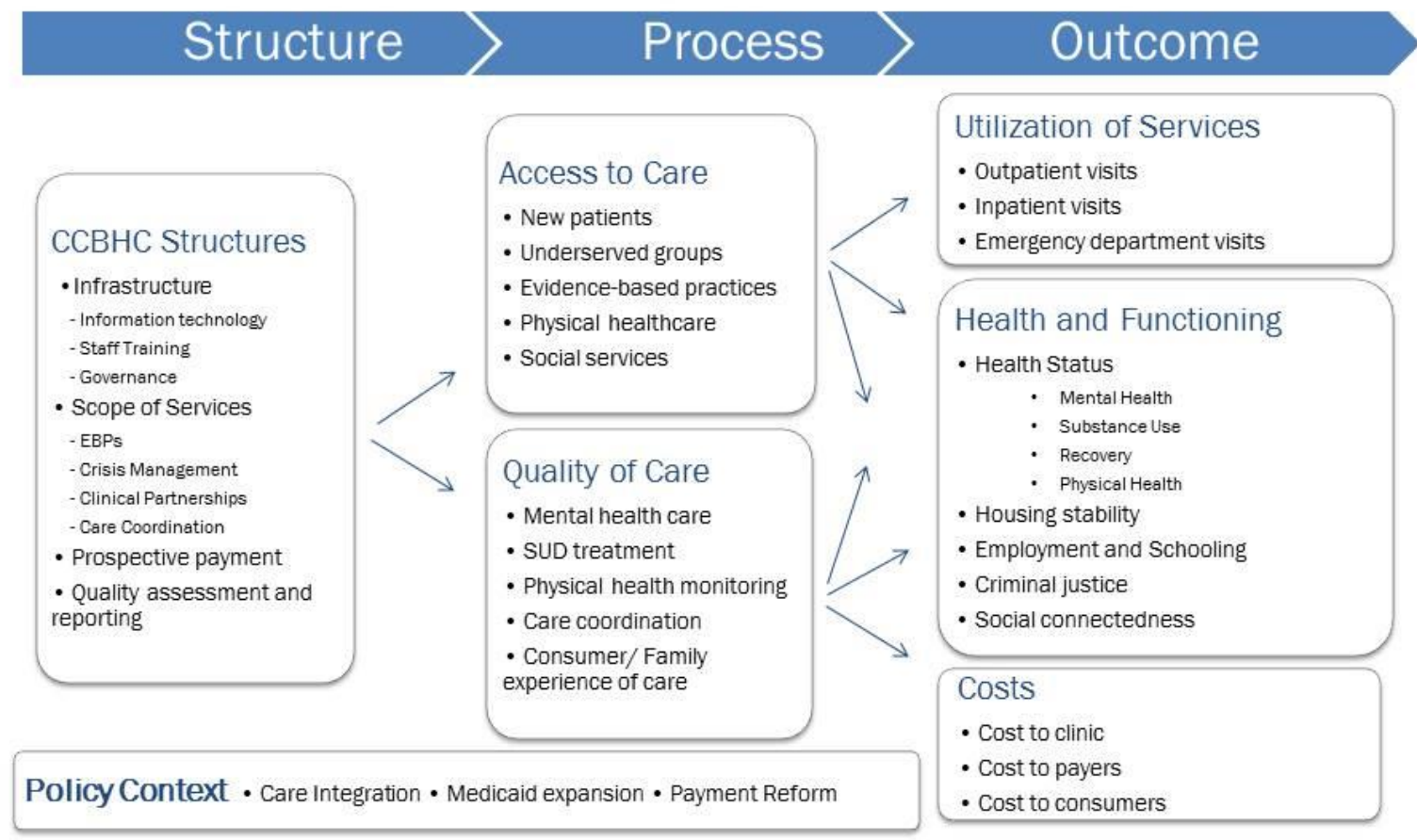

SOURCE: Authors' analysis.

\section{Structure}

CCBHC structures: The distinctive features of the CCBHCs involve four major components of clinic structure that make them distinct from prior models of CMHCs:

- First, CCBHCs are required to meet standards for their operational infrastructure that, as noted, are significantly higher than the current norms in behavioral health. These requirements include specific technology, such as an electronic health record (EHR), as well as administrative systems, such as staff training and governance.

- Second, the certification process requires CCBHCs to provide or coordinate a much broader scope of services than generally available through CMHCs, such as 24-hour crisis teams, primary care screening, and outpatient SUD treatment. CCBHCs are required to provide some services on-site or through a specific subcontracted provider, known as a designated collaborating organization (DCO), and establish referral networks with a broader network of external providers of medical and social services.

- Third, the CCBHCs will be reimbursed by Medicaid based on historical and estimated costs using a PPS, a payment mechanism that has been used in other areas of health care to a much greater degree than in mental health. The payment system offers providers greater flexibility in meeting the medical needs of their patients, but its complexity imposes an administrative burden on clinics and state mental health systems.

- Fourth, CCBHCs and states will be required to report on their performance on designated quality measures. The required reporting, which is uncommon in CMHCs at present (Patel et al., 2015), provides a basis for data-driven quality improvement efforts (Glied et 
al., 2015). Clinics will be able to compare their performance on the quality measures with their prior assessments, with those of other clinics collecting comparable data, or with state or national benchmarks.

\section{Process}

Access to care: The PAMA was designed to increase access to comprehensive behavioral health treatment among adults with SUDs or SMI and children with serious emotional distress, recognizing that only a minority of people with these conditions receive treatment (SAMHSA, 2010).

CCBHC certification criteria include specific requirements designed to increase accessibility of services, such as 24-hour Internet or phone access to clinic services, crisis intervention services, and tracking of the speed at which clinics respond to patients' initial requests for care. In addition, given the importance of outreach efforts to engage difficult-to-reach individuals with unmet needs, such as homeless individuals with mental illness (Rowe, Styron, and David, 2016; Rosenheck, 2000), assessing CCBHC outreach should also be an important component of the evaluation. The broad scope of services integrated into the $\mathrm{CCBHC}$ is meant to ensure that consumers with complex medical needs can access a diverse range of services.

Two aspects of access to care can be distinguished, both important goals of the PAMA. First, the legislation aims to increase the likelihood of treatment initiation among people with mental health treatment needs who have not previously been engaged in treatment. Outreach efforts and expanded crisis intervention services can contribute to this goal. Second, the legislation aims to increase the breadth and quality of services to which consumers have access once they have engaged in treatment. The CCBHC is designed to ensure that its consumers are more likely to receive evidence-based outpatient treatments than in traditional treatment settings. The expanded scope of services and care coordination components of the CCBHC can contribute to this goal. Given the different methods for achieving these two components of access, they should be tracked and evaluated separately.

Quality of care: Certification criteria are designed to improve quality of behavioral health care through required quality measure (RQM) reporting and monitoring, continuous quality improvement, EBPs, and care coordination. By quality, we refer to measures that assess the concordance of behavioral health treatment that consumers receive with established behavioral health clinical care guidelines, including quality measures that have been endorsed by such national agencies as the National Quality Forum (NQF). If CCBHCs are successful, the consumers they treat should be more likely to receive evidence-based mental health treatments and treatment for SUDs than they would have been had they been in an existing treatment setting (Goldman et al., 2001; Druss et al., 2008). Quality also includes patient and family experience with care, a particular concern given the emphasis of the CCBHC criteria on patient-centered care delivery.

\section{Outcome}

Utilization patterns: $\mathrm{CCBHCs}$ also are intended to have broader effects on patterns of utilization of health care beyond that provided directly by specialty behavioral health providers. 
Over the long term, the goal is to shift care from acute care settings, EDs, and hospitals, in particular, to outpatient settings through improved utilization of preventive care. This is true both for behavioral health care, in which improvements to outpatient care and care coordination are intended to reduce visits to the ED and inpatient hospitalization for behavioral conditions (Brown et al., 2012), and for physical health care, in which better identification and management of chronic physical illnesses aim to curb ED visits and inpatient hospitalization for physical conditions (Cahoon et al., 2013). At the same time, utilization of prescription medications would increase as identification of conditions and patient adherence to prescribed treatment improve. Reductions in utilization of EDs and hospitals might not occur over the short term of the CCBHC demonstration. In fact, if the CCBHCs are successful in identifying previously untreated conditions, utilization of acute care services might increase.

Cost of care: CCBHCs can have multiple countervailing impacts on costs of care for their consumers. The per-person cost to Medicaid is likely to increase because the payment system will be calibrated to historical costs, whereas historical reimbursement rates are thought to be lower than costs for most behavioral health services. In addition, providing a broader scope of services than consumers are currently receiving will also increase the cost per consumer. Increasing access to care involves providing services to individuals who are not currently receiving care, thereby increasing the number of consumers treated and therefore total Medicaid costs. At the same time, there are some significant potential cost savings expected from changes in care associated with the $\mathrm{CCBHC}$, primarily with respect to reduced utilization of ED and inpatient services. Better disease management for both behavioral and physical health conditions can reduce complications and thereby cut total health care costs. Finally, CCBHCs also can have an impact that is more challenging to measure on the use of social services, such as homeless shelters that affect state and local government costs but not Medicaid. CCBHCs could reduce utilization of some services if the needs were better met through improved treatment, but they could also increase utilization by connecting underserved individuals with care.

Health and functioning: The ultimate goal of the CCBHC model is to improve the health and functioning of adults with mental health or SUDs and children with serious emotional distress. This outcome domain can be conceived broadly to include not only health status with respect to symptoms of psychiatric and SUDs but also successful management of chronic physical health conditions, housing status, employment status, and social connectedness.

\section{Research Questions}

Following the logic model presented in Chapter One, we discuss two types of high-priority research questions for each domain, implementation questions related to the way in which the $\mathrm{CCBHC}$ model is realized in practice, and impact questions related to the effect that the CCBHCs could have on patients and the health system. It is important to note that the research questions presented in this chapter are not meant to be fully specified with respect to the methods that will be used to address them. Rather, the goal is to first identify the topics that are most relevant to drawing conclusions about the value of the CCBHCs relative to other policy options. Subsequent chapters on data sources, comparison groups, and research designs will link the questions specified here with particular research methods. 


\section{Questions About Implementation of the CCBHC Criteria}

The implementation questions concern mainly the CCBHC structures described in the logic model, with particular emphasis on the ways in which CCBHC structures are designed to affect access to and quality of care. Answering these questions should provide a detailed description of what the CCBHCs did to meet the certification criteria and provide the required services over the course of the demonstration period. The data to answer these questions will be drawn largely from the CCBHCs, with some additional information potentially drawn from claims or other data provided by the state agencies that oversee the CCBHCs.

What Types Of Behavioral Health Services, Including Care Management And Coordination, Do CCBHCs Offer?

The certification criteria make CCBHCs responsible for providing comprehensive behavioral health care, either directly or through DCOs, including screening and assessment, personcentered treatment planning, case management, peer support, outpatient treatment, and psychiatric rehabilitation. A primary question for the evaluation will concern the specific services that CCBHCs elect to offer to their patients and the ways in which they go about providing those services. More than an inventory of services, this question involves assessment of the fidelity with which the services are provided, the numbers of patients receiving the services, and the challenges that clinics face in maintaining the services over time. More-detailed questions on the behavioral health and care coordination services provided by CCBHCs include the following:

- What EBPs are being used?

- What are the qualifications of the providers?

- To what extent are services being provided with fidelity?

- How do clinics meet the staffing requirements of the $\mathrm{CCBHC}$ criteria?

- cultural competence?

- translation services?

- telemedicine?

- Which services are provided directly by the clinic and which by contracted providers?

- What were factors influencing these decisions?

- Which services are the most difficult for CCBHCs to provide?

- What are the challenges that CCBHCs face in providing different types of services?

- workforce shortages?

- patient demand?

- costs of services? 
- What arrangements do CCBHCs implement for care coordination and/or case management?

- How does the scope of services change over time?

How Do CCBHCs Establish And Maintain Formal And Informal Relationships With Other Providers?

$\mathrm{CCBHCs}$ are expected to have relationships with an array of care providers in their communities used by the consumers they treat. These connections include formal relationships with DCOs, which provide core CCBHC services and are reimbursed through the PPS, as well as a broader range of additional relationships, which might or might not be formalized, with other providers. The broader range of relationships can involve exchanges of information, facilitated referrals and referral tracking, or other reciprocal agreements. Given the innovative nature of these relationships and their centrality to the CCBHC model, providing a detailed description of how they are formed and maintained over time will be an important component of the evaluation. More-detailed questions include the following:

- What types of relationships do CCBHCs establish with other providers?

- behavioral health providers?

- primary care providers

- EDs?

- FQHCs?

- hospitals?

- social service providers?

- law enforcement?

- How are data shared among these providers?

- What types of formal data-sharing agreements are in place?

- What systems do CCBHCs use to coordinate care among multiple providers?

- referrals and referral tracking?

- multidisciplinary team meetings?

- tracking across care transitions?

\section{How Do CCBHCs Respond to the PPS?}

The PPSs that will be used to reimburse CCBHCs are innovative for behavioral health providers and can present administrative challenges. The process of implementation, which can require new systems for monitoring service provision and submitting claims, might be informative for future programs using this type of payment mechanism. Moreover, the payment systems are meant to change the economic incentives that shape care delivery for clinics. Both the daily and monthly systems are designed to allow clinicians greater flexibility in providing a personalized set of services tailored to an individual's medical and social needs. The evaluation 
can contribute to understanding how these new incentives affect management and clinical decisionmaking. More-detailed questions include the following:

- Do CCBHCs successfully bill under the PPS?

- Is the administrative burden of submitting claims different for consumers covered by the PPS?

- How are services captured and reported?

- How are consumers covered by the PPS distinguished from other consumers in claims and encounter data?

- Do clinics manage services for consumers covered by the PPS differently from the way they manage services for other consumers?

- Are Medicaid consumers tracked separately from other consumers?

- Do clinics with PPS-2 systems track or target performance on measures linked to the quality bonus payment?

- How do CCBHCs notify consumers about payment options?

- Medicaid enrollment?

- sliding fee scale?

How Do States Establish And Maintain Prospective Payment Rates?

The PPS also presents new challenges for states, in particular challenges related to ratesetting, assessing the adequacy of the rates after the fact, and establishing new rates based on the CCBHC's initial experience. The data available initially to set rates for the CCBHCs are limited, because the scope of services covered by the rates is broader than any previous single model of care. In the first period, cost reports (CRs) will include projected cost information on services expected to be rendered. However, actual cost experience for all services might not be available. The PPS-2 system, with its quality bonus payment, will be particularly challenging. Documenting the processes of rate-setting and administration at the state level will have important questions for future implementation of similar payment mechanisms, including the following:

- What data are used for initial rate-setting and rebasing?

- Is there variation across states in the services covered by the rates?

- In states using PPS-2, how are the quality bonus payment systems established?

- What proportion of eligible CCBHCs meet standards for the quality bonus payment?

- How do states identify claims originating from CCBHCs or comparison groups?

- How do states ensure that actual services provided are captured in the claims or encounter data?

- Do some states use a shadow billing system to capture this information?

How Do CCBHCS Attempt To Improve Access To Care?

An important task for the evaluation will be documenting the methods that CCBHCs use to improve access to care, including efforts to bring new patients into treatment and broaden the 
range of services for consumer use. These efforts can be described in detail and their results compared against the stated program goals, as well as the standards of timely care specified in the certification criteria. In some cases, CCBHCs might have specific goals to improve access among particular sectors of the population, such as minority cultural or linguistic groups. Moredetailed questions include the following:

- What policies do CCBHCs implement to expand accessibility?

- changes in working hours?

- telephone and/or Internet access to clinicians?

- How successful are CCBHCs in conducting timely assessments of new consumers?

- initial assessments?

- comprehensive assessments?

- follow-up of identified needs?

- Do CCBHCs conduct outreach programs to bring new patients into care?

- outreach to social services agencies, such as homeless shelters?

- outreach to other community organizations, such as police or schools?

- Are CCBHCs tracking the success of these efforts?

- Are outreach efforts targeted to Medicaid consumers?

- How do CCBHCs connect clients with a broad range of needed services?

- Are services checked against comprehensive assessments?

- Are referrals to DCOs and other external providers tracked?

- Do established consumers have timely access to outpatient care?

- Do consumers have access to crisis management services?

- rapid access?

- follow-up after crisis intervention?

- What barriers do CCBHCs report to improving access to care?

- workforce shortages?

- financial constraints?

- limited provider networks in the community?

How Do Clinics Collect, Report, And Use Information To Improve Quality Of Care?

The reporting required of $\mathrm{CCBHCs}$ by the certification criteria represents a significant advance beyond the current reporting practices in behavioral health. The required measures can provide a description of the quality of care that can potentially be compared with other state or national performance benchmarks or with the clinic's own performance across time. However, the quality reporting requirements are likely to impact the quality of care only if CCBHCs are able to accurately collect the relevant data and use those data systematically to improve their 
performance on the quality indicators. Particularly during the initial period of the demonstration, the extent to which CCBHCs are successful in collecting and reporting data and establishing systems for quality improvement will be more important for the evaluation than the values that they achieve on the quality measures. More-detailed questions include the following:

- What is the process for generating quality measure reports for required measures?

- Are CCBHC EHR systems capable of generating all measures?

- Do clinics generate and monitor other quality or outcome measures?

- How do clinics collect and review information on care provided by DCOs?

- What kind of data-sharing agreements are in place?

- How is the information used to manage the care provided by DCOs?

- How are staff qualifications of contracted providers assessed and monitored?

- Are quality measures used for non-Medicaid and/or dual-eligible clients?

- How is information on quality of care used to improve performance?

- Do CCBHCs implement quality improvement plans?

- Do clinicians receive feedback on care for individual consumers?

- Is information on quality used in care team meetings?

- Do quality measures inform changes in clinic policies?

- How do CCBHCs use data to inform population health management?

- How do CCBHCs monitor health and social outcomes?

- behavioral health status?

- physical health conditions?

- employment/Education?

- housing?

How Do States Collect, Report And Use Information On Quality Of Care?

The same issues regarding collecting, reporting, and acting on information on quality of care identified at the CCBHC level will also be of concern with respect to state-level quality reporting. During the initial period of the demonstration, the major tasks for states will be developing systems for assessing the required measures and conveying the information to clinics so that the results can impact practice. In some states, the required reporting can involve integration of data systems from multiple agencies. For instance, reporting on housing status of CCBHC consumers might require integration of Medicaid data with other social service agency data systems in the state. In addition, some states might elect to broaden the scope of their quality measurement for $\mathrm{CCBHC}$ or for their behavioral health care providers more generally. The evaluation will have the opportunity to document these processes as they are developed and identify important lessons for states as they aim to integrate claims data into quality improvement systems in behavioral health. More-detailed questions include the following: 
- How do states identify and analyze information on the quality of care in CCBHCs using Medicaid claims?

- How do states identify claims for care provided in CCBHCs?

- How are encounter records specified and processed?

- How do states use claims data to assess quality of care in CCBHCs?

- Are states able to report fully on required measures?

- Do states examine other measures of quality of care?

- Are other sources of information used to collect information on required measures?

\section{Questions About the Impact of CCBHCs}

The impact questions address the process and outcome domains of the logic model. These questions are analytically more complex, because each requires a comparison of data on the $\mathrm{CCBHC}$ with data on another clinical setting. Considerations regarding the data sources for the comparison groups are discussed in Chapters Three and Four.

\section{Relative To Comparison Groups, Do CCBHCs Expand Access To Behavioral Health Care?}

CCBHCs are designed to improve access to comprehensive behavioral health care, but they are not the only policy approaches currently being implemented to achieve that goal. Health home and other integrated care systems that also are designed to improve access to behavioral health care can have different incentives, strengths, and weaknesses. For instance, health home programs that focus on care coordination, such as those in New York, can be more effective in reaching individuals with undertreated conditions but less effective in connecting them with comprehensive care. Investigating these effects can provide valuable information on the potential role for $\mathrm{CCBHCs}$ within emerging integrated care systems. More-detailed questions include the following:

- Are CCBHCs successful in bringing consumers into treatment?

- behavioral health care?

- other medical care?

- Are CCBHCs successful in providing a broader range of services to their consumers?

- behavioral health care?

- other medical care?

- Does CCBHC consumer health-profile change in response to PPS incentives?

- Do CCBHCs have lower-risk or lower-cost consumers on average?

- Are consumer health-profile patterns different for PPS-1 and PPS-2 CCBHCs?

Relative To Comparison Groups, Do CCBHCs Improve The Quality Of Behavioral Health Care?

The implementation questions focus on the quality of behavioral care provided in the $\mathrm{CCBHCs}$ and the systems using this information to improve performance. The evaluation can 
also address the model's effect on quality of care, i.e., whether the care consumers receive in a $\mathrm{CCBHC}$ is better than in another care setting. The quality of behavioral health care includes not only the strictly medical components of care, such as medication adherence, but also a broader range of services that address social functioning and impairment. As noted above, the models of care with which CCBHCs are compared can vary across states. For instance, CCBHCs could be compared with traditional freestanding CMHCs on the one hand or with integrated mental health and substance abuse treatment centers on the other. More-detailed questions include the following:

- Do consumers in CCBHCs receive a broader mix of medical and supportive services?

- medication adherence?

- rehabilitation?

- vocational and/or educational support?

- continuity of care?

- Are consumers in CCBHCs more likely to receive evidence-based substance use treatment?

\section{Relative To Comparison Groups, Do CCBHCs Improve Patterns Of Total Health Care Utilization?}

Improved integration between specialty mental health clinics and general medical care providers is a central goal not only of CCBHCs but also of other service delivery models being examined in many states. The evaluation can contribute to understanding these alternatives by comparing of the impact of the CCBHCs and those of other models in providing physical health care to their consumers. The impact on physical health care is likely to be complex. In some cases, improving care will result in increasing utilization, such as outpatient management of chronic physical health conditions. In other cases, improvements in care aim to reduce utilization - frequent ED visits and inpatient stays for physical health conditions in particular. More-detailed questions include the following:

- Are consumers treated in CCBHCs more likely to receive outpatient treatment for chronic physical health conditions?

- Are consumers treated in CCBHCs less likely to be frequent users of ED and inpatient services?

- for mental health care?

- for physical health care?

- Are care utilization patterns different for PPS-1 and PPS-2 CCBHCs?

- Medicaid-covered consumers?

- other consumers? 
Relative To Comparison Groups, Do CCBHCs Improve Consumers' Health And Functioning Outcomes?

Ultimately, the goal of the CCBHC is to improve consumer outcomes of care. The outcomes should include health status. Social functioning in daily life, including housing tenure and labor market participation, also should be considered primary targets. In particular, the CCBHC's focus on comprehensive behavioral health care is designed to directly target the broader social functioning issues that have a large impact on quality of life and can be less likely to be successfully addressed in nonspecialty settings. More-detailed questions include the following:

- Do CCBHCs improve consumers' behavioral health status?

- Do CCBHCs improve consumers' physical health status?

- Do CCBHCs improve consumers' social functioning?

- housing?

- employment and schooling?

- criminal justice?

- social connectedness?

Relative To Comparison Groups, Do CCBHCs Impact Federal And State Costs For Behavioral Health Services?

The CCBHC model's effect on costs of care is likely to be affected by several direct and indirect factors and can have different effects on clinic, state, and federal costs. The most-direct effects will derive from the fact that the payment systems will be based on costs of providing care and likely to be considerably higher than the prior Medicaid reimbursement rates. This will increase costs to Medicaid as clinic reimbursement rises. The extent of these differences can be assessed through simulations of the costs under different assumed payment systems. However, Medicaid costs are also affected by the total health care utilization by consumers. Thus, if utilization of costlier ED and inpatient services is reduced by the CCBHC, Medicaid will receive an offset of the payments to the CCBHCs. In addition, CCBHCs can incur additional costs because they are required to provide a wider scope of services. Finally, consumers also incur costs in seeking care, both financial and otherwise, and the CCBHC model can affect those costs. For instance, the ability to receive multiple types of care in a single setting can decrease the time that consumers spend traveling to access care. More-detailed questions include the following:

- How are clinic finances affected by the CCBHC payment systems?

- impact on costs of care for Medicaid consumers?

- impact on total Medicaid reimbursement? 
- What impact does the CCBHC have on costs to Medicaid?

- outpatient behavioral health costs?

- other outpatient medical care?

- ED visits and hospital stays?

- behavioral health versus physical health?

- total costs?

\section{Conclusion}

In this chapter, we describe the research questions that the evaluation should address in each evaluation domain that, if answered, would provide policymakers with valuable information in deciding among existing delivery models currently under consideration. These questions are meant to reflect the important theoretical issues rather than the practical matters of collecting and analyzing data under a fixed budget. Consideration in the subsequent chapters of the data sources, design options, and costs will provide more-substantive guidance for addressing the questions laid out in this chapter. It is important to note at this point that an evaluation would be unlikely to address all of these questions. 


\section{Chapter Three. Data Sources}

This chapter presents findings regarding the data sources that could be used by the evaluation to address the questions outlined in Chapter Two. As described in Appendix C, the findings are based on key informant discussions with state officials and representatives from relevant national policy organizations, reviews of recent policy evaluations, and a review of the proposals submitted by states for CCBHC planning grants. For each data source, we consider the content and availability, taking account of the likely time lag involved with obtaining data, the feasibility of collecting the data, its costs to an evaluation in terms of both data collection and analysis, and the burden that reporting would impose on clinics or state agencies. The data sources can be classified into the following five categories:

- Clinical data are those generated in the process of providing care to clients, including medical records maintained in an EHR.

- Clinic operations data are records of or reports on the operation of the clinic, including personnel, services provided, and contractual relationships with other providers. This information can be collected if the evaluator institutes quarterly or semiannual reporting.

- Claims/encounter data are records of services submitted to payers for purposes of billing and/or oversight.

- Surveys can be conducted of consumers, family members, state officials, providers, and/or clinic administrators.

- Qualitative data, particularly on challenges that clinics face while implementing the CCBHC model, can be collected through key informant interviews and/or site visits to clinics.

\section{Primary and Secondary Data Sources}

To some extent, data pertinent to each of the domains (structure, access, quality, utilization, cost, and health and functioning) is already routinely produced by some clinics or will be produced to meet $\mathrm{CCBHC}$ reporting requirements to states and the federal government (Table 3.1). The certification process itself, which will be carried out by state agencies, will involve documentation of clinic characteristics in sufficient detail to assess their compliance with the certification criteria. For instance, states will have to collect information from clinics to determine whether they have appropriate staffing (scope of services) and health information technology infrastructure and whether they provide services on some nights and weekends (access to care). The results of the certification process will be summarized in the demonstration applications that will be available to the evaluator (while further details might have to be collected through site visits or interviews). Cost reporting by CCBHCs used to establish and rebase prospective payments will also provide the evaluator with helpful information on costs of care. In addition, CCBHCs and states will be required to report a set of quality measures, which are relevant to the above domains. For instance, $\mathrm{CCBHCs}$ are required to report on the number or percentage of new clients with an initial evaluation provided within ten days, an important 
component of access to care, and states are required to report on follow-up after hospitalization for a mental illness, an important indicator of quality of care at the system level. Some states might be currently reporting at least a portion of the required measures, such as the Medicaid core measures, as part of CMS's voluntary reporting program (Patel et al., 2015). However, current reporting by states is unlikely to be at the clinic level, unless the reporting is connected to a specific grant program.

Table 3.1. Existing Data Sources for Evaluation, by Domain

\begin{tabular}{lcccc}
\hline Domain & $\begin{array}{c}\text { Demonstration } \\
\text { Application }\end{array}$ & RQMs & CRs & Claims Data \\
\hline Structure & $\checkmark$ & - & - & - \\
Access & $\checkmark$ & $\checkmark$ & - & - \\
Quality & - & $\checkmark$ & - & $\checkmark$ \\
Utilization & - & $\checkmark$ & $\checkmark$ & $\checkmark$ \\
Cost & - & - & $\checkmark$ & $\checkmark$ \\
Health and functioning & - & $\checkmark$ & - & - \\
\hline
\end{tabular}

SOURCE: Authors' analysis.

While the use of existing data has obvious advantages in reducing costs to the evaluation and burden to the CCBHCs, there are likely to be important aspects of each of the domains not well covered by existing data sources, requiring new data collection efforts for evaluation purposes. Identifying potential data sources and exploring their associated feasibility, validity, and cost are important during the planning stage for states to make necessary preparations. States might be able to implement systems for data collection from CCBHCs that will extend to the elements needed specifically for the evaluation. In particular, states can use the planning phase to suggest potential comparison clinics or groups and put systems in place to collect evaluation data from those clinics or groups.

\section{Clinic Operations Data}

Information on the administration of the CCBHCs will be important to the evaluation, particularly with respect to its ability to describe the domains of structure, access, and cost. Examples include payroll records, staff hiring and training, use of health information technology, CRs, use of EBPs, care coordination activities, client and family representation on boards or panels, clinic participation in technical assistance activities, participation in other delivery system reform activities, and consumer engagement activities that address core CCBHC goals. Consumer engagement might include efforts to establish and maintain relationships with a network of providers in the community (including DCOs) and efforts at outreach to homeless shelters, prisons, or other community organizations that serve adults with SMI or children with 
SED. Data on these activities are unlikely to be systematically collected and reported without specific targeted systems in place for evaluation purposes. Yet, these activities are vital to the success of CCBHCs in achieving their primary aims.

We identified six potential sources of operations data that could inform the evaluation study.

\section{Demonstration Application}

States will be collecting information on clinics' administrative structures as part of the process of certifying CCBHCs, and those data will be summarized in their applications for the demonstration. The evaluator will have access to the applications and can be able to gather additional related data through interviews. Many of the certification criteria are relevant to the evaluation domains. For instance, the certification criteria regarding staffing and hours of operation are directly relevant to access to care and scope of services. However, state governments will have certified CCBHCs before the evaluation begins, so efforts will be required to collect uniform data across states post hoc. It might be possible to construct a standardized data set of clinic certification criteria based on diverse reporting methods from states (which the evaluator can access by reviewing the demonstration applications and requesting any reporting the state might have instituted). In addition, while the statute requires an initial certification, it does not specify procedures for ongoing oversight and reevaluation beyond annual financial reporting during the demonstration. This leaves a critical gap with respect to collection of operations data over time.

\section{Cost Reports}

CCBHCs are required to submit detailed CRs annually during the demonstration. These reports contain information on a wide range of inputs into the operating costs of the clinics, including the number and type of staff, the number of patients seen daily or monthly (depending on which PPS model the state chooses), and the direct (e.g., wages) and indirect (e.g., rent) costs of providing care. In addition to reporting current costs, $\mathrm{CCBHCs}$ are required to provide details on possible adjustments in the future. For example, if a staff psychologist begins to perform some administrative tasks, the compensation is split between these two jobs: clinician and administrator.

The wealth of information contained in these reports makes them an attractive source of data for tracking important aspects of CCBHC operation during the demonstration. The evaluation could use these data to describe changes in the number of patients seen over time or how CCBHC staffing changes. However, there are some possible drawbacks to using these data. First, it is unclear how much of a burden the CCBHCs face in providing these detailed reports. If the burden is very high, the quality of the data can decline as CCBHCs stop being able to complete the reports with as much detail and accuracy. This could be addressed through the audit requirements built into the demonstration. However, the National Council for Behavioral Health estimates that the actual costs of performing these audits will be substantially higher than provided for in the legislation (National Council for Behavioral Health, 2015). If that is the case, the states might not be able to audit the reports thoroughly, and this could reinforce a decline in data quality over time. 
A drawback to using these cost data for the evaluation is that it is unlikely that comparison providers will be able to provide the same level of detail. That will limit the evaluation's ability to confidently estimate changes caused by the demonstration. It can be possible in some states with existing reporting requirements to get comparable data from comparison providers. It can also be possible to identify a subset of the data in the CCBHC CRs and ask comparison providers to obtain the same data. A lower burden on the comparison providers can make collection feasible.

\section{Administrative Data}

Our key informant discussions with state agencies revealed that many states have electronic reporting systems for administrative data on mental health clinics that could be used for evaluation purposes. For example, one state reported that its system "currently collects [from CMHCs] consumer, service, funding, expenditure, cost, and administrative data via in-house developed automated data collection platforms ... including biennial staffing and waitlist surveys." These systems vary dramatically state to state, and they can be lacking in key information. For example, several states that collect some administrative data reported that they would not collect information on outreach activities conducted by CMHCs unless a specific grant program funded those activities. As with the state certification processes, data from these systems would have to be standardized by states prior to their use by the evaluation or by the evaluation team itself, which could require considerable investment of resources.

\section{Quarterly Reports}

Experience from prior evaluations suggests that regular reporting of operations data by clinics can be required without imposing a large burden on clinics or costs on the evaluation. For example, SAMHSA typically requires grantees to submit quarterly reports (QRs). Perhaps a similar requirement could be added for the evaluation. This type of information can also be collected through provider surveys (more on these surveys later in this chapter). QRs can contain qualitative information about grantee accomplishments, changes in staffing, the involvement of consumers and families, barriers to program accomplishment, infrastructure activities, progress with data collection, program components implemented through grant activity, funding sources, staff involvement in technical assistance activities, and other grant programs. A limitation of some QRs is a reliance on open-ended questions, answers to which are difficult or impossible to standardize across clinics. As a result, it can be unclear to evaluators whether an activity described in one report was the same as that noted in a previous report, as opposed to an entirely new activity, or whether the absence of a mention of some activity was a reliable indication that the activity was, in fact, not happening. Clinics also might not consistently report when certain activities are discontinued. This limitation of the $\mathrm{QR}$ could be addressed by creating a more fully structured reporting form for the CCBHC demonstration program that could include information not available elsewhere, such as outreach activities. 


\section{State-Reported Data}

States report data on mental health services directly to the federal government as a condition of their participation in Medicaid or the block-grant programs, which can be useful for evaluation. The Uniform Reporting System (URS) is a reporting system used by state mental health agencies (SMHAs) to compile and provide SAMHSA's Center for Mental Health Services (CMHS) with state-level data to describe the public mental health system and the outcomes of its programs. The URS provides annual aggregate information on numbers and sociodemographic characteristics of clients served by the states' psychiatric hospitals and community mental health programs, outcomes of care, use of selected EBPs, client assessment of care, insurance status, living situation, employment status, and readmission to state psychiatric hospitals within 30 and 180 days (Healthy People, 2010; NRI, undated[c]).

The Treatment Episodes Data Set (TEDS) is a record of all episodes of treatment in substance abuse treatment centers that receive any federal funding (SAMHSA, undated). Data for the TEDS are compiled by each state and reported to SAMHSA. The data at the federal level are unlikely to be useful for evaluation purposes because they do not include individual identifiers that allow linking episodes of care for the same person. However, many states collect the data from residential treatment centers and outpatient providers in a format that includes such identifiers, and this could allow for linkage with other sources of data. Inclusion of such data would fill a gap that exists in many states' Medicaid claims data sets with respect to treatment for SUDs, much of which is not reimbursed by Medicaid. As one key informant pointed out, the availability of state-level data on substance abuse treatment episodes that would allow for linkage with claims data will need to be investigated in each state.

\section{Transformation Accountability System}

Another potential source of data is SAMHSA's Transformation Accountability System (TRAC). All programs that receive discretionary grants from SAMHSA are required to report client-level data directly to TRAC using a standardized instrument known as the National Outcomes Measures (NOMs) surveys. The NOMs determine behavioral health service use and consumer outcomes (including the Mental Health Statistics Improvement Program [MHSIP] described in greater detail later in this chapter). The data are submitted electronically to SAMHSA using a web-based data-entry and reporting system that provides a data repository for CMHS program performance measures. Information in TRAC includes demographics, functioning, stability in housing, education and employment, crime and criminal justice status, perception of care, social connectedness, services received, and status at reassessment and clinical discharge. For CCBHCs already reporting this information, it is another potential source of data on consumer outcomes. In addition, the repository of NOM data from other grant programs can provide relevant comparison data for the evaluation. However, the costs of using the TRAC system for the CCBHC evaluation can prove prohibitive. 


\section{Claims and Encounter Data}

\section{Description}

We include in this category enrollment, claims, and encounter data collected by the state or managed care companies for billing or care management purposes. They will also include the encounter records that CMS will require CCBHCs to submit for care covered by the PPS payments. The encounter records will describe procedures using the same codes as are used for non-PPS Medicaid claims. These data sources contain detailed information on utilization and spending and are a valuable source of information on a number of evaluation measures for CCBHC clients and for the comparison population. ${ }^{3}$

Medicaid enrollment data contain demographic details on enrollees, as well as period of enrollment. Linked claims data contain records of all billed services, including the date, the diagnosis, and the medical procedures provided. In addition, prescription drug information is often included in these data. In a FFS setting, a record is generated when a provider bills a service to an insurer. Managed care contracts do not always require a separate record for each encounter because reimbursement is often bundled in a per-member-per-month payment; however, managed care organizations (MCOs) often require encounter records that track individual encounters for reporting purposes. In an FFS contract, the record includes the amount billed for the service and often includes the amount actually paid for the service. In a managed care contract, the amount paid for the service is not relevant and is therefore often not included on encounter records. Some states require a detailed encounter record for each encounter that might also include the amount paid, along with information similar to what is recorded in FFS claims records; however, the amount of information captured in encounter records varies by state. The evaluation can decide not to include $\mathrm{MCO}$ encounter records in analyses about spending or will need to estimate the amount spent on services for records that do not include the amount spent on the individual service.

\section{Strengths}

Claims and encounter data can be useful for the evaluation because they provide information on the total covered medical and behavioral care provided to enrollees, including spending. This means they can be used to compute measures beyond those reported by the CCBHCs and can help validate the reported measures. In addition, in cases in which patient characteristics, rather than the site of care, define the comparison population, these data are important for generating the relevant comparison measures.

\footnotetext{
${ }^{3}$ The evaluation is not specific on how claiming will take place. There is a small possibility that any given participating state could submit a claim for a daily or monthly visit instead of utilizing procedure codes. In this case, the state would also be required to submit an encounter record for actual services provided at the CCBHC.
} 


\section{Data Availability}

Medicaid claims and encounter data can be obtained from CMS in standardized analytic data sets, but the time lag between the service delivery and the availability of these data is likely to be too long to be practical for the evaluation. Further, not every state is submitting its Medicaid data files to CMS. For example, 11 of the 24 planning grant states will not have data in the CMS 2013 Medicaid Analytic Extract (MAX) files. There are versions of the MAX files, called alphaMAX, that have a similar structure and can be available more quickly than the final MAX files, but these files are not standardized and cleaned in the way that the regular MAX files are. While the alphaMAX files are more current, there is still a lag between the date of service and the date the files are released. Furthermore, the evaluator will need to work on the files before they are ready for analysis. Medicaid data are generally available directly from state agencies more quickly. State representatives with whom we spoke estimated that most adjudicated FFS claims are available three to six months following a service. The time lag for receipt of encounter data by states from managed care varies more, although the managed care companies receive encounter-level information at least as quickly as states obtain FFS claims. Acquiring data from any of these sources will require completing data-use agreements with each, a process that can take some time to complete. As we note below, some MCOs may also charge fees for access to data. It is possible that the alphaMAX files can be easier to acquire, although the evaluator will need to determine whether they are current enough or complete enough to be useful.

\section{Challenges}

Medicaid enrollees who are also eligible for coverage through Medicare (referred to as dual eligibles) are likely to receive care in CCBHCs. Because Medicare and Medicaid are paying for their care, claims and encounters for dual eligibles will be split between these two sources. Relying only on Medicaid claims will provide information on only a portion of the care for dual eligibles. To get complete information for these enrollees, the evaluation would need to also acquire Medicare claims. If the evaluator chooses to do this, it poses a significant challenge and likely adds significant expense to the evaluation. Medicare enrollment and claims data are in standard format and are relatively straightforward to analyze; however, it will be difficult and expensive to get Medicare claims data for the dual eligibles. Possible exceptions are those states

participating in the Financial Alignment Demonstration (nine of 24 states), which can receive Medicare claims data for their dual eligible beneficiaries. As with the other claims and encounter data, the evaluator will need to complete a data-use agreement and arrange payment with CMS (which provides Medicare claims data). Acquiring the data for the dual eligibles will be challenging. It can be possible to provide CMS with a list of identifiers that can be used to pull claims to send to the evaluator. However, creating that list might prove very difficult because it will require that the Medicaid data contain Medicare identifiers. Alternatively, the evaluator could try to acquire data for all dual eligibles in the full demonstration and comparison populations from CMS (for example, all dual-eligibles in the demonstration states) and attempt to identify the CCBHC consumers from this larger set. Any attempt to get Medicare claims for a specific population would require careful planning and significant time for CMS to complete. 
Key informants at national organizations, including two interviews with representatives from managed behavioral health care organizations, and state representatives endorsed the use of claims and encounter data but noted a number of challenges. The flow of data from provider to state agency or MCO is complicated and varies by state (see Appendix E for a detailed example). Clinics that have both FFS and MCO consumers will be challenging to evaluate because there are challenges to combining FFS claims and MCO encounters. The encounter data that state governments receive and can report to an evaluator tend to have gaps because of incomplete reporting and inconsistent data formats across providers and payers. Many states fail to report Medicaid encounters that occur in managed care settings to CMS, as required by Medicaid regulations (Office of Inspector General, 2015). However, the encounter data might be available directly from MCOs, which tend to have more-complete data, along with quality measures at the provider level, for their own internal management purposes. These data exist, but they can be obtained from the MCO directly only in some cases. States might have multiple MCOs for physical health care management and behavioral health carve-outs. Combining information data from these different sources into a single picture of care for a CCBHC's consumers will be challenging. Even the MCOs might not have complete information from the CCBHC partners (DCOs).

The states that received planning grants have varying levels of Medicaid enrollees covered by managed care. Table 3.2 indicates the share of Medicaid beneficiaries in each state who were enrolled in comprehensive Medicaid MCOs as of July 1, 2015. Some states, such as Alaska or Oklahoma, provide all Medicaid services through FFS contracts. New Jersey and Oregon, on the other hand, provide Medicaid coverage almost entirely through managed care. Some states might "carve out" some or all behavioral health benefits to be provided and financed by another MCO or on an FFS basis. For example, as of 2013, California, Colorado, and Kentucky used managed care for mental health but not for SUD services (SAMHSA, 2015b). One state representative pointed out that different MCOs manage behavioral and physical health care and linking information on the same enrollee across the company data sets is challenging because they carve out behavioral health services. In such situations, those in which claims for behavioral and medical services are processed through distinct systems, including information on the quality of medical care provided to CCBHC consumers can be particularly challenging. States with high managed care penetration can also have multiple managed care companies that might collect and manage data differently. For example, Oregon has nine different Medicaid MCOs (Henry J. Kaiser Family Foundation, undated). This implies that an evaluator might need to coordinate with each state and potentially each $\mathrm{MCO}$ in order to receive its data. There can also be a significant cost to acquire data from the MCOs. One key informant with whom we spoke was told that the cost of acquiring encounter data for another project was at least $\$ 50,000$ per MCO. In addition, the files from the different sources will need to be processed in order to be comparable. 
Table 3.2. Medicaid Managed Care Penetration Rate, by State, 2015, as Percentages

\begin{tabular}{|c|c|}
\hline State & Penetration Rate \\
\hline Alaska & 0 \\
\hline Connecticut & 0 \\
\hline North Carolina & 0 \\
\hline Oklahoma & 0 \\
\hline Colorado & 9 \\
\hline lowa & 12 \\
\hline Missouri & 51 \\
\hline Massachusetts & 52 \\
\hline Illinois & 53 \\
\hline Virginia & 66 \\
\hline Nevada & 68 \\
\hline Pennsylvania & 70 \\
\hline Minnesota & 73 \\
\hline California & 77 \\
\hline Michigan & 77 \\
\hline Indiana & 78 \\
\hline New York & 78 \\
\hline Maryland & 82 \\
\hline New Mexico & 88 \\
\hline Rhode Island & 88 \\
\hline Texas & 88 \\
\hline Kentucky & 91 \\
\hline New Jersey & 93 \\
\hline Oregon & 93 \\
\hline
\end{tabular}

SOURCE: Henry J. Kaiser Family Foundation, 2015.

Another issue raised in our state discussions that applies to both FFS and managed care is the ability to identify CCBHCs in the claims or encounter data, a requirement for certification. A related issue is how to attribute consumers to CCBHCs (or to comparison sites of care). Some states with whose representatives we spoke have begun the process of creating new provider 
identifier codes or were exploring alternative methods for flagging CCBHCs in their claims, such as creating a new place-of-service code or special procedure modifier code. For example, some states planned to select CCBHCs from among existing behavioral health homes that already had unique provider identifier codes in their data. The process for assigning clients to CCBHCs has not been well developed, although one state with whose representative we spoke said that it would either have the CCBHC provide a list of its clients or develop an algorithm for attribution.

\section{Summary}

The evaluator faces a choice between data complexity and data currency and completeness. The MAX files are in a standardized format from a single source. This makes them relatively easy to acquire and analyze. However, they are likely to cover claims and encounters that are at least two to three years old, and managed care encounters are often not included. Claims and encounter data acquired from the individual states and MCOs will be more current (including encounters from as recent as six months) and complete, but they will be more complex. Coordinating data collection from several sources will be challenging, and converting each data source into a standard format for analysis will take a great deal of effort.

\section{Clinical Data}

Clinical records are a critical source of data, particularly with respect to the assessment of the quality of care provided by CCBHCs. Many quality measures, especially process measures, are computed using clinical records. However, the use of clinical data is largely dependent on the existence of an EHR capable of automatically generating quality measures directly from information entered in the process of care delivery. EHRs can produce many of the quality measures described in Chapter One and Appendix B that are required by the CCBHC certification criteria and potentially additional measures that could inform the evaluation. Collection of information using non-EHR-based methods is possible but likely to impose a significant nonreimbursed burden on the clinics. In addition, the utility of clinical data to the evaluation will depend on the availability of comparable data from comparison clinics.

\section{EHRs in CCBHCs}

Each $\mathrm{CCBHC}$ will be required by the certification criteria to have a health information technology system that includes EHRs with specific reporting capabilities. The system must allow clinics to capture patient care data, including diagnoses, medications, and lab results, as well as demographic data. By generating patient reports, these systems are intended to help clinics with clinical decisions supporting best practices. In addition, the systems must allow $\mathrm{CCBHCs}$ to report data and quality measures required for the demonstration. Evidence from the proposals and our interviews with state officials suggests that all states plan to either select providers with existing EHRs or use funds during the planning grant to develop these systems for providers that lack them at present. While this requirement establishes a standard for data collection capabilities in CCBHCs, it is also important to consider that successful operation of these systems cannot be guaranteed. States that have participated in similar demonstrations have 
indicated that providers require training and buy-in before they use the EHR systems as intended. Literature on the adoption of EHR systems in other settings suggests that they can help to improve outcomes in the long term but can also be a burden for staff during the adoption and implementation phase (Hersh, 2004; DesRoches et al., 2008; Nutting et al., 2009). Therefore, it is possible that clinics with newer EHR systems will not be as capable of using them to produce high-quality data reports as clinics with longer EHR experience. This means the evaluation might choose to focus on a set of measures that can be reported with consistency regardless of EHR familiarity or might have to account for variation in quality of reporting through, for example, a stratified analysis.

At present, there is wide variation across states and within states in the use of EHRs.

Table 3.3 presents data collected on EHR use among community mental health providers from a 2015 survey of state mental health agencies collected by NRI from the 24 states that received CCBHC planning grants (NRI, undated[b]). The counts for most states are at the clinic level, although some states, such as Pennsylvania, provided data on individual providers. In ten of the 24 planning grant states, 100 percent of community mental health providers have EHRs.

However, the proportion with EHRs is less than 10 percent in three of the states, and nine of the states did not provide survey responses.

Table 3.3. EHR Adoption from the State Mental Health Agency Profiling System, 2015

\begin{tabular}{|c|c|c|c|}
\hline State & $\begin{array}{c}\text { Number of Community } \\
\text { Mental Health Providers } \\
\text { That Have Implemented } \\
\text { EHRs }\end{array}$ & $\begin{array}{l}\text { Total Number of } \\
\text { Community Mental } \\
\text { Health Providers }\end{array}$ & $\begin{array}{c}\text { Percentage } \\
\text { of } \\
\text { Community } \\
\text { Mental } \\
\text { Health } \\
\text { Providers } \\
\text { with EHRs }\end{array}$ \\
\hline Massachusetts & 5 & 145 & 3 \\
\hline Connecticut & 6 & 103 & 6 \\
\hline New Jersey & 10 & 115 & 9 \\
\hline Alaska & 45 & 80 & 56 \\
\hline Colorado & 17 & 19 & 90 \\
\hline Indiana & 25 & 25 & 100 \\
\hline Kentucky & 14 & 14 & 100 \\
\hline Michigan & 46 & 46 & 100 \\
\hline Missouri & 30 & 30 & 100 \\
\hline Nevada & 24 & 24 & 100 \\
\hline Oklahoma & 14 & 14 & 100 \\
\hline Oregon & 36 & 36 & 100 \\
\hline Rhode Island & 8 & 8 & 100 \\
\hline Texas & 38 & 38 & 100 \\
\hline Virginia & 40 & 40 & 100 \\
\hline California & - & - & - \\
\hline Illinois & - & 180 & - \\
\hline
\end{tabular}




\begin{tabular}{lccc}
\hline \multicolumn{1}{c}{ State } & $\begin{array}{c}\text { Number of Community } \\
\text { Mental Health Providers } \\
\text { That Have Implemented } \\
\text { EHRs }\end{array}$ & $\begin{array}{c}\text { Total Number of } \\
\text { Community Mental } \\
\text { Health Providers }\end{array}$ & $\begin{array}{c}\text { Percentage } \\
\text { of } \\
\text { Community } \\
\text { Mental } \\
\text { Health } \\
\text { Providers } \\
\text { with EHRs }\end{array}$ \\
\hline lowa & - & 25 & - \\
Maryland & - & $488^{\mathrm{a}}$ & - \\
Minnesota & - & $600^{\mathrm{a}}$ & - \\
Pennsylvania & - & $1,400^{\mathrm{a}}$ & -
\end{tabular}

SOURCES: NRI, undated(a); data are the source for the first two columns, with the exception of Colorado. The source for the total number of CMHCs in Colorado is our discussion with a state official.

NOTE: Total number of community mental health providers is the sum of community mental health providers that are SMHA operated (only) and community mental health providers that are SMHA funded (not including state-operated programs). $-=$ not reported.

${ }^{a}$ These states report very high numbers of community mental health providers. Those large variations are most likely because of differences in how these providers are licensed and counted in the state.

Even within states with high EHR adoption, there can be variation in the sophistication of the clinic-level systems, certification, and EHR vendors. One state whose representative we interviewed relayed that there are six or seven different EHR systems among its 15 CMHCs. The official expressed the challenge of collecting consistent data even for basic measures from these clinics as follows:

"Even though all CCBHCs will have certified EHRs, each system might code and record data in a slightly different format. For example, height can be recorded in inches or centimeters. It is imperative that all data be normalized before aggregation and analysis."

Another state reported that all of its CMHCs are utilizing the same EHR product but that some centers have older versions with less functionality and some have implemented significant customization. Many behavioral health providers were not eligible for EHR incentive programs, so they either have not adopted EHRs or might have adopted noncertified EHRs. While certified EHR systems can have minimum standards related to collecting and reporting data, there are no such standards guaranteed for noncertified systems.

A key consideration for the evaluation is the extent to which the EHR systems in the CCBHCs can exchange information with systems in other settings for tracking the services an individual receives. These data could extend the information on the services within the CCBHC to include information on the network of providers from which a client receives care. In some cases, they can include nonmedical social services, such as residential care or vocational training, in addition to primary or specialty medical care, ED visits, and hospitalizations. The ability of clinics to exchange information faces significant structural barriers. For instance, there are at least 1,900 certified outpatient EHR vendors and 1,300 inpatient vendors in the United States (Office of the National Coordinator of Health Information Technology [ONC], 2014), which can customize systems to provider and setting. As a result, hospital systems might not interface with clinic systems, and sharing data about ED visits or admissions electronically might not be possible absent a functioning health information exchange (HIE). In a 2015 report, the ONC 
found that about 40 percent of acute care hospitals were able to exchange patient information electronically with other providers. The ability to exchange information with behavioral health providers was lower, less than 30 percent (ONC, 2015).

Some states offer either free or low-cost EHR systems for their CMHCs, and states have participated in other demonstrations that require EHR systems, but these systems do not necessarily share information across providers. Table 3.4 summarizes information gathered from state mental health authorities about current data-sharing capabilities between CMHC EHRs and other community providers. Very few of the planning grant states report the ability to share data among CMHCs and other providers or through HIEs, although several propose implementing an information technology infrastructure to support data-sharing.

Table 3.4. Agreements Allowing EHR Patient-Level Data-Sharing from State Mental Health Agency Profiling System, 2015

\begin{tabular}{|c|c|c|c|c|}
\hline State & $\begin{array}{l}\text { Between Community } \\
\text { Providers and State } \\
\text { Psychiatric Hospitals }\end{array}$ & $\begin{array}{l}\text { Between Health } \\
\text { Maintenance Organizations } \\
\text { and Other Managed Care } \\
\text { Firms and the SMHA }\end{array}$ & $\begin{array}{l}\text { Between } \\
\text { Community } \\
\text { Providers }\end{array}$ & $\begin{array}{c}\text { Through } \\
\text { an HIE }\end{array}$ \\
\hline Alaska & No & No & Yes & No \\
\hline California & - & - & - & - \\
\hline Colorado & No & Yes & No & No \\
\hline Connecticut & No & No & No & No \\
\hline Illinois & No & No & No & No \\
\hline Indiana & No & No & No & No \\
\hline lowa & - & - & - & - \\
\hline Kentucky & No & No & No & - \\
\hline Maryland & No & No & No & No \\
\hline Massachusetts & Yes & No & No & No \\
\hline Michigan & No & Yes & Yes & Yes \\
\hline Minnesota & No & No & No & No \\
\hline Missouri & No & No & No & No \\
\hline Nevada & Yes & No & Yes & No \\
\hline New Mexico & - & - & - & - \\
\hline New York & Yes & Yes & Yes & No \\
\hline New Jersey & - & - & - & - \\
\hline North Carolina & - & Yes & - & - \\
\hline Oklahoma & No & No & No & Yes \\
\hline Oregon & No & No & No & Yes \\
\hline Pennsylvania & - & - & - & - \\
\hline Rhode Island & No & Yes & Yes & Yes \\
\hline Texas & Yes & No & Yes & No \\
\hline Virginia & Yes & No & No & Yes \\
\hline
\end{tabular}




\begin{tabular}{lcccc} 
Between Community & $\begin{array}{c}\text { Between Health } \\
\text { Providers and State } \\
\text { Psychiatric Hospitals }\end{array}$ & $\begin{array}{c}\text { Maintenance Organizations } \\
\text { and Other Managed Care } \\
\text { Firms and the SMHA }\end{array}$ & $\begin{array}{c}\text { Between } \\
\text { Community } \\
\text { Providers }\end{array}$ & $\begin{array}{c}\text { Through } \\
\text { an HIE }\end{array}$ \\
\hline Total & 5 & 5 & 6 & 5 \\
\hline
\end{tabular}

SOURCE: NRI, Inc., 2015.

NOTE: $-=$ not reported.

In our discussions, several states described well-developed health information technology systems that facilitate the exchange and/or merging of data. For example, two states are utilizing a commercial registry product that extracts client records from the CMHC EHRs, claims and encounter data from the Medicaid Management Information System (MMIS), and other data sources to compile required measures at the clinic level. Another state reported that it is considering buying this product or developing its own registry. Other states would likely have to use more manual processes to extract EHR data and merge them with other sources. States' choices on whether and how to combine data likely will yield additional variations in availability and quality of data.

\section{EHRs in Potential Comparison Clinics}

While the EHR requirements in the certification criteria suggest that clinical data will be available to describe the performance of CCBHCs in some detail, the ability of the evaluation to construct meaningful comparisons using these data will depend on the availability of EHRs in non-CCBHC clinics. However, behavioral health providers have been slower than providers in other sectors of the health care system to implement EHR technology, partly because of cost, privacy concerns, and the absence of products that meet their needs (DeRoches et al., 2008; Health IT Buzz, 2013; Healthcare IT News, 2014; Audet, Squires, and Doty, 2014).

\section{Non-EHR Clinical Data}

There are three potential gaps in the EHR data that might need to be filled from other sources, such as paper records or supplemental clinic registries. First, data from the pre-CCBHC time period might exist only in paper form for $\mathrm{CCBHCs}$ that have only recently introduced EHRs. Second, given the wide variation in the functionality of EHRs, it is likely that supplemental systems would be required to collect the full range of data desired for evaluation purposes in some CCBHCs. For example, data on DCOs or services provided away from the clinic might not be captured in the EHR. This can be true for clinics with older EHR systems with limited functionality. Third, data on the comparison populations, either comparison sites or patient populations, might also be in paper form at the clinic level both before and during the demonstration period. Compared with EHRs, paper health records could present additional challenges to the evaluation. Getting data from paper to an analytic data set adds complexity and cost. If used, these data will have to be collected and standardized before they can be utilized in an analysis. 


\section{Qualitative Methods}

Qualitative data collection, including information in QRs (described earlier in this chapter), unstructured or semistructured discussions with CCBHC clinic staff and state officials, site visits to CCBHCs, and focus groups with consumers and family members, can also provide useful information to an evaluation that cannot be collected by other means. It is important to note both the strengths and limitations of these methods. Qualitative methods provide rich contextual information that can help evaluators understand the constraints on implementers, identify important dimensions of consumer experience, and suggest strategies for addressing specific implementation challenges that might be generalizable across clinics. In particular, qualitative methods can identify unanticipated and unintended effects of implementation not captured through more-structured evaluation tools. However, qualitative methods generally are not representative of a well-defined population or set of programs and can be unstandardized, further limiting their generalizability. Rigorous qualitative data collection can address this limitation.

Given their distinctive strengths for evaluation, qualitative methods are best used in a highly targeted way, with sites and topics for investigation selected on the basis of prior knowledge. For instance, unanticipated implementation issues can come to light in QRs (described earlier in this chapter) or in quality reporting. These issues could then be explored in phone interviews, which allow for a relatively large sample at low cost. Site visits could then be made to a small and select group of clinics, perhaps one with high performance and another with low performance on the same indicator, enabling evaluators to explore implementation barriers and solutions to those barriers in greater depth. Targeted use of qualitative methods to compare and contrast clinics with specific features of interest is likely to be a more-efficient use of evaluation resources than use of these methods to collect data intended to represent CCBHC processes or outcomes in general.

\section{Surveys}

Surveys are a potential source of data that cannot be captured in the administrative data sets described earlier, in particular for information that can be collected only from consumers, family members, or providers. The costs of conducting surveys can be minimized through the use of existing surveys, which assess consumer experiences with care and can be used to measure both access and quality. Many states already use consumer surveys for their Medicaid population, although the sampling frame for these surveys might not be designed to assess the client populations for specific providers. There are also provider surveys that can be used to assess clinic culture, care coordination, and whether staff is being used efficiently within the clinic. These measures could provide insight into why some clinics can provide higher-quality care than others. Some of this information can also be available through the clinic operations data sets described earlier in this chapter. 


\section{Consumer and Family Surveys}

\section{Description}

There is one set of surveys that has clear strategic advantages for evaluation purposes over other options: the Mental Health Statistics Improvement Program (MHSIP) Consumer and Family surveys. The MHSIP, developed by the CMHS, has been in wide use since its development in the 1990s (Teague et al., 1997; Eisen, Shaul, Clarridge, et al., 1999; Eisen, Shaul, Leff, et al., 2001; CMHS, 2006), is used in the reporting required of states as a condition of their receipt of Mental Health Block Grants, and is included in the reporting required of CCBHCs for the demonstration. The MHSIP Consumer Survey assesses seven domains: general satisfaction with care, perception of access to services, perception of quality and appropriateness of care, perception of participation in treatment planning, perception of outcomes of services, perception of functioning, and perception of social connectedness in both outpatient and inpatient care settings for adults and youth. The Adult Consumer Survey version was designed to complement this information with a focus on concerns of access, quality, satisfaction, and outcomes. A version for adolescents and their parents, the Youth Services Survey-Family, has also been developed (CMHS, 2006).

\section{Strengths}

The MHSIP surveys have a clear advantage because they are in wide use among states, contain validated items included in states' URS requirements from state mental health authorities, and already are required to be reported by CCBHCs as part of the quality measure set. The University of Washington's Washington Institute for Mental Health Research and Training, 2013, reports almost all states are using versions of the MHSIP Adult Survey and Youth Services Survey-Family that are comparable but often state-specific. Nearly all of the 24 states that received planning grants are using both the adult and youth versions of the MHSIP; the one exception is Rhode Island, which is reporting results only from the adult version. However, states vary widely regarding the sampling approach and survey administration methodologies used to conduct this survey.

\section{Availability}

As shown in Table 3.4, which compiles data from SAMHSA's URS and 2014 state survey methodology documentation, there is considerable variation across states in the way in which the survey is administered and the sampling strategy utilized, because each state is allowed to choose its approach to sampling consumers and administering the survey. States may choose to frame their samples by convenience, random, or stratified or can choose to focus on a population-based samples, such as all consumers, those with SMI, or clients of certain providers. Finally, mode of administration can vary from face-to-face, phone, web, or mail. For instance, in California, the survey is administered face-to-face, while, in Pennsylvania, the survey is conducted by mail. Detailed sampling plans are not available, although some states clearly restrict the target population to groups receiving particular services. Michigan, for instance, surveys only recipients of Assertive Community Treatment. We could not determine for every state whether consumer surveys could be identified at the clinic level or whether they were all currently 
aggregated up to the state level. We were able to confirm through key informant interviews that Missouri and Oklahoma currently have consumer survey data at the clinic level, and Oregon is adding an identifier for individual clinics; for all other states that received planning grants, we assume that consumer survey data are collected following a state-level sampling design and are not available in large-enough samples to assess individual clinics. There is also variation in response rates to each state's MHSIP because of sampling, as well as the capacity and additional effort by the administrating entity to follow up on responses.

Table 3.5. Grantee State Administration of the MHSIP Adult Consumer Surveys from 2014 Survey Methodology and Sample Information

\begin{tabular}{|c|c|c|c|c|}
\hline Grantee State & Sample Type & Survey Methodology & $\begin{array}{l}\text { Consumers } \\
\text { Sampled }\end{array}$ & $\begin{array}{l}\text { Administered } \\
\text { at State or } \\
\text { Local level }\end{array}$ \\
\hline Alaska & Other & Mail only & Current and former & Both \\
\hline California & Convenience & Face-to-face only & Current only & Local \\
\hline Colorado & Convenience & Face-to-face only & Current only & Local \\
\hline Connecticut & Convenience & Face-to-face only & Current only & State \\
\hline Illinois & $\mathrm{n} / \mathrm{r}$ & $n / r$ & $n / r$ & $n / r$ \\
\hline Indiana & Convenience & Face-to-face only & Current only & State \\
\hline lowa & Convenience & Face-to-face only & Current only & State \\
\hline Kentucky & Convenience & Face-to-face only & Current only & Local \\
\hline Maryland & Stratified & Phone only & Current and former & State \\
\hline Massachusetts & Stratified & $\begin{array}{l}\text { Multiple methods: mail } \\
\text { and web }\end{array}$ & Current only & State \\
\hline Michigan & Other & Face-to-face only & Current only & Local \\
\hline Minnesota & Stratified & $\begin{array}{l}\text { Multiple methods: phone, } \\
\text { mail, web, and face-to-face }\end{array}$ & Current and former & State \\
\hline Missouri & Convenience & Face-to-face only & Current only & Both \\
\hline Nevada & Convenience & $\begin{array}{l}\text { Multiple methods: mail } \\
\text { and face-to-face }\end{array}$ & Current and former & State \\
\hline New Jersey & Stratified & Mail only & Current only & State \\
\hline New Mexico & Random & $\begin{array}{l}\text { Multiple methods: phone } \\
\text { and face-to-face }\end{array}$ & Current only & State \\
\hline New York & Convenience & $\begin{array}{l}\text { Multiple methods: web } \\
\text { and face-to-face }\end{array}$ & Current only & State \\
\hline North Carolina & Convenience & Face-to-face only & Current only & Local \\
\hline Oklahoma & Stratified & Mail only & Current and former & State \\
\hline Oregon & Stratified & $\begin{array}{l}\text { Multiple methods: mail } \\
\text { and web }\end{array}$ & Current and former & State \\
\hline Pennsylvania & Random & Mail only & Current and former & State \\
\hline Rhode Island & Other & $\begin{array}{l}\text { Multiple methods: mail } \\
\text { and face-to-face }\end{array}$ & Current only & Both \\
\hline
\end{tabular}




\begin{tabular}{|c|c|c|c|c|}
\hline Grantee State & Sample Type & Survey Methodology & $\begin{array}{l}\text { Consumers } \\
\text { Sampled }\end{array}$ & $\begin{array}{l}\text { Administered } \\
\text { at State or } \\
\text { Local level }\end{array}$ \\
\hline Texas & Stratified & $\begin{array}{l}\text { Multiple methods: mail } \\
\text { and web }\end{array}$ & Current only & State \\
\hline Virginia & $n / r$ & $n / r$ & $n / r$ & $n / r$ \\
\hline
\end{tabular}

SOURCE: NRI, 2016.

NOTE: $\mathrm{n} / \mathrm{r}=$ not reported.

\section{Challenges}

The state-specific approaches in sample frame and survey mode have allowed states to make within-state comparisons over time; however, the variation means that existing MHSIP data are not a reliable source for comparing consumer experience of care across states. A comparison across states would be very difficult to maybe impossible. However, a targeted survey of CCBHC consumers using the MHSIP instruments can be feasible for the evaluation because it is validated and most states have experience administering and collecting the MHSIP. Requiring changes to the sample frame and survey mode for the evaluation could cause a state to lose the ability to continue monitoring within-state trends, so consideration should be given to states that would be negatively affected by any new method requirements.

\section{Summary}

Ideally, the same provider-level sampling approach would exist in all demonstration states. This would reduce the variation and allow for state-to-state comparison. Possible alternatives would be to 1) compare only states using the same methods, 2) compare only within states for all demonstration states regardless of method, and 3) compare only within states for demonstration states with rigorous methods.

\section{Provider Surveys}

Surveys of clinicians and staff can be used to measure the clinic's structural capabilities, as well as provider experience. These surveys have been used in other evaluations with mixed results in terms of response rates. As an example, an evaluation of the CMS FQHC Advanced Primary Care Practice demonstration fielded two versions of a scannable paper-based survey instrument that was assembled by the Patient-Centered Medical Home Evaluators Collaborative Measurement Workgroup on Clinician and Staff Experience survey (Kahn et al., 2015). One version was for physicians, nurse practitioners, and physician assistants; the other version was for other clinical and nonclinical staff. Domains of the survey included work content, work perceptions, culture, demonstration-specific domains, and FQHC-specific domains. The evaluators randomly selected three clinician and three staff respondents from each of the 500 participating clinics. They surveyed 3,011 clinicians and other staff members in the participating clinics; 564 responded to both surveys, yielding a response rate of 19 percent. The study team attributes the low response rate to a lack of buy-in from clinic leaders. If provider surveys are used in the CCBHC demonstration evaluation, the evaluator will need to consider how to encourage enough participation to yield reliable results. The evaluation might be able to use 
existing items and scales; however, some might need to be modified to account for the unique aspects of care for mental health and SUDs.

\section{Required Quality Reporting by CCBHCs and States}

The certification criteria include reporting requirements for CCBHCs and states. The required measures are listed in Appendix B. The ultimate source of the information on which the measures will be based is described earlier in this chapter. Most of the CCBHC measures will be based on clinical data, and most of the state measures will be based on claims or encounter data. Because reporting of the measures is required, it can be a resource to the evaluation without imposing any additional burden on clinics or states. The measures will provide two types of information to the evaluation. First, the reporting and use of the measures can be tracked as a way of assessing the ability of CCBHCs to use information on their clinical care to make improvements in quality. In most states, systematic use of information for quality improvement will require the development of new data systems and feedback mechanisms. Second, the measures will allow the evaluation to assess CCBHC performance on several of the evaluation domains. In particular, as shown in Table 3.6, the required measures provide information on four evaluation domains: access, quality, utilization, and health and functioning. For each of these domains, the measures can be used to describe the performance of CCBHCs and, potentially, to compare that performance with other entities in the state reporting the same measures, the past performance of a clinic that became a $\mathrm{CCBHC}$, or national performance benchmarks where they are available.

The ability to use the required reporting to analyze the impact of $\mathrm{CCBHCs}$, relative to other models of care, will depend on the type of measure and the specific data sources in each state. For measures based on clinical records, an analysis of impact will need to have access to the same measures based on the same type of reporting system for the comparison group. Given the low level of penetration of quality measurement in the specialty mental health sector, there can be few opportunities for this type of comparison. On the other hand, for the claims-based measures, the evaluation should be able to specify the required measures for any comparison group that can be identified in the claims data sets. 
Table 3.6. Required Quality Measures and Potential Supplemental Measure Content Areas for CCBHC- and State-Level Reporting

\begin{tabular}{|c|c|c|}
\hline Domain: Research Question & Required CCBHC Measure & Required State Measure \\
\hline \multirow{2}{*}{$\begin{array}{l}\text { Access: Relative to comparison } \\
\text { groups, do CCBHCs expand access } \\
\text { to behavioral health care? }\end{array}$} & $\begin{array}{l}\text { Number/percentage of new } \\
\text { clients with initial evaluation } \\
\text { provided within } 10 \text { days }\end{array}$ & - \\
\hline & $\begin{array}{l}\text { MHSIP Consumer and Family } \\
\text { Survey }\end{array}$ & - \\
\hline \multirow{9}{*}{$\begin{array}{l}\text { Quality: Relative to comparison } \\
\text { groups, do CCBHCs improve the } \\
\text { quality of behavioral health care? }\end{array}$} & $\begin{array}{l}\text { Screening and follow-up } \\
\text { plan for depression }\end{array}$ & $\begin{array}{l}\text { Follow-up care for children prescribed } \\
\text { attention deficit hyperactivity disorder } \\
\text { medication }\end{array}$ \\
\hline & $\begin{array}{l}\text { Suicide risk assessment: adults } \\
\text { with major depressive disorder }\end{array}$ & Antidepressant medication management \\
\hline & $\begin{array}{l}\text { Suicide risk assessment: } \\
\text { children/adolescents with } \\
\text { major depressive disorder }\end{array}$ & $\begin{array}{l}\text { Adherence to antipsychotic medications for } \\
\text { individuals with schizophrenia }\end{array}$ \\
\hline & $\begin{array}{l}\text { Initiation and engagement with } \\
\text { alcohol/drug treatment }\end{array}$ & $\begin{array}{c}\text { Diabetes screening for people with } \\
\text { schizophrenia or bipolar disorder who are } \\
\text { using antipsychotic medications }\end{array}$ \\
\hline & $\begin{array}{c}\begin{array}{c}\text { Screening and brief intervention: } \\
\text { unhealthy alcohol use }\end{array} \\
\end{array}$ & $\begin{array}{c}\text { Follow-up after hospitalization for mental } \\
\text { illness (adult) }\end{array}$ \\
\hline & $\begin{array}{l}\text { Tobacco use: screening } \\
\text { and cessation intervention }\end{array}$ & $\begin{array}{c}\text { Follow-up after hospitalization for mental } \\
\text { illness (child/adolescent) }\end{array}$ \\
\hline & $\begin{array}{l}\text { Body mass index screening } \\
\text { and follow-up (adult) }\end{array}$ & $\begin{array}{l}\text { Follow-up after discharge from the ED for } \\
\text { mental health or alcohol or other dependence }\end{array}$ \\
\hline & $\begin{array}{l}\text { Weight screening and } \\
\text { counseling for adolescents }\end{array}$ & - \\
\hline & $\begin{array}{l}\text { MHSIP Consumer and Family } \\
\text { Survey }\end{array}$ & \\
\hline $\begin{array}{l}\text { Utilization: Relative to comparison } \\
\text { groups, do CCBHCs improve } \\
\text { patterns of total health care } \\
\text { utilization? }\end{array}$ & - & Plan all-cause readmissions \\
\hline \multirow{2}{*}{$\begin{array}{l}\text { Health and Functioning: Relative } \\
\text { to comparison groups, do CCBHCs } \\
\text { improve consumers' health and } \\
\text { functioning outcomes? }\end{array}$} & $\begin{array}{l}\text { Depression remission } \\
\text { at } 12 \text { months }\end{array}$ & $\begin{array}{c}\text { Housing status (residential status at } \\
\text { admission or start of the reporting period } \\
\text { compared with residential status at discharge } \\
\text { or end of the reporting period) }\end{array}$ \\
\hline & $\begin{array}{l}\text { MHSIP Consumer and Family } \\
\text { Survey }\end{array}$ & - \\
\hline
\end{tabular}

SOURCE: Authors' analysis.

\section{Sources of Data for Each Evaluation Domain}

Table 3.7 summarizes our conclusions regarding the availability of data for each evaluation domain. As shown in the table, all of the evaluation domains are at least in part covered by the four major sources of existing data, documentation of the certification process conducted by states as found in the demonstration application, or obtained directly from the states, clinical data derived from EHRs (including the RQMs), claims and encounter records, and CRs. These sources alone have the potential to provide a robust description of CCBHC implementation in the demonstration states. However, these data sources are highly variable in format and detailed content across states and across providers and payers within states. Some states already have 
Table 3.7. Evaluation Data Sources, by Domain

\begin{tabular}{|c|c|c|c|c|c|c|}
\hline Data Source & Structure & Access & Quality & Utilization & Costs & $\begin{array}{l}\text { Health and } \\
\text { Functioning }\end{array}$ \\
\hline $\begin{array}{l}\text { Existing clinic } \\
\text { operations data }\end{array}$ & $\begin{array}{l}\text { Demonstration } \\
\text { application }\end{array}$ & - & $\begin{array}{l}\text { Demonstration } \\
\text { application }\end{array}$ & CRs & CRs & TRAC/NOMs \\
\hline $\begin{array}{l}\text { New clinic operations } \\
\text { data }\end{array}$ & QRs & QRs & - & - & QRs & - \\
\hline $\begin{array}{l}\text { Existing } \\
\text { claims/encounter } \\
\text { data }\end{array}$ & - & $\begin{array}{l}\text { Required } \\
\text { measures }\end{array}$ & $\begin{array}{l}\text { Required } \\
\text { measures }\end{array}$ & $\begin{array}{l}\text { Required } \\
\text { measures }\end{array}$ & $\begin{array}{l}\text { Required } \\
\text { measures }\end{array}$ & - \\
\hline $\begin{array}{l}\text { New } \\
\text { claims/encounter } \\
\text { data }\end{array}$ & - & $\begin{array}{l}\text { Additional } \\
\text { measures }\end{array}$ & $\begin{array}{l}\text { Additional } \\
\text { measures }\end{array}$ & $\begin{array}{l}\text { Additional } \\
\text { measures }\end{array}$ & $\begin{array}{l}\text { Additional } \\
\text { measures }\end{array}$ & - \\
\hline Existing clinical data & - & $\begin{array}{l}\text { EHRs/ } \\
\text { quality } \\
\text { measure }^{a}\end{array}$ & $\begin{array}{l}\text { EHRs/ } \\
\text { quality } \\
\text { measures }\end{array}$ & $\begin{array}{l}\text { EHRs/ } \\
\text { quality } \\
\text { measure }^{b}\end{array}$ & - & $\begin{array}{c}\text { EHRs/ } \\
\text { quality } \\
\text { measures }^{c}\end{array}$ \\
\hline New clinical data & - & $\begin{array}{l}\text { EHRs/ } \\
\text { additional } \\
\text { measures }\end{array}$ & $\begin{array}{l}\text { EHRs/ } \\
\text { additional } \\
\text { measures }\end{array}$ & $\begin{array}{l}\text { EHRs/ } \\
\text { additional } \\
\text { measures }\end{array}$ & - & $\begin{array}{l}\text { EHRs/ } \\
\text { additional } \\
\text { measures }\end{array}$ \\
\hline Existing surveys & - & $\begin{array}{c}\text { MHSIP } \\
\text { Consumer } \\
\text { and Family }\end{array}$ & $\begin{array}{c}\text { MHSIP } \\
\text { Consumer and } \\
\text { Family }\end{array}$ & - & - & $\begin{array}{l}\text { MHSIP, quality } \\
\text { measure }^{d}\end{array}$ \\
\hline New surveys & $\begin{array}{l}\text { Provider/ } \\
\text { clinic survey }\end{array}$ & $\begin{array}{l}\text { Provider/ } \\
\text { clinic survey }\end{array}$ & $\begin{array}{c}\text { Provider/ clinic } \\
\text { survey }\end{array}$ & - & - & - \\
\hline $\begin{array}{l}\text { New qualitative } \\
\text { data }\end{array}$ & $\begin{array}{l}\text { Interviews, } \\
\text { site visits }\end{array}$ & Site visits & $\begin{array}{l}\text { Consumer } \\
\text { focus groups }\end{array}$ & - & Site visits & - \\
\hline
\end{tabular}

SOURCE: Authors' analysis.

a Clinics must report a measure of timely access to care.

${ }^{\mathrm{b}}$ Clinics must report a measure of hospital readmissions.

${ }^{\mathrm{c}}$ Clinics must report a measure of depression remission.

${ }^{\mathrm{d}}$ States must report one measure of housing status for $\mathrm{CCBHC}$ clients.

sophisticated, integrated data systems that can create uniform, detailed, and reliable data on clinic performance, but most states are not yet at that point. In addition, state data systems are all in flux, with new capabilities being added frequently. The quality and timing of data also vary depending on whether a consumer is covered under Medicaid FFS, an MCO, or some combination of the two. The evaluation design will need to take these variations into account in assessing the potential use of data sources in each demonstration state.

Gaps in the reporting requirements with respect to utilization and structure could be filled through strategically targeted new data collection efforts, which would most likely include additional structured reporting of operational data by CCBHCs, surveys of providers, and 
qualitative investigations of specific operational issues. Additional EHR-based quality measures could be requested from CCBHCs, provided that the additional reporting burden is minimal, and additional quality measures could be constructed by the evaluator once it has access to the claims or encounter data. Data collection and reporting systems put in place for the reporting required by the demonstration could be expanded to include additional instruments to minimize costs and burden.

\section{Data Sources for Comparison Groups}

As anticipated, collection of data for comparison purposes presents additional challenges. A goal of the evaluation will be comparing the services that consumers treated in CCBHCs receive with services received by consumers treated in other types of clinical settings. (The design of the comparison is addressed in detail in Chapter Four.) Clinical data and claims and encounter data are likely to be available for comparison purposes for the evaluation, provided that an appropriate comparison group can be identified in the relevant data set. For EHR-based measures, this requires that comparison clinics be found with EHRs that can produce measures to the same specifications. For claims and encounter data, this requires that states or MCOs have place-of-service codes or provider identifiers that will allow them to reliably attribute consumers to specific clinics. In fact, several states are using their planning grants to put such systems in place.

Collection of operational and survey data from comparison sites presents more-serious challenges. Some states might already have systematic reporting by CMHCs that could be used to provide data comparable to those collected for CCBHCs, but those systems are even more variable across states than the claims and encounter data systems. Some clinics in some states might already be reporting similar data to SAMHSA because they are participating in other federal programs. Existing consumer survey data, which exist in the majority of states, offer another potential source of comparison data, but sampling methods vary across states and might not provide appropriate controls without specific adjustments for that purpose. There is no alternative to investigating these potential data sources on a state-by-state basis. New data collection efforts at comparison clinics are feasible but likely to be costly.

\section{Burden of Data Collection for Clinics and States}

Assessing the burden posed by data collection is a critical component of evaluation design and a requirement of the Office of Management and Budget in certain circumstances. ${ }^{4}$ The evaluator must weigh the benefit of new data collection by CCBHCs, and potentially comparison sites, against the burden on clinic staff and the resulting quality of the data. If providing data beyond the demonstration requirements is very burdensome on participating clinic staff, they are less likely to put in the effort needed to ensure completeness or validity of data. This is especially

${ }^{4}$ The Paperwork Reduction Act (Public Law 104-13, 1995) requires a process of obtaining approval from the Office of Management and Budget for federally sponsored data collections. 
a concern for comparison sites because they do not face the same incentives to produce even the data required of participating sites by the demonstration. In Table 3.8, we indicate those data elements required for $\mathrm{CCBHCs}$ and those that would represent new requirements and additional burden for both CCBHCs and potentially for comparison sites. (For purposes of potential Office of Management and Budget clearance, we estimate the burden of each type of new data collection in Appendix F.) We do not include the burden of submitting claims or encounter data because these data are currently submitted by CMHCs to the states or MCOs.

The largest burden would likely result from a request for EHR-based measures from CCBHCs or comparison clinics if they are not currently reporting those measures. The burden of additional EHR-based quality measures would depend on the CCBHCs' ability to specify them within their systems. In some cases, reporting on an additional measure could be a relatively simple change to make, but the same measure might not be easily reported in other cases. Likewise, collecting the data from comparison clinics will depend on the EHR systems in those clinics, which can be less sophisticated technologically than the CCBHCs'. Additional burden would be imposed on CCBHCs should the evaluation require QRs, a consumer survey other than the MHSIP, a provider survey, provider interviews, or site visits (rough estimates of the time required for each are included in Appendix F). Ideally, the evaluator would collect analogous information from comparison sites, but doing so might require some type of incentives offered by the state or the evaluator. 
Table 3.8. Potential Data Collection Burden for CCBHCs and Comparison Clinics for Evaluation Data Source Options

\begin{tabular}{|c|c|c|c|c|}
\hline \multirow[b]{2}{*}{ Data Type } & \multirow[b]{2}{*}{ Data Source } & \multirow[b]{2}{*}{$\begin{array}{c}\text { Required } \\
\text { CCBHC } \\
\text { Reporting }\end{array}$} & \multicolumn{2}{|c|}{ Potential Evaluation Data Sources } \\
\hline & & & $\begin{array}{c}\text { New Data } \\
\text { Collection } \\
\text { for CCBHCs }\end{array}$ & $\begin{array}{c}\text { New Data } \\
\text { Collection for } \\
\text { Comparison } \\
\text { Clinics }\end{array}$ \\
\hline Clinical Data & EHR & $x^{a}$ & $x$ & $x$ \\
\hline \multirow{3}{*}{$\begin{array}{l}\text { Clinic Operations } \\
\text { Data }\end{array}$} & CRs & $x$ & - & - \\
\hline & Demonstration application & $x$ & - & - \\
\hline & QRs & - & $\mathrm{X}$ & - \\
\hline \multirow[t]{2}{*}{$\begin{array}{l}\text { Consumer/Family } \\
\text { Survey }\end{array}$} & MHSIP & $x$ & - & $?$ \\
\hline & Other & - & $x$ & $x$ \\
\hline \multirow{2}{*}{ Provider Survey } & Web survey & - & $x$ & $x$ \\
\hline & Paper survey & & $\mathrm{X}$ & $\mathrm{X}$ \\
\hline \multirow{2}{*}{ Qualitative Methods } & Phone interviews & - & $x$ & $x$ \\
\hline & Site visits & - & $\mathrm{X}$ & $x$ \\
\hline
\end{tabular}

SOURCE: Authors' analysis.

NOTE: ? = unknown; $-=$ not reported.

${ }^{\mathrm{a}}$ Many of the required measures for CCBHCs are based on EHR data.

\section{Cost of Data Collection and Analysis}

The evaluator must also consider the costs associated with developing data collection instruments, purchasing data from other sources, fielding surveys or conducting interviews and site visits, and processing and analyzing data. For each of these elements, we assign a relative cost to the evaluation for both CCBHCs and potential comparison groups (Table 3.9). We do not include the potential cost of incentives for comparison clinics, which might be required for some or all data collection activities. 
Table 3.9. Relative Costs of Data Collection for Evaluation

\begin{tabular}{|c|c|c|c|c|c|}
\hline Data Type & Data Source & $\begin{array}{c}\text { Data for } \\
\text { CCBHC/ } \\
\text { Comparison/ } \\
\text { Both }\end{array}$ & Development & $\begin{array}{l}\text { Acquisition } \\
\text { and Fielding }\end{array}$ & $\begin{array}{c}\text { Processing } \\
\text { and } \\
\text { Analysis }\end{array}$ \\
\hline \multirow{3}{*}{$\begin{array}{l}\text { Clinic } \\
\text { operations data }\end{array}$} & CRs & $\mathrm{CCBHC}$ & 0 & 0 & Low \\
\hline & QRs & $\mathrm{CCBHC}$ & Medium & 0 & Low \\
\hline & Demonstration application & $\mathrm{CCBHC}$ & 0 & 0 & Medium \\
\hline \multirow{4}{*}{$\begin{array}{l}\text { Claims/ } \\
\text { encounter data }\end{array}$} & State & Both & Low & 0 & High \\
\hline & CMS, MAX & Both & Low & 0 & Medium \\
\hline & CMS, alphaMAX & Both & Low & 0 & High \\
\hline & $\begin{array}{l}\text { CMS, Medicare } \\
\text { (dual-eligibles) }\end{array}$ & Both & High & 0 & High \\
\hline \multirow{3}{*}{ Clinical data } & MCO & Both & Medium & $?$ & $?$ \\
\hline & Required EHR-based & $\mathrm{CCBHC}$ & 0 & 0 & Low \\
\hline & measures & Comparison & 0 & Low & Low \\
\hline \multirow{3}{*}{$\begin{array}{l}\text { Consumer } \\
\text { survey }\end{array}$} & New EHR-based measures & Both & Medium & Low & Medium \\
\hline & MHSIP & Both & 0 & $?$ & Medium \\
\hline & Other & Both & High & High & $?$ \\
\hline \multirow{2}{*}{ Provider survey } & Web survey & Both & High & Medium & Low \\
\hline & Paper survey & Both & High & Low & $?$ \\
\hline \multirow{2}{*}{$\begin{array}{l}\text { Qualitative } \\
\text { methods }\end{array}$} & Phone interviews & Both & Low & Medium & Low \\
\hline & Site visits & Both & Medium & High & Low \\
\hline
\end{tabular}

SOURCE: Authors' analysis.

NOTE: ? = unknown.

Operations data: In order for QRs to be useful and digestible, an investment in their development would be required. If they are highly structured and specific, the cost of analysis would be relatively low. They are not required to be reported on a standardized form (i.e., each state can use its own form). Certification information from the demonstration application, however, could vary tremendously across states and thus require additional time for analysis.

Claims/encounter data: For each of the sources in this category, there would be some investment of time to determine the exact data set required by the evaluation, particularly for Medicare data requested for dual eligibles. We assume that there would be no cost for obtaining Medicaid data directly from the demonstration states. We also assume that there would be no cost for obtaining Medicaid and/or Medicare data from CMS (as a partner in the demonstration, CMS would likely waive the fee). MCOs might or might not charge for encounter data provided for the evaluation. The cost of processing and analysis would likely be the highest for data obtained directly from the states because, unlike most of the CMS data, they will arrive in a variety of formats.

Clinical data: The cost to the evaluation associated with obtaining the same EHR-based measures from comparison sites to compare with the measures required for CCBHCs would be relatively low because the measure specifications would already be developed and would need to 
be implemented at sites that do not already collect data on the same measures. There can be some administrative costs to collecting the data from the comparison sites. The cost of analysis would also be low, assuming that the sites can submit the data as specified. New EHR-based measures not already developed for the demonstration would be expensive given the cost of developing the specifications and reporting tool and cleaning and processing the data.

Consumer survey: The costs associated with using the MHSIP for evaluation purposes are difficult to predict given the variability in versions utilized and sampling methods across states. In the best case, states would be able to provide survey results for CCBHCs and comparison groups such that the only cost to the evaluation would be the analysis of results. The use of some other consumer survey would involve costs associated with identifying or developing an appropriate instrument, fielding the survey (the cost of which might be borne by the evaluation or the states), and analyzing the results.

Provider survey: The largest portion of the cost of a provider survey would likely be in the development and testing phase. If the survey were administered via the Internet, there might also be a subscription cost. Paper surveys could be provided on scannable forms to avoid data entry costs. The cost of analysis of evaluator-developed surveys would be relatively low.

Qualitative methods: Phone interview protocols would be relatively low cost to develop, because they would be based on a review of QRs or other data sources. An investment of time would be required for scheduling the interviews and then conducting them with a questioner and a note taker, and there can be transcription costs. Site visits require considerable planning and preparation, as well as travel time and costs for at least two individuals for each site. The analysis of both interview and site visit notes could be done with low-cost commercial software, such as Dedoose.

\section{Limitations of Available Data}

Our exploration of data sources has also identified two important gaps that can limit the evaluation in significant ways. First, while the PAMA intends to have population-level impacts on access to behavioral health care, data to support population-based measures of access are lacking. It can be possible to link data from clinic records to population data from the census on the catchment areas that the CCBHCs are designed to serve. However, the population of untreated seriously mentally ill adults is likely to be poorly tracked in the census data and highly mobile across catchment areas. Second, data on use of nonmedical social services also are lacking. Many consumers also can receive services, such as temporary housing, funded through state or local services. Lack of more-comprehensive data on service use is concerning because of the possibility of shifting care between providers. For instance, consumers who are receiving services from locally funded providers can instead opt to receive those services from CCBHCs, where they will be funded through Medicaid. In the absence of data on the locally funded services, this shift in payers will appear to be an increase in utilization. 


\section{Chapter Four. Comparison Groups}

\section{Introduction}

While the descriptive questions outlined in the research questions in Chapter Two draw on data about the CCBCHs, many of the analytic questions, which address the impact of the CCBHCs, require a comparison group to distinguish the impact of CCBHCs from the effects of other changes on behavioral health care. The selection of an appropriate comparison group is particularly important given that states are implementing the multiple concurrent innovative policies affecting care for the seriously mentally ill. In particular, comparison groups will be essential for determining whether access to care, quality of care, and utilization patterns observed in the CCBHCs are better or worse than in existing care models within the same states.

Identifying appropriate comparisons for the CCBHCs within each demonstration state presents a combination of theoretical and practical challenges. The theoretical challenges concern the identification of a group of consumers or clinical settings similar to the CCBHCs in all respects other than the clinic model. Identifying potential comparisons will require investigation of the data available within each state to identify comparison groups and the actual models in which care is being provided. The practical issues of obtaining data are also likely to be considerable, given that the collection of new data from non-CCBHC settings for comparison purposes is likely to be prohibitively expensive. Data on comparison groups are likely to be restricted to existing sources, primarily claims or encounter data. Next, we briefly summarize the strategies that states proposed for the selection of comparison groups in their planning grant applications. This information is important for considering the range of possible data sources. Then, we address both theoretical and practical issues concerning identification of comparison groups as answers to a series of questions.

\section{Comparison Groups in the Planning Grant Proposals}

In their applications for planning grants, states were asked to describe possible strategies in identifying comparison groups for evaluating the CCBHCs if they were selected to participate in the demonstration project. Table 4.1 summarizes differences across states in the proposed methods of selecting comparison groups with respect to the level of analysis, clinic or individual, and the data elements they propose using to match comparisons. Most states, 13 of 24, proposed selecting comparisons at the clinic level, i.e., selecting comparison clinics similar to the CCBHCs, and nine of the 24 states proposed selecting comparisons at the individual level, i.e., selecting individuals who are similar to the individuals treated in the CCBHCs. Table 4.1 also shows the types of information on clinics and individuals that states propose to use to select comparisons. 
Table 4.1. State-Suggested Comparison Group Selection Methods

\begin{tabular}{ccc}
\hline $\begin{array}{c}\text { Proposed } \\
\text { Comparison } \\
\text { Method }\end{array}$ & $\begin{array}{c}\text { Number of } \\
\text { states } \\
(\boldsymbol{n}=\mathbf{2 4})\end{array}$ & Criteria for Matching \\
\hline Clinic level & 13 & $\begin{array}{l}\text { Rural/urban status, proximity to CCBHC, client demographics, regional } \\
\text { prevalence estimates, clinic size, clinic services, transportation resources, } \\
\text { historical access to care, density of services in the region }\end{array}$ \\
Individual level & 9 & $\begin{array}{l}\text { Client demographics, region, Medicaid eligibility type, utilization of services, } \\
\text { psychiatric diagnosis, substance use, medical conditions, level of client } \\
\text { functioning, payment type (FFS or managed care) }\end{array}$ \\
Multiple levels & 1 & - \\
Not specified & 1 & - \\
SOURCE: Authors' analysis. &
\end{tabular}

States also commented on the potential sources of data available on comparison groups for the evaluation. Nearly all of the 24 states indicated that the primary or sole source of information would be Medicaid claims or encounter data. A small number of states proposed using data on managed care encounters obtained directly from managed care providers or obtaining information from EHRs in comparison clinics. Some states proposed possible incentives for collection of data from non-CCBHC clinics, such as paying financial stipends, providing technical support, or allowing clinics that provide information to the evaluation to be "first in line" to become CCBHCs after the end of the demonstration period.

\section{Theoretical Questions}

\section{What Is The Right Level Of Analysis For Assessing The Impact Of CCBHCs?}

There are two primary options for selecting within-state comparison groups for the CCBHCs: the clinic level and the individual consumer level. The clinic-level comparison would proceed by selecting non-CCBHC clinical sites from within the state that have similar target populations to that of the CCBHCs. The care provided in the CCBHCs would then be compared with the care in those selected clinical sites. The individual-level comparison would start with the consumers treated in the CCBHCs and select as comparisons otherwise-similar consumers who were not treated in CCBHCs. Treatment characteristics, such as clinical services at an outpatient psychiatric clinic, could be included among the factors used to match individual consumers. Care received by the $\mathrm{CCBHC}$ consumers could then be compared with that received by non-CCBHC consumers. A third alternative, which is mentioned in the statute, is to compare care provided in $\mathrm{CCBHCs}$ with care provided in other states. There are benefits and drawbacks to each of these levels of analysis.

The main rationale for a clinic-level analysis is that the $\mathrm{CCBHC}$ is a clinic-level intervention. The goal of the legislation is for the CCBHC to provide care that meets specific standards. Comparisons with other clinical settings provide the most-direct test of this intended impact. In addition, some sources of data may be available only at the clinic level, such as quality reports that some states or MCOs might be collecting. A drawback of the clinic-level analysis is that the 
evaluator might not be able to adequately control for differences in populations seen by clinics. A clinic with a more complex client mix or consumers who have more-severe disorders on average can appear to perform worse on some measures. It will be important to control for differences in client mix and risk. Case-mix adjustment can be particularly challenging for CCBHCs actively recruiting difficult-to-reach consumers, such as homeless adults or children from non-English-speaking households.

There are several reasons to consider selection of a comparison group at the individual level rather than or in addition to selecting a comparison group at the clinic level. For instance, the way clinical sites are recorded in Medicaid claims in some states can make identification of a comparable clinical site difficult or impossible. In addition, depending on the availability of individual-level information, selection on the individual level can result in a comparison group more closely matched to the CCBHC-treated group. In particular, analyses focusing on subgroups, such as veterans, might be feasible only with individual-level comparisons, perhaps pooling across CCBHCs.

It can be possible to compare states over time to answer some research questions. If states implement the demonstration among a large set of clinics or all of their clinics, it can be feasible to compare performance over time as one measure of the demonstration's impact. State-level data can be relatively easy to collect using existing reports (such as URS or TEDS). As described above, differences between states can make it difficult to identify the impact of the demonstration using state-to-state comparisons, so the evaluator will need to think carefully about how to address these differences before performing such an analysis. It is possible that individual-level analyses can be performed between states beacuse there is more information available on the individual consumers, but it is likely that between-state differences can still contaminate the estimate of the demonstration impact.

\section{With What Type of Clinical Setting Should CCBHCs Be Compared?}

As noted, there are multiple innovative models of care that focus on the same target population as the CCBHC being tested in many states. These models represent a range of integration strategies, some of which focus on greater integration of behavioral health services with general medical, some on integration of substance use and mental health treatment within behavioral health settings, and some on integration of general medical services into specialty behavioral health care. This variety could be seen as a challenge to selecting a comparison group because of the difficulty in identifying a clinical setting or comparison group of consumers who represent "usual care," i.e., treatment in a traditional CMHC. Indeed, usual care is difficult to define in the context of a rapidly changing health system. Comparisons with traditional CMHCs might provide one important evaluation approach, but they would have limited relevance if other models of care are already becoming common. If the evaluation is able to characterize the clinical settings serving as comparisons for the CCBHCs, it will be able to provide results that are more relevant to current policy decisions among these policy options.

Choice of comparison groups will be constrained by the models of care being concurrently implemented in the selected demonstration states. An inventory of these clinical models and 
assessment of their identifiability in available data will be a necessary early stage in the evaluation design.

\section{What Is The Best Analytic Model For Assessing The Impact Of CCBHCs?}

There are two major design considerations with respect to the analytic model used to assess the impact of CCBHCs, adjusting for individual-level predictors of service use outcomes and adjusting for concurrent temporal trends in service use outcomes. With respect to individuallevel predictors of service use, the ability to account for differences will be limited to the data in the data source being used. For instance, claims data include information on clinical diagnoses, prior service utilization, and limited demographic information (age, sex, race/ethnicity). Matching on these characteristics will account for confounding of estimated effects of the CCBHCs by preexisting differences between individuals treated in different settings.

Adjustment for temporal trends is best accomplished through a difference-in-differences (DD) approach, in which trends in the CCBHC are compared with contemporaneous trends in comparison sites (or individuals) (Dimick and Ryan, 2014). For instance, the Center for Medicare and Medicaid Innovation recommends use of DD models in evaluations with access to longitudinal information (Howell, Conway, and Rajkumar, 2015). The most-conservative DD model would compare the trajectories of the same groups of individuals, those treated in $\mathrm{CCBHCs}$ and comparisons, over the time period in which the CCBHC model was introduced. However, following the same group of individuals over time can limit the sample size considerably because of the frequent movement in and out of treatment that occurs in mental health clinics. In addition, limiting the analytic sample to individuals treated continuously over two or more years can restrict the sample to one that is not representative of the target population. A less-conservative approach would be to compare change over that time period in the care provided by CCBHCs and comparison clinics, regardless of whether the individuals treated in each time period are the same.

The DD model has the potential to adjust for differences between CCBHCs and comparison clinics in the characteristics of the consumers they treat. This is because the comparison is made in the temporal trend, i.e., clinics are initially compared with themselves at a prior period of time. In the absence of external factors changing over time that affect CCBHCs differently from comparison clinics, other than the CCBHC implementation itself, differences in the client populations would not undermine the DD model. The evaluation should monitor policy changes in each demonstration state to evaluate whether there are any factors that might influence the CCBHCs and comparison clinics in this way. The assumptions of the DD model regarding parallel trends across groups in the absence of the intervention can also be tested using claims data from prior years.

\section{How Can The Two Payment Mechanisms, PPS-1 and PPS-2, Be Compared With Each Other?}

All CCBHCs will use a cost-based PPS, which is highly innovative for public mental health services. However, there is also interest in which of the two options, the daily rate of PPS-1 or 
the monthly rate of PPS-2, is better in the long term for Medicaid, individual states, and consumers. In Chapter Five, we describe some ways in which the two systems can be compared financially using the CR information. It also can be possible to compare the two systems with respect to their impact on utilization of particular services and patterns of utilization of care. The leading hypotheses would concern the likelihood that consumers in states using PPS-2 receive a broader mix of nonmedical support services, such as vocational training or educational support, than consumers in states using PPS-1. In addition, it also would be valuable to test for evidence of adverse impacts of the financial incentives that each payment system creates for providers. PPS-1 incentivizes frequent low-intensity visits, while PPS-2 incentivizes infrequent visits beyond the initial visit in each month and a low level of clinical services on average.

Comparing the two payment systems will be challenging because the selection of a payment system will be made at the state level, with all CCBHCs in a state using the same system. Moreover, it is likely that states that implement PPS-1 will differ from those that implement PPS-2. In particular, PPS-2 is much more complex to establish, monitor, and administer than PPS-1, making it likely that it will be chosen only by the states with the mostsophisticated data collection and analysis systems in place. However, despite this limitation, cross-state comparisons of the two models could provide valuable information on their differential impacts on care. Such comparisons depend on implementation of the two systems in sufficient numbers of states from which comparable data from the predemonstration and demonstration periods are available. The data necessary for such a comparison include the full range of services of interest, some of which might not be recorded in claims data, particularly during the predemonstration period.

\section{How Can The Scope Of Services, Including Nonmedical Supportive Services Provided By CCBHCs, Be Compared With That Provided In Other Clinics?}

Whether or not there are existing sources of data to answer this question varies by state. Some states already collect details on the individual clinics that include scope of services. States participating in other care model demonstrations will likely have data related to those demonstrations. Claims and encounter data can also be used to identify the services for which clinics receive compensation or are required to report to MCOs. If these existing sources are not available in a state, collecting new data through site visits or provider surveys can be an alternative.

\section{Can Existing Data Collected By States On Mental Health And Substance Use Disorder Services Be Used In The Evaluation?}

As mentioned in Chapter Three, states collect a large variety of data on the operation of their CMHCs, including surveys of patients and families, substance use treatment services, CRs, quality measures, caseload censuses, and other operational data. These systems are state specific, so it is not possible to know in advance whether they will be useful to an evaluation of the CCBHC demonstration project. Nonetheless, the opportunity to access data on comparable clinical sites or patient samples is important to note. 


\section{What Data Sources Can Be Used To Compare CCBHCs With Community-Based Mental Health Services As Required By The Statute?}

The PAMA statute mentions two particular comparisons that should be drawn in reports to Congress. First, the statute requires comparison of areas served by CCBHCs with other areas of the same state with respect to access to care. This comparison can be made using URS measures of access to care, the CCBHC-reported quality measure related to access to care, and claimsbased measures. While these comparisons will provide useful benchmarks for understanding the performance of CCBHCs, they will not necessarily address the impact questions described in Chapter Two. Second, the statute requires a comparison of CCBHCs with community-based mental health services in other states and other areas of the same state with respect to quality of care and scope of services. This comparison can be made using URS reporting from within the same state as the CCBHC or from neighboring states, reporting of the Medicaid core measures of quality of care, and claims or encounter data. Because of differences across states in their mental health service delivery systems, comparisons across states should be interpreted as benchmarks rather than estimates of the impact of the CCBHC model.

\section{Other Considerations Regarding Comparison Groups}

There are a number of practical issues to consider. The first is how to identify a comparison group. In addition to the theoretical issues described earlier, a practical point is how members of the comparison group are identified in data. Data sources that mask patient identifiers and characteristics will make it very challenging to find a suitable comparison population at the consumer level and track it over time. If a comparison clinic submits claims or encounter data to multiple payers (e.g., multiple MCOs), it can be challenging to identify the clinic across those sources if the payers do not all use the same identifier.

Another practical issue is the timely availability of data. Data from clinic-level reports or surveys can be hard to obtain from comparison sites. For example, clinic-level quality reports required for CCBHCs might not be available for other clinics. It will take time to develop the reporting capability in other clinics, and, without any reimbursement or reporting requirement, it can be difficult to obtain the data in a reasonable time frame.

Obtaining data from a comparison population might be too burdensome for the clinics or too costly for the evaluation. The cost to the evaluation includes the possibility of purchasing additional data, as well as the additional administrative cost of coordinating the collection of data from clinics not participating in the demonstration.

Finally, the analysis of comparison data adds complexity and therefore cost to the evaluation.

\section{Conclusion}

Decisions regarding comparison groups will be critical to the design of the analytic component of the evaluation. However, because of the variation across states not only in the data sources and formats, but also in the service delivery systems, these decisions will need to take careful account of state-specific contexts. The most-important conceptual decisions will concern 
the type of delivery model that is compared with the CCBHC. Some states might offer opportunities to compare CCBHCs with other innovative models of integrated care systems or with more-traditional specialty outpatient mental health clinics. No single state is likely to offer opportunities to the broad range of comparisons that can be constructed across the demonstration states. Regardless of the particular models selected, a careful description of how they differ from the CCBHCs in the state will ensure that the results are relevant to pressing policy questions.

Budget will also be a primary concern in designing the analytic comparisons. In particular, the cost of collecting data from non-CCBHC comparison sites is likely to be prohibitive. NonCCBHC sites would have no incentive to collect data without a substantial reimbursement from the evaluation project. In addition, only a very small number of specific comparison clinics could be included, a disadvantage to this method relative to the use of claims or encounter data in which a larger number of comparison sites can be identified. As discussed in Chapter Five, budget considerations strengthen the justification for use of claims and encounter data as the primary data source for addressing the evaluation's analytic questions. 


\section{Chapter Five. Design Recommendations}

\section{Overview}

In this chapter, we present a framework for the evaluation design of the CCBHC demonstration project, drawing on the findings and discussion in the earlier chapters. The goal is to present recommendations that balance the research priorities with the likely budget constraints, not a detailed design plan. To that end, we present a set of recommendations for core components of the evaluation that should be given highest priority and a set of recommendations for supplemental components that could be added depending on the budget. These are not meant to be hard and fast recommendations. The core components could be expanded or scaled back with corresponding changes to the resources devoted to the supplemental components.

The recommended design has three components. The first component is a compilation of state profiles that describe the context of CCBHC implementation in each of the demonstration states. This component can draw on existing publicly available data, as well as key informant discussions with state officials, and will provide background on which the subsequent two components can draw. The second component is a descriptive analysis that answers the implementation questions presented in Chapter Two. These questions can each be addressed to some degree using existing sources, information from the certification process, the required quality reporting, and the CRs in particular. However, the evaluation will provide much more indepth information on these topics with the addition of some of the supplemental data collection efforts, such as QRs, key informant interviews, and site visits. The third component addresses the impact questions described in Chapter Two using claims or encounter data acquired from the states, an MCO, or CMS to construct quasi-experimental estimates of the impact of the CCBHCs, relative to well-characterized clinical care arrangements. The evaluation will need to make decisions based on the state profiles and available resources regarding the specific comparisons and measures, including those the states are required to report, which will be examined.

\section{State Profiling}

As noted at several points in the preceding chapters, final decisions about the evaluation design can be made only after the eight demonstration states have been selected and their strategies for certifying clinics as CCBHCs are known. Key evaluation design decisions will depend on the strategies that the states use, e.g., the number and location of clinics they choose to certify, the nature of their existing mental health systems, the availability and quality of data sources, and concurrent or planned implementation of other innovative service delivery models. For this reason, we also recommend that the evaluation devote resources to compilations of detailed state mental health and SUD system profiles for each demonstration state using publicly available information and discussions with state officials. These profiles will play an important role in the design of a state-by-state evaluation plan. 
Detailed profiles of the selected states, which can be compiled by the evaluation team as an initial phase of the evaluation, can inform a state-by-state evaluation design that will take advantage of differences across the states to provide the most-robust analysis of CCBHCs and make the best use of available resources. These profiles should focus on the circumstances in the state prior to the $\mathrm{CCBHC}$ demonstration that could impact its implementation and the resources available for evaluation. For instance, some states can have particularly good data sources or particularly appropriate comparison groups for addressing the impact of CCBHCs relative to other delivery system models. For instance, a state might have a CCBHC in one region and a health home-integrated care program in another region, both clearly identifiable in claims data. In some states, a single managed care company might be in a position to provide data on a CCBHC and a comparison clinical setting, thereby providing a relatively simple and robust design for analyzing the impact of the CCBHC. A focus on the states that offer the clearest contrasts and highest-quality data might require that only some of the demonstration states be included in this component of the evaluation. By collecting information on states, using publicly available sources and key informant discussions with state officials, the evaluation will be able to focus its efforts on the most-informative settings. State profiles should include but not be limited to the following content areas:

- existing CMHCs and SUD clinics in the state: How are they organized with respect to care integration? What types of payment systems are in place? Where are they located in relation to the designated CCBHCs? Is there overlap with the CCBHC caseload? Specific attention might be given to clinics that applied to be CCBHCs and were not selected for the demonstration because those clinics are likely to be most similar to the clinics that become CCBHCs.

- other policy initiatives affecting care for SMI and/or SED: Are there other efforts to integrate or expand care for the same population as that targeted by the CCBHC? Are these distinguishable from the CCBHC in a way that can be compared?

- payment systems for behavioral health care: What are the existing payment arrangements for Medicaid coverage of behavioral health care? What portion of substance use treatment does Medicaid cover? What portion of the Medicaid population is covered through managed care? What is the nature of those arrangements, and how do they overlap with the CCBHC?

- availability and specifications of claims and encounter data: What is the time frame for availability of different sources of claims data? Are CCBHCs and potential comparison groups identifiable in the data sets? What is the plan for managed care encounter records for the CCBHCs, and can they be compared with services provided in other clinical settings in the state?

- data used for rate-setting: How did the state arrive at its PPS rate for the CCBHC? How will the state monitor the concordance of the rate with costs over time?

- other data collection on behavioral health care in the state: What information does the state collect from other mental health and SUD treatment provides? Do any of those sources provide meaningful comparisons for the CCBHCs, either as benchmarks or as quantitative controls for identifying effects of the CCBHCs? 
- process for certification of CCBHCs in the state: How did the state assess whether CCBHCs met the certification criteria, and what data on the CCBHCs were generated in this process?

We recommend that a detailed evaluation plan, taking account of state profiles, be produced during the first six months of the evaluation. Producing the state profiles will involve costs to the evaluation for performing interviews with officials in each of the eight states, reviewing publicly accessible information, examining available claims data, creating an analysis plan, and presenting the information in a report.

\section{Implementation Questions}

The implementation questions can be addressed using a combination of existing data, including the required reporting by $\mathrm{CCBHCs}$, and new data collected for the evaluation. In this chapter, we summarize the potential contributions of both types of data. Table 5.1 summarizes the content that can be covered by the existing data and new data collection efforts for each evaluation domain. As Table 5.1 shows, there will be existing data available to address some questions in each domain, but the additional data collection efforts will provide greater depth, in particular highlighting barriers to $\mathrm{CCBHC}$ implementation that could be essential for informing efforts to modify the model in the future. In some cases, the additional data collection can also expand the breadth of the evaluation by incorporating content areas not covered by existing reporting requirements.

Table 5.1. Sources of Data for Addressing Implementation Research Questions

\begin{tabular}{|c|c|c|}
\hline \multirow{2}{*}{ Implementation Question } & \multicolumn{2}{|c|}{ Data Source } \\
\hline & Existing & Supplemental \\
\hline \multicolumn{3}{|l|}{$\begin{array}{l}\text { What types of behavioral health services, including care management } \\
\text { and coordination, do CCBHCs offer? }\end{array}$} \\
\hline What EBPs are being used? & Demo application & - \\
\hline What are the qualifications of the providers? & Demo application & - \\
\hline To what extent are services being provided with fidelity? & - & QR, survey \\
\hline How do clinics meet the staffing requirements of the CCBHC criteria? & Demo application & - \\
\hline Cultural competence? & Demo application & - \\
\hline Translation services? & Demo application & - \\
\hline Telemedicine? & Demo application & - \\
\hline $\begin{array}{l}\text { Which services are provided directly by the clinic and which by contracted } \\
\text { providers? }\end{array}$ & Demo application & - \\
\hline What were factors influencing these decisions? & - & $\begin{array}{c}\text { Survey, } \\
\text { qualitative }\end{array}$ \\
\hline Which services are the most difficult for CCBHCs to provide? & - & QR, Survey \\
\hline $\begin{array}{l}\text { What are the challenges that CCBHCs face in providing different types of } \\
\text { services? }\end{array}$ & - & QR, Survey \\
\hline Workforce shortages? & - & QR, Survey \\
\hline Patient demand? & - & QR, Survey \\
\hline Costs of services? & - & QR, Survey \\
\hline
\end{tabular}




\begin{tabular}{|c|c|c|}
\hline \multirow{2}{*}{ Implementation Question } & \multicolumn{2}{|c|}{ Data Source } \\
\hline & Existing & Supplemental \\
\hline $\begin{array}{l}\text { What arrangements do CCBHCs implement for care coordination and/or } \\
\text { case management? }\end{array}$ & Demo application & QR \\
\hline How does the scope of services change over time? & - & QR \\
\hline $\begin{array}{l}\text { How do CCBHCs establish and maintain formal and informal } \\
\text { relationships with other providers? }\end{array}$ & - & - \\
\hline What types of relationships do CCBHCs establish with other providers? & Demo application & QR, Survey \\
\hline Behavioral health providers? & Demo application & QR, Survey \\
\hline Primary care providers & Demo application & QR, Survey \\
\hline EDs? & Demo application & QR, Survey \\
\hline FQHCs? & Demo application & QR, Survey \\
\hline Hospitals? & Demo application & QR, Survey \\
\hline Social service providers? & Demo application & QR, Survey \\
\hline Law enforcement? & Demo application & QR, Survey \\
\hline How are data shared among providers? & - & QR \\
\hline What types of formal data-sharing agreements are in place? & - & QR \\
\hline $\begin{array}{l}\text { What systems do CCBHCs use to coordinate care among multiple } \\
\text { providers? }\end{array}$ & - & QR \\
\hline Referrals and referral tracking? & - & QR \\
\hline Multidisciplinary team meetings? & - & QR \\
\hline Tracking across care transitions? & - & QR \\
\hline \multicolumn{3}{|l|}{ How do CCBHCs respond to the PPS? } \\
\hline $\begin{array}{l}\text { Do CCBHCs successfully report PPS claims and encounter records for } \\
\text { procedures? }\end{array}$ & RQM, CRs & - \\
\hline $\begin{array}{l}\text { Is the administrative burden of submitting claims different for consumers } \\
\text { covered by the PPS system? }\end{array}$ & - & $\begin{array}{c}\text { Survey, } \\
\text { qualitative }\end{array}$ \\
\hline $\begin{array}{l}\text { How are encounter records (reports of clinical procedures submitted along } \\
\text { with PPS reimbursement claims) captured and reported? }\end{array}$ & - & $\begin{array}{l}\text { Survey, } \\
\text { qualitative }\end{array}$ \\
\hline $\begin{array}{l}\text { How are consumers covered by the PPS distinguished from other } \\
\text { consumers? }\end{array}$ & - & $\begin{array}{l}\text { Survey, } \\
\text { qualitative }\end{array}$ \\
\hline $\begin{array}{l}\text { Do clinics manage services for consumers covered by the PPS differently } \\
\text { from the way they manage services for other consumers? }\end{array}$ & - & $\begin{array}{l}\text { Survey, } \\
\text { qualitative }\end{array}$ \\
\hline Are Medicaid consumers tracked separately from other consumers? & - & $\begin{array}{l}\text { Survey, } \\
\text { qualitative }\end{array}$ \\
\hline $\begin{array}{l}\text { Do clinics with PPS-2 systems track or target performance on measures } \\
\text { linked to the quality bonus payment? }\end{array}$ & - & $\begin{array}{l}\text { Survey, } \\
\text { qualitative }\end{array}$ \\
\hline How do CCBHCs notify consumers about payment options? & - & $\begin{array}{l}\text { Survey, } \\
\text { qualitative }\end{array}$ \\
\hline Medicaid enrollment? & - & $\begin{array}{c}\text { Survey, } \\
\text { qualitative }\end{array}$ \\
\hline Sliding fee scale? & - & $\begin{array}{l}\text { Survey, } \\
\text { qualitative }\end{array}$ \\
\hline \multicolumn{3}{|l|}{ How do states establish and maintain prospective payment rates? } \\
\hline What data are used for initial rate-setting and rebasing? & Demo application & - \\
\hline Is there variation across states in the services covered by the rates? & Demo application & - \\
\hline $\begin{array}{l}\text { In states using PPS-2, how are the quality bonus payment systems } \\
\text { established? }\end{array}$ & - & Qualitative \\
\hline $\begin{array}{l}\text { What proportion of eligible CCBHCs meet standards for the quality bonus } \\
\text { payment? }\end{array}$ & - & Qualitative \\
\hline How do CCBHCs attempt to improve access to care? & & \\
\hline
\end{tabular}




\begin{tabular}{|c|c|c|}
\hline \multirow{2}{*}{ Implementation Question } & \multicolumn{2}{|c|}{ Data Source } \\
\hline & Existing & Supplemental \\
\hline What policies do CCBHCs implement to expand accessibility? & Demo application & - \\
\hline Changes in working hours? & Demo application & - \\
\hline Telephone and/or Internet access to clinicians? & Demo application & - \\
\hline $\begin{array}{l}\text { How successful are CCBHCs in conducting timely assessments of new } \\
\text { consumers }\end{array}$ & RQM & - \\
\hline Initial assessments? & RQM & - \\
\hline Comprehensive assessments? & RQM & - \\
\hline Follow-up of identified needs? & - & SQM \\
\hline Do CCBHCs conduct outreach programs to bring new patients into care? & - & QR, survey \\
\hline Outreach to social services agencies, such as homeless shelters? & - & QR, survey \\
\hline Outreach to other community organizations, such as police or schools? & - & QR, survey \\
\hline Are CCBHCs tracking the success of these efforts? & - & QR, survey \\
\hline Are outreach efforts targeted to Medicaid consumers? & - & QR, survey \\
\hline How do CCBHCs connect clients with a broad range of needed services? & - & QR, qualitative \\
\hline Are services checked against comprehensive assessments? & - & QR, qualitative \\
\hline Are referrals to DCOs and other external providers tracked? & - & QR, qualitative \\
\hline Do established clients have timely access to outpatient care? & RQM & - \\
\hline Do consumers have access to crisis management services? & Demo application & - \\
\hline Rapid access? & Demo application & - \\
\hline Follow-up after crisis intervention? & - & SQM \\
\hline What barriers do CCBHCs report to improving access to care? & - & QR, qualitative \\
\hline Workforce shortages? & - & QR, qualitative \\
\hline Financial constraints? & - & QR, qualitative \\
\hline Limited provider networks in the community? & - & QR, qualitative \\
\hline \multicolumn{3}{|l|}{$\begin{array}{l}\text { How do clinics collect, report, and use information to improve quality } \\
\text { of care? }\end{array}$} \\
\hline $\begin{array}{l}\text { What is the process for generating quality measure reports for required } \\
\text { measures? }\end{array}$ & Demo application & - \\
\hline Are CCBHC EHR systems capable of generating all measures? & - & QR, survey \\
\hline Do clinics generate and monitor other quality or outcome measures? & - & SQM, QR \\
\hline How do clinics collect and review information on care provided by DCOs? & - & QR, survey \\
\hline What kind of data-sharing agreements are in place? & - & QR, qualitative \\
\hline How is the information used to manage the care provided by DCOs? & - & Qualitative \\
\hline $\begin{array}{l}\text { How are staff qualifications of contracted providers assessed and } \\
\text { monitored? }\end{array}$ & - & QR, qualitative \\
\hline Are quality measures used for non-Medicaid and/or dual eligible clients? & - & QR \\
\hline How is information on quality of care used to improve performance? & - & QR, qualitative \\
\hline Do CCBHCs implement quality improvement plans? & Demo application & - \\
\hline Do clinicians receive feedback on care for individual consumers? & - & QR, qualitative \\
\hline Is information on quality used in care team meetings? & - & QR, qualitative \\
\hline Do quality measures inform changes in clinic policies? & - & QR, qualitative \\
\hline How do CCBHCs use data to inform population health management? & - & QR, qualitative \\
\hline
\end{tabular}




\begin{tabular}{|c|c|c|}
\hline \multirow{2}{*}{ Implementation Question } & \multicolumn{2}{|c|}{ Data Source } \\
\hline & Existing & Supplemental \\
\hline How do CCBHCs monitor health and social outcomes? & - & QR, survey \\
\hline Behavioral health status? & - & QR, survey \\
\hline Physical health conditions? & - & QR, survey \\
\hline Employment/Education? & - & QR, survey \\
\hline Housing? & - & QR, survey \\
\hline \multicolumn{3}{|l|}{ How do states collect, report, and use information on quality of care? } \\
\hline $\begin{array}{l}\text { How do states identify and analyze information on the quality of care in } \\
\text { CCBHCs using Medicaid claims? }\end{array}$ & RQM & - \\
\hline How do states identify claims for care provided in CCBHCs? & - & Qualitative \\
\hline How are encounter records specified and processed? & - & Qualitative \\
\hline How do states use claims data to assess quality of care in CCBHCs? & - & Qualitative \\
\hline Are states able to report fully on required measures? & - & Qualitative \\
\hline Do states examine other measures of quality of care? & - & SQM \\
\hline
\end{tabular}

SOURCE: Authors' analysis.

NOTES: $Q R=$ quarterly report. Survey = survey of providers or clinics. Qualitative $=$ data collected using qualitative methods, including interviews, site visits, and focus groups. SQM = supplemental quality measure.

\section{Description of CCBHC Implementation Using Existing Data}

The current reporting required for CCBHCs will provide a rich source of information for describing how the programs were implemented. Systematic descriptions of the CCBHC implementation over time will help assess whether the program is achieving its goals with respect to services and help identify unanticipated barriers to implementation. Three main sources of data can inform this component:

- Demonstration application: States will be responsible for collecting information from $\mathrm{CCBHCs}$ to make a determination that the certification criteria have been met. This process will require detailed accounting of the types of EBPs being offered, the staffing of the clinics, rehabilitation and social services, access hours and policies, crisis services, and networks of care. To the extent that this information is included in the demonstration applications or can be collected through interviews, the evaluation can use this information to document structures of care in CCBHCs and address research questions concerning the correspondence between the CCBHC services and the criteria specified in the statute. If the certification process is repeated to ensure continued compliance with the criteria, the information could be used to provide a longitudinal description of clinics over the course of the demonstration project. A standardized reporting form for the certification criteria could make this part of the evaluation less costly and provide more comparable data across states.

- Quality reporting: The required reports of quality measures by the CCBHCs and the states will provide a valuable source of information for describing the care provided by the CCBHCs. At a minimum, the following five aspects of CCBHC implementation can be tracked using these data: 
- Ability of CCBHCs and states to report quality information: Successful reporting of information on quality in a timely manner, following official specifications is itself an important measure of CCBHC implementation, regardless of the actual values reported.

- Timely access to care: CCBHCs are required to report a measure of the time between a consumer's initial contact with the clinic and the initial assessment.

- Quality of care provided by CCBHCs: As described in Chapter Three, the RQMs provide direct information on the quality of some types of behavioral health care provided by CCBHCs. In some states, supplemental information can be available to compare measures of quality in CCBHCs with statewide performance benchmarks. Quality could also be compared to national benchmarks.

- Care coordination: The required quality reporting also includes measures of successful care coordination, such as measures of follow-up after discharge from an ED mental health or substance use treatment and receipt of care for physical health conditions.

- Patient experience of care: States are required to report results of the MHSIP survey, which includes measures of consumer satisfaction with care. Although sampling designs for this survey can differ across states, preventing cross-state comparisons, there can be opportunities to compare CCBHC consumers with other populations of mental health consumers within each demonstration state.

- Cost reporting: The CCBHCs are required to provide detailed annual CRs. The purpose of these reports is to set the PPS rates. They include details on clinic staffing and services, as well as number of patients, along with clinic operations costs broken down into categories, such as staff compensation, direct costs of care (e.g., medical supplies, transportation), and indirect costs (e.g., rent, utilities). For states that choose PPS-2, the service details include counts of patients by risk group. The evaluation can use these reports to describe changes in clinic staffing, operation, and costs over the course of the demonstration. Because they are required, CCBHC CRs will be a relatively low-cost source of data for the evaluation. However, because the same details are unlikely to be collected for comparison providers, the evaluator will need to think carefully about how to best use the CRs. Assuming that the quality of the data in the reports remains high throughout the demonstration, they can provide useful information related to how clinics adapt to the new payment system, as well as the sustainability of the models.

The cost to the evaluation for using these data to describe the implementation will consist of the time required to collect them from the states and put them into a format that allows for analysis, performing analysis of the qualitative and cost data, and presenting the information in a report.

\section{Description of CCBHC Implementation Using Supplemental Data}

Supplemental data sources can be used to extend the description of CCBHC implementation in several ways. Table 5.1 shows how answers to each of the research questions concerning implementation can be strengthened and deepened using the supplemental data sources described below: 
- Additional operational data reporting from clinics: The description of the CCBHC implementation, particularly with respect to the domains of structure, access, and cost, could be greatly enhanced at relatively low cost to the evaluation and low burden on the clinics through additional reporting of operational data on a quarterly or semiannual basis. These reports could include patient registry data, numbers of services provided by type, staffing changes, changes in access policies, referral tracking data, changes to contractual relationships with external providers, and general information on barriers to implementation of the CCBHC model. The reporting would impose a low burden if the data collection systems were embedded within the existing reporting infrastructure. Reporting of this type will be particularly important for services provided to patients but not reported in encounter records, which could include psychiatric rehabilitation, social support related to housing, education, and employment; case management; and care coordination. For these services, additional reporting to the evaluation could be the only way to capture information on services facilitated by the PPS.

- Collection of consumer-level outcomes from CCBHCs: At present, the required reporting includes only one standardized assessment of health status: depression remission. Clinics could report individual longitudinal data on depression screening, psychological distress, housing, employment, and school transitions. The costs involved for this component would be the time required for development of the data collection instrument, analysis across sites, and writing the report.

\section{- Qualitative methods}

- Key informant discussions: Descriptions of the implementation of CCBHC model would be greatly enhanced with information from open-ended discussions with administrators, providers, and state-level officials. At a minimum, we recommend discussions with one state official and one CCBHC director from each state during each year of the demonstration. The discussions would be used strategically to learn about challenges to implementation not captured in the required reporting. The discussion protocols could include both standardized questions asked of individuals in all states and specialized state- or CCBHC-specific questions based on prior reporting. For instance, if a CCBHC reports difficulty in making referrals to primary care physicians, the key informant discussion could focus on that particular barrier and potential solutions that have been attempted. Key informant discussions could also be useful in capturing strategies that CCBHCs develop to improve care, taking advantage of the flexibility offered by the PPS. The costs associated with these discussions would consist of the time required to create the questions, schedule the discussions, hold the discussions, analyze results across discussions, and describe the results in a report.

- Site visits: Collection of detailed qualitative information from a variety of CCBHC staff and observation of clinic functioning could be accomplished through selective site visits. Criteria for the selection of sites would need to be established taking into account diversity in the geographic location, clientele served, and payment model utilized. Costs associated with site visits include the selection of sites, scheduling the visits, the development of discussion protocols, travel time and expenses, time for the visit, summarizing and analyzing the information collected, and writing the report.

- Case studies: More in-depth analysis and description of clinics illustrative of particular settings, e.g., rural versus urban or organizational arrangements or 
freestanding clinics versus hospital-affiliated clinics could be achieved through case studies. The summaries could combine quantitative and qualitative information gathered from existing data sources, claims data, site visits, interviews, and surveys. The cost of case studies to the evaluation would depend on the data sources utilized and the number of sites involved.

- Provider survey: Given that provider perspectives are not captured systematically in the RQMs, a survey of providers could add a valuable dimension to the evaluation. Because they are directly involved in care in the CCBHCs, providers are uniquely positioned to report on remaining barriers to implementation of the $\mathrm{CCBHC}$ model and draw on past experiences with other models of care to suggest potential solutions. Providers can be a valuable source of information on how the financial incentives created by the payment systems affect clinical care decisionmaking. Provider surveys can be conducted relatively inexpensively using either online or phone survey methods. However, sampling of providers is difficult without a full roster of the target population (i.e., a sampling frame), and response rates in some provider surveys are so low that their representativeness is in question. The evaluation should be able to describe a strategy for reaching and assessing coverage of a well-defined target population. A nonrepresentative survey can provide valuable insights, particularly if it allows for open-ended responses that can uncover unanticipated issues, but will not address the actual range of opinion among CCBHC providers.

- Comparisons with other existing state data sets: In the process of constructing the state profiles, the evaluation might identify additional state-level data sources that might provide context or direct comparison with data from the CCBHCs. These data might include NOMs, TEDS data on SUD treatment, CRs, quality measures, or other administrative or operational information. Access to these data might be inexpensive, but analysis costs might be relatively high because of variation across states in how the data are collected and stored.

\section{Approaches to the Implementation Questions}

Table 5.1 shows the data sources, both existing and supplemental, that could be used to address each of the research questions described in Chapter Two. As the table shows, existing data drawn from the reporting requirements specified in legislation will provide information relevant to each of the implementation questions. However, the answers based solely on existing data will be limited to basic descriptions. Supplemental data collection efforts will be required to provide more in-depth information, particularly with respect to barriers to implementation and factors affecting decisionmaking within CCBHCs.

Table 5.2 summarizes the extent to which the evaluation could address each of the top-level research questions using only the existing data and with the addition of supplemental data. We discuss each of the questions briefly:

1. What types of behavioral health services, including care management and coordination, do CCBHCs offer? Information from the certification process can be used to provide a basic description of the services from each $\mathrm{CCBHC}$, including the qualifications of staff providing each type of service. The description could include details regarding use of telemedicine, training for cultural competence, and availability of 
translation services. Additional data collection will be required to address more in-depth questions regarding fidelity of EBPs, changes in services over time, and, importantly, the challenges that CCBHCs face in implementing their plans and the reasons that $\mathrm{CCBHCs}$ make particular decisions regarding service provision over the course of the demonstration project.

2. How do CCBHCs establish and maintain formal and informal relationships with other providers? Information from the certification process that is included in the demonstration applications can be used to describe the ways in which CCBHCs establish relationships with a network of providers in order to provide the required scope of service. Given that the details of the certification process are not known in detail, it is reasonable to expect that additional reporting will be required to enable a full description of these relationships, which might change over time. In addition, important details about the functioning of these relationships, such as information-sharing agreements, can be studied only with supplementary data collection efforts.

3. How do CCBHCs respond to the PPS? Information on how the clinics manage payment and reporting through the PPS will be available from the RQMs and the CRs, but this information will address only the most-basic questions about the operation of the payment system. To collect more-detailed information about the administrative burden of the system and how clinic procedures change in response to the payment system, the evaluation will need to collect additional information from clinic administrators.

4. How do states establish and maintain prospective payment rates? The information and methods used to establish rates for the CCBHCs will be public and, therefore, accessible to the evaluation. Qualitative interviews with state officials can be used to collect data on details of how the payment systems operate, including the reporting and monitoring of PPS claims, reporting of encounters, reporting to CMS, and payment arrangements for dually eligible beneficiaries.

5. How do CCBHCs attempt to improve access to care? Information from the certification process will describe some of the policies that CCBHCs put in place to expand access to care, and the required reporting will include information on the timeliness of clinical assessments for new patients. Additional data collection will be required to address other efforts that clinics might make to improve access, such as outreach programs, tracking of referrals to care after initial assessments, and barriers to improving access that affect CCBHC performance and decisionmaking.

6. How do clinics collect, report, and use information to improve quality of care? States are required to certify that $\mathrm{CCBHCs}$ have the capability to report quality measures and continuous quality improvement plans to use those measures to improve care. In addition, the required reporting of quality measures by CCBHCs will demonstrate their ability, or lack thereof, to successfully fulfill the reporting requirements. Additional data collection will be required to provide more-detailed descriptions of how CCBHCs use data to improve quality of care.

7. How do states collect, report, and use information on quality of care? Required quality reporting will provide information on how states are using various data sources to assess quality of care provided by CCBHCs. As with the CCBHC quality reporting, additional data collection will be required to describe how this information is used systematically to improve care. 
Table 5.2. Coverage of Implementation Questions by Core and Supplemental Data Elements

\begin{tabular}{|c|c|c|}
\hline Research Question & Core Data Element & Supplemental Data Element \\
\hline $\begin{array}{l}\text { What types of behavioral health services, } \\
\text { including care management and coordination, do } \\
\text { CCBHCs offer? }\end{array}$ & $\begin{array}{l}\text { Description of services and } \\
\text { staffing }\end{array}$ & $\begin{array}{l}\text { Challenges of providing } \\
\text { services; factors influencing } \\
\text { selection of services; change } \\
\text { in services over time }\end{array}$ \\
\hline $\begin{array}{l}\text { How do CCBHCs establish and maintain formal } \\
\text { and informal relationships with other providers? }\end{array}$ & $\begin{array}{l}\text { Description of relationships } \\
\text { with DCOs }\end{array}$ & $\begin{array}{l}\text { Relationships with network of } \\
\text { community providers; data- } \\
\text { sharing agreements; referral } \\
\text { tracking }\end{array}$ \\
\hline How do CCBHCs respond to the PPSs? & $\begin{array}{l}\text { Submitted claim or encounter } \\
\text { data and CRs. }\end{array}$ & $\begin{array}{l}\text { Administrators' and clinicians' } \\
\text { perspectives; accounts of } \\
\text { operational impact }\end{array}$ \\
\hline $\begin{array}{l}\text { How do states establish and maintain prospective } \\
\text { payment rates? }\end{array}$ & $\begin{array}{l}\text { Analyses supporting rate- } \\
\text { setting and revision. }\end{array}$ & Policymakers' perspectives \\
\hline $\begin{array}{l}\text { How do CCBHCs attempt to improve access to } \\
\text { care? }\end{array}$ & $\begin{array}{l}\text { Policies as described in } \\
\text { certification process; } \\
\text { timeliness of care as described } \\
\text { in quality measures }\end{array}$ & $\begin{array}{l}\text { Outreach efforts; clinical } \\
\text { processes for tracking access; } \\
\text { barriers to increasing access }\end{array}$ \\
\hline $\begin{array}{l}\text { How do clinics collect, report, and use information } \\
\text { to improve quality of care? }\end{array}$ & $\begin{array}{l}\text { Extent of reporting of required } \\
\text { measures }\end{array}$ & $\begin{array}{l}\text { Use of data to improve quality; } \\
\text { monitoring of quality beyond } \\
\text { required measures }\end{array}$ \\
\hline $\begin{array}{l}\text { How do states collect, report, and use information } \\
\text { on quality of care? }\end{array}$ & $\begin{array}{l}\text { Extent of reporting of required } \\
\text { measures }\end{array}$ & $\begin{array}{l}\text { Use of data to improve quality; } \\
\text { monitoring of quality beyond } \\
\text { required measures }\end{array}$ \\
\hline
\end{tabular}

SOURCE: Authors' analysis.

\section{Impact Questions}

The majority of the impact questions described in Chapter Two are best addressed using claims and/or encounter data. As with other data sources, there are many details regarding these data sets that vary state to state that will need to be taken into account. Investigation of the usefulness of the state claims and encounter data will be an important part of the state profiling described earlier. Additional analyses can make use of other required reports - in particular, the CRs - or other state data sources identified through the state profiling process.

\section{Analysis of Impact Using Claims or Encounter Data}

The advantage of claims and encounter data is that they allow analysis of multiple outcomes within a single existing data source using a consistent statistical methodology. There is a large 
body of research using claims data to address similar questions on which the evaluation can draw. It is important to emphasize that such work requires considerable investment in data analysis, specifically in data management, prior to estimating intervention effects. The evaluation should take account of costs associated with preliminary analytic work required to inform statistical estimates of intervention effects.

Presuming that the best sources of claims data have been identified as part of the state profile process described earlier, at least six additional steps in the claims data analysis should be distinguished. First, the evaluation should assess the claims data sets for utility in estimating the impact of the CCBHCs. This includes assessing the ability to identify CCBHCs and the appropriate comparison groups in the claims data and determination of whether the time lag for availability of the data will allow for access to data covering the time period of CCBHC implementation. Second, we recommend preliminary analyses of data from years prior to the CCBHC demonstration, which will be available earlier in the project period. These analyses can be used to gain experience with the data sets and describe baseline patterns of care and variation in those patterns across clinical settings. Third, state-specific operationalization of CCBHC and comparison group definitions should be tested and validated against external data, such as enrollment data. Fourth, the encounter records that CCBHCs submit as descriptors of care covered by the PPS should be examined and tested for coverage, granularity, and comparability with other claims. Fifth, specifications for the outcome measures will need to be developed and validated. Because of differences across states, these specifications can also vary. Sixth, and finally, after the preliminary data management and assessment, the statistical models for estimating the impact of CCBHCs can be specified with a high degree of confidence that they will produce meaningful results.

Claims data are limited in that they do not include information on health status outcomes, but they do provide a wealth of information on processes of care that the CCBHC model is designed to improve, as well as information on costs of care to Medicaid. The evaluation should give priority to quality measures that have been vetted and endorsed by national organizations, such as the NQF. However, we do not make specific recommendations for claims-based quality measures in this report because of the likelihood that new and better measures will be developed by the time the evaluation takes place. Also, there are likely to be content areas of interest to the evaluation not covered by endorsed measures. The claims-based outcomes that could be examined during the evaluation can be divided into two large groups: measures of the scope and quality of care provided by CCBHCs and measures of the integration of care received by $\mathrm{CCBHC}$ consumers between $\mathrm{CCBHCs}$ and other medical providers. Both types of measures can be linked to analyses of care processes and care costs.

Measures of care provided by CCBHCs allow assessment of the impact of the model on the core processes of behavioral health care, such as frequency of outpatient visits and use of medications. These measures can be extended to indicators of the correspondence of care patterns to clinical treatment guidelines and, depending on the coding practices within the demonstration states, more-specific information about use of particular EBPs. Examples that might be considered beyond the required measures include measures of polypharmacy for psychiatric disorders and medical monitoring of side effects of antipsychotic medications. 
Measures could also be added to complete the picture of care processes for particular conditions. For instance, the criteria require reporting of initiation and engagement in substance use treatment, but this measure can be interpreted consistently only when the screening for substance use conditions is known. Although reporting is required for screening for alcohol use, there is no required reporting for screening for other drug use. Addition of a measure of drug screening, provided that screening is reflected in claims, would make the interpretation of the initiation and engagement in treatment measure more meaningful.

Measures of care integration address the ways that the often-complex multisystem medical conditions of adults with SMI are treated. These include measures that address integration of care between inpatient and outpatient psychiatric settings (such as outpatient follow-up after discharge from a hospital for a psychiatric diagnosis), between mental health and SUD treatment providers, and between the CCBHCs and providers of outpatient medical services. Examples of additional integration measures that might be considered include frequent visits to an ED (e.g., three or more in a year) for a physical health condition and receipt of indicated screening for colorectal cancer (National Quality Forum 0034). The cost to the evaluation for the use of claims and encounter data consists of the time required to obtain the data, the cost of purchasing data if necessary, the time required to process the data should they come in different formats, time for analysis, and time for report writing.

\section{Analysis of Impact Using Supplemental Data}

Data collection systems in some states can provide additional opportunities to examine the impact of CCBHCs on outcomes that cannot be assessed using claims alone. For instance, some states might maintain data sets from other state agencies that could be linked to Medicaid data to provide additional information on housing, criminal justice contacts, or education. The same methods used for analyzing impact with claims data could be applied to these supplemental data. While this possibility should be explored early in the evaluation, as the state profiles are compiled, additional data sets should be added only when they have a clear benefit and pose minimal burden to the evaluation beyond that required for the claims analysis. Decisions to expand the breadth of the analysis by including additional data sources will have to be weighed against the potential for greater depth of analysis of the claims data sets.

\section{Approaches to the Impact Questions}

As shown in Table 5.3, four of the five impact questions can be addressed using claims and/or encounter data. This conclusion is based on an important assumption that might not hold for all states regarding the availability of the data over a substantial time period in a format that allows for identification of claims associated with CCBHCs and comparison groups. Analysis of questions related to the health and functioning domain will require data from a source other than claims. In this domain, only information on housing is included in the RQMs and the availability of data for comparison groups is likely to be low. Identification of data to address the impact of $\mathrm{CCBHCs}$ in this domain will be an important priority of the state profiling process. 
Table 5.3. Sources of Data for Addressing Impact Research Questions

\begin{tabular}{|c|c|c|c|c|}
\hline Domain & Impact Question & $\begin{array}{c}\text { Claims/ } \\
\text { Encounters }\end{array}$ & CR & Other State Data \\
\hline \multirow{7}{*}{ Access } & \multicolumn{4}{|l|}{$\begin{array}{l}\text { Relative to comparison groups, } \\
\text { do CCBHCs expand access to } \\
\text { behavioral health care? }\end{array}$} \\
\hline & $\begin{array}{l}\text { Are CCBHCs successful in } \\
\text { bringing consumers into } \\
\text { treatment? }\end{array}$ & $X$ & - & $\mathrm{X}$ \\
\hline & Behavioral health care? & $\mathrm{X}$ & - & $X$ \\
\hline & Other medical care? & $X$ & - & - \\
\hline & $\begin{array}{l}\text { Are CCBHCs successful in } \\
\text { providing a broader range of } \\
\text { services to their consumers? }\end{array}$ & $\mathrm{X}$ & - & - \\
\hline & Behavioral health care? & $x$ & - & - \\
\hline & Other medical care? & $x$ & - & - \\
\hline \multirow{7}{*}{ Quality } & \multicolumn{4}{|l|}{$\begin{array}{l}\text { Relative to comparison groups, } \\
\text { do CCBHCs improve the quality } \\
\text { of behavioral health care? }\end{array}$} \\
\hline & $\begin{array}{l}\text { Do consumers in CCBHCs receive } \\
\text { a broader mix of medical and } \\
\text { supportive services? }\end{array}$ & $X$ & - & - \\
\hline & Medication adherence? & $x$ & - & - \\
\hline & Rehabilitation? & $x$ & - & - \\
\hline & $\begin{array}{l}\text { Vocational/educational } \\
\text { support? }\end{array}$ & - & - & $X$ \\
\hline & Continuity of care? & $x$ & - & - \\
\hline & $\begin{array}{l}\text { Are consumers in CCBHCs more } \\
\text { likely to receive substance use } \\
\text { treatment? }\end{array}$ & $\mathrm{X}$ & - & - \\
\hline \multirow{8}{*}{ Utilization } & \multicolumn{4}{|l|}{$\begin{array}{l}\text { Relative to comparison groups, } \\
\text { do CCBHCs improve patterns of } \\
\text { total health care utilization? }\end{array}$} \\
\hline & $\begin{array}{l}\text { Are consumers treated in } \\
\text { CCBHCs more likely to receive } \\
\text { outpatient treatment for chronic } \\
\text { physical health conditions? }\end{array}$ & $X$ & - & - \\
\hline & $\begin{array}{l}\text { Are consumers treated in } \\
\text { CCBHCs less likely to be frequent } \\
\text { users of ED and inpatient } \\
\text { services? }\end{array}$ & $\mathrm{X}$ & - & - \\
\hline & For mental health care? & $x$ & - & - \\
\hline & For physical health care? & $\mathrm{X}$ & - & - \\
\hline & $\begin{array}{l}\text { Are care utilization patterns } \\
\text { different for PPS-1 and PPS-2 } \\
\text { CCBHCs? }\end{array}$ & $X$ & - & - \\
\hline & $\begin{array}{l}\text { Medicaid-covered } \\
\text { consumers? }\end{array}$ & $X$ & - & - \\
\hline & Dual eligible consumers? & $\mathrm{X}$ & - & - \\
\hline
\end{tabular}




\begin{tabular}{|c|c|c|c|c|}
\hline Domain & Impact Question & $\begin{array}{l}\text { Claims/ } \\
\text { Encounters }\end{array}$ & CR & Other State Data \\
\hline \multirow{7}{*}{$\begin{array}{l}\text { Health and } \\
\text { functioning }\end{array}$} & \multicolumn{4}{|l|}{$\begin{array}{l}\text { Relative to comparison groups, } \\
\text { do CCBHCs improve } \\
\text { consumers' health and } \\
\text { functioning outcomes? }\end{array}$} \\
\hline & Behavioral health status? & - & - & $x$ \\
\hline & Physical health status? & - & - & $x$ \\
\hline & Social functioning? & - & - & $x$ \\
\hline & Housing? & - & - & $x$ \\
\hline & Employment and schooling? & - & - & $x$ \\
\hline & Criminal justice? & - & - & $x$ \\
\hline \multirow{10}{*}{ Cost } & \multicolumn{4}{|l|}{$\begin{array}{l}\text { Relative to comparison groups, } \\
\text { do CCBHCs impact Federal and } \\
\text { State costs for behavioral } \\
\text { health services? }\end{array}$} \\
\hline & $\begin{array}{l}\text { How are clinic finances affected } \\
\text { by the CCBHC payment systems? }\end{array}$ & $x$ & $x$ & - \\
\hline & $\begin{array}{l}\text { Impact on costs of care for } \\
\text { Medicaid consumers? }\end{array}$ & $x$ & $\mathrm{x}$ & - \\
\hline & $\begin{array}{l}\text { Impact on total Medicaid } \\
\text { reimbursements? }\end{array}$ & $x$ & $X$ & - \\
\hline & $\begin{array}{l}\text { What impact does the CCBHC } \\
\text { have on costs to Medicaid? }\end{array}$ & $x$ & - & - \\
\hline & $\begin{array}{l}\text { Outpatient behavioral health } \\
\text { costs? }\end{array}$ & $x$ & - & - \\
\hline & $\begin{array}{l}\text { Other outpatient medical } \\
\text { care? }\end{array}$ & $x$ & - & - \\
\hline & ED visits and hospital stays? & $x$ & - & - \\
\hline & $\begin{array}{l}\text { Behavioral health versus } \\
\text { physical health? }\end{array}$ & $x$ & - & - \\
\hline & Total costs? & $x$ & - & - \\
\hline
\end{tabular}

SOURCE: Authors' analysis.

The analytic approach to the impact questions is likely to follow a consistent approach across domains in which outcomes will be compared between CCBHCs and comparison groups using a DD modeling approach as described earlier. Outcomes can be defined using claims for access, quality, utilization, and cost:

- access: Expansion of access to new patients can be assessed by measuring the number of patients initiating care during the CCBHC implementation period. Expansion of access to a better mix of services can be assessed using summary measures of all the behavioral health services used by Medicaid-enrolled CCBHC consumers.

- quality: Improvement in quality of care can be assessed using quality measures, including, to, the claims-based measures that states are required to report. To address the impact questions, the evaluation will need to develop specifications for each of the 
quality measures, including those reported by states. Data from other sources might be available to address the impact questions related to services not recorded in claims, such as vocation or educational support.

- utilization: Claims-based measures can be specified to assess utilization outcomes. One of the required state-based measures covers this domain, but this measure will need to be specified independently by the evaluation for the purposes of comparing outcomes between the CCBHCs and comparison groups.

- cost: Claims data can also be used to address questions related to the costs of care to Medicaid. The CR information submitted by CCBHCs can be used to address questions related to the costs of care to the clinics. Together, these two sources of data provide a strong basis for simulating the financial impact of alternative payment scenarios.

In contrast, the impact questions in the health and functioning domain will require additional data, not from claims or encounter data. Data to answer these questions are likely to be highly variable across states.

\section{State Selection}

Given limited resources for the evaluation, the evaluator might need to limit the impact analyses to a strategically selected subset of the demonstration states. A focus on fewer states will allow for more in-depth analysis and more-robust analytic results. In the following section, we discuss the factors that should be considered in selecting states for inclusion in this component of the evaluation. These recommendations balance the need to include a diversity of states with the need to focus on the states from which the evaluation is most likely to draw informative results. We list both inclusion criteria and priority factors. Inclusion criteria rule out states where data challenges are likely to impede analysis. Priority factors highlight selection factors we believe should be considered in the design.

Inclusion Criteria

- timely availability of data: The time required to produce complete data sets of claims and encounters for data analysis varies across states. Claims data acquired from CMS through the Research Data Assistance Center are generally greater than two years old. Claims data might be acquired from the states directly with much shorter time lags, but the data sets each have their own unique data structures and might require considerable cleaning and processing prior to analysis. While the amount of processing required to produce analytic data sets will affect the priority given to a state (see following section), an initial determination will need to be made that data covering the relevant time period are available.

- ability to identify CCBHC consumers: States will be required to create codes that enable consumers treated in CCBHCs to be identified in their Medicaid claims data. However, it will be important for the evaluation to independently confirm that this has been done successfully.

- availability of data on a comparison group: The ability of the evaluator to access data on a comparison group comparable to the data on the CCBHCs is also likely to vary across states. For instance, if consumers in comparison groups are more likely to be 
covered by MCOs than consumers in the CCBHCs, the analysis could be affected by differences in the information in MCO encounter records and FFS claims. If data on a comparison group are not available, it will not be possible to include a state in the impact analysis.

\section{Priority Factors}

\section{- Data issues}

- data cleaning: The extent to which the evaluator will need to process data received from the state Medicaid agencies will vary across states. Some states have developed systems for creating standardized analytic data files, and data from those states require less processing by the evaluator. Other states might not be able to provide data files that are prepared for analysis. The amount of time and resources required to prepare the data sets for analysis should be a factor in selecting states.

- encounter data: CCBHCs will be required to report encounter data in addition to the daily or monthly visit claims. These data should be granular enough to characterize the quality of care according to standard specifications. States in which the encounter data are not reported with sufficient granularity will be lower priority than states with a greater level of detailed information on the services received by $\mathrm{CCBHC}$ consumers.

- comparability of encounter data with other state claims and encounter data: CCBHCs will be reporting encounter data in addition to PPS claims, and these encounter data will be the only source of individual-level information on services received by $\mathrm{CCBHC}$ consumers. States can vary in the extent to which these encounter data record procedures in a consistent way with other reporting systems (e.g., encounters reported by other clinics for services covered by MCOs) in the state from which the comparison groups will be drawn. States that use uniform systems that allow for direct comparison of procedures across clinical settings should be given higher priority.

\section{- Comparison group issues}

- delivery system: As noted earlier, it will be helpful for the evaluator to have an understanding of the characteristics of the treatment settings and the delivery system in which the comparison group is treated. This information will be important when interpreting results, particularly when drawing conclusions across states with different delivery systems. Moreover, reforms implemented during the period of time covered by the evaluation should also be taken into account because they can affect the outcomes of the comparison group independently of the CCBHC demonstration. States in which the comparison groups can be well characterized using information from the state profiles should be given higher priority.

- alternative models of care: States can also be selected because the particular models of care in place provide particularly interesting comparisons with the CCBHC. For instance, a state with an innovative health home program that targets adults with SMI can be given higher priority because of the importance of comparing CCBHCs with this existing model. 


\section{- CCBHC design and placement}

- mix of services: CCBHCs will vary across and within states in the way in which they meet the certification criteria. For instance, some CCBHCs can provide more services on-site, while others can provide more services through contracted partners. The evaluator can select states so that the analysis can contrast different strategies for meeting the $\mathrm{CCBHC}$ criteria.

- payment systems: The evaluator can select states to ensure representation of states implementing both of the PPSs.

- geography: The evaluator should aim to include states representing a variety of geographic locations across the United States.

\section{Conclusion}

The CCBHC demonstration program addresses longstanding problems of fragmentation in behavioral health care at a time when multiple models of integration are being tested as part of far-reaching changes in the health care system through state and federal initiatives. In this context, the evaluation has the potential to impact policies in the behavioral health arena in a fundamental way, providing guidance on the value of strengthening and growing the traditional model of CMHCs through expansion of their scope and reform of their financial structure. Results of this evaluation can inform the direction of future efforts at integration of behavioral health into the health care system at this critical time of transformation.

The framework for the evaluation described in this report suggests strategies for a meaningful and efficient evaluation of the demonstration project. While there are many ways in which the elements described can be combined into an evaluation for the same total budget, the framework suggests some elements that should be considered essential (those described as core components) and some that should be considered optional (those described as supplemental). Alternative evaluation designs that meet these criteria can differ in detail and focus, but they are likely to provide policymakers with the information they need to make future decisions regarding the CCBHCs and related system delivery models for behavioral health care. 


\section{Appendix A. Planning Grant Awardees}

Table A.1. States Awarded Planning Grants and Grant Amounts, in Dollars

\begin{tabular}{|c|c|}
\hline State Awardee & Grant Amount \\
\hline Alaska & 769,015 \\
\hline California & 982,373 \\
\hline Colorado & 982,373 \\
\hline Connecticut & 982,373 \\
\hline Illinois & 982,373 \\
\hline Indiana & 982,373 \\
\hline lowa & 982,373 \\
\hline Kentucky & 982,373 \\
\hline Maryland & 982,373 \\
\hline Massachusetts & 982,373 \\
\hline Michigan & 982,373 \\
\hline Minnesota & 982,373 \\
\hline Missouri & 982,373 \\
\hline Nevada & 933,067 \\
\hline New Mexico & 982,373 \\
\hline New York & 982,373 \\
\hline New Jersey & 982,373 \\
\hline North Carolina & 978,401 \\
\hline Oklahoma & 982,373 \\
\hline Oregon & 728,054 \\
\hline Pennsylvania & 886,200 \\
\hline Rhode Island & 982,373 \\
\hline Texas & 982,373 \\
\hline Virginia & 982,373 \\
\hline Total & $22,959,824$ \\
\hline
\end{tabular}

SOURCE: Authors' analysis. 


\section{Appendix B. Required Quality Measures}

Table B.1. CCBHC-Required Measures

\begin{tabular}{|l|l|l|}
\hline \multicolumn{1}{|c|}{ Measure or Other Reporting Requirement } & \multicolumn{1}{|c|}{ Potential Source } & \multicolumn{1}{c|}{ NQF Measure } \\
\hline $\begin{array}{l}\text { Number/percentage of new clients with initial evaluation } \\
\text { provided within } 10 \text { business days, and mean number of days } \\
\text { until initial evaluation for new clients }\end{array}$ & $\begin{array}{l}\text { EHR, patient records, } \\
\text { electronic scheduler }\end{array}$ & N/A \\
\hline Patient experience-of-care survey & $\begin{array}{l}\text { MHSIP Consumer } \\
\text { survey }\end{array}$ & N/A \\
\hline Family experience-of-care survey & MHSIP Family survey & N/A \\
\hline $\begin{array}{l}\text { Preventive care and screening: adult body mass index } \\
\text { screening and follow-up }\end{array}$ & EHR, patient records & 0421 \\
\hline $\begin{array}{l}\text { Weight assessment and counseling for nutrition and physical } \\
\text { activity for children/adolescents }\end{array}$ & EHR, encounter data & 0024 \\
\hline $\begin{array}{l}\text { Preventive care and screening: tobacco use, screening, and } \\
\text { cessation intervention }\end{array}$ & EHR, encounter data & 0028 \\
\hline $\begin{array}{l}\text { Preventive care and screening: unhealthy alcohol use, } \\
\text { screening, and brief counseling }\end{array}$ & EHR, patient records & 2152 \\
\hline $\begin{array}{l}\text { Initiation and engagement of alcohol and other drug } \\
\text { dependence treatment }\end{array}$ & EHR, patient records & 0004 \\
\hline $\begin{array}{l}\text { Child and adolescent major depressive disorder: suicide risk } \\
\text { assessment }\end{array}$ & EHR, patient records & 1365 \\
\hline Adult major depressive disorder: suicide risk assessment & EHR, patient records & 0104 \\
\hline Screening for clinical depression and follow-up plan & EHR, patient records & 0418 \\
\hline Depression remission at 12 months & EHR, patient records; & 0710 \\
\hline
\end{tabular}

SOURCE: Authors' analysis. NOTE: N/A = not available.

Table B.2. State-Required Measures

\begin{tabular}{|l|l|l|}
\hline \multicolumn{1}{|c|}{ Measure or Other Reporting Requirement } & Potential Source & NQF Measure \\
\hline $\begin{array}{l}\text { Housing status (residential status at admission or start of the } \\
\text { reporting period compared to residential status at discharge or } \\
\text { end of the reporting period) }\end{array}$ & URS & N/A \\
\hline $\begin{array}{l}\text { Follow-up after discharge from the ED for mental health or } \\
\text { alcohol or other dependence }\end{array}$ & $\begin{array}{l}\text { Claims } \\
\text { data/encounter data }\end{array}$ & 2605 \\
\hline Plan all-cause readmission rate & $\begin{array}{l}\text { Claims } \\
\text { data/encounter data }\end{array}$ & 1768 \\
\hline $\begin{array}{l}\text { Diabetes screening for people with schizophrenia or bipolar } \\
\text { disorder who are using antipsychotic medications }\end{array}$ & $\begin{array}{l}\text { Claims } \\
\text { data/encounter data }\end{array}$ & 1932 \\
\hline $\begin{array}{l}\text { Adherence to antipsychotic medications for individuals with } \\
\text { schizophrenia }\end{array}$ & $\begin{array}{l}\text { Claims } \\
\text { data/encounter data }\end{array}$ & 0576 \\
\hline $\begin{array}{l}\text { Follow-up after hospitalization for mental illness, ages 21 and } \\
\text { older }\end{array}$ & $\begin{array}{l}\text { Claims } \\
\text { data/encounter data }\end{array}$ & 0576 \\
\hline $\begin{array}{l}\text { Follow-up after hospitalization for mental illness, ages } 6 \text { to 21 } \\
\text { Claims } \\
\text { data/encounter data }\end{array}$ & $\begin{array}{l}\text { Claims } \\
\text { data/encounter data }\end{array}$ & 0108 \\
\hline $\begin{array}{l}\text { Follow-up care for children prescribed attention deficit } \\
\text { hyperactivity disorder medication }\end{array}$ & $\begin{array}{l}\text { Claims } \\
\text { data/encounter data }\end{array}$ & 0105 \\
\hline Antidepressant medication management & \\
\hline
\end{tabular}

SOURCE: Authors' analysis. NOTE: N/A = not available. 


\section{Appendix C. Methods for Evaluation Design}

\section{Key Informant Discussions with Representatives from National Organizations}

\section{Selection of Informants}

A list of organizations with relevant expertise, which included specific individuals in these organizations where possible, was developed by the RAND team and shared with ASPE. The list was amended to include additional suggestions from ASPE, including suggestions of highpriority informants. Table C.1 lists the organizations. Additional informants representing MCOs were identified in our discussion with the Association for Behavioral Health and Wellness.

Table C.1. Completed Discussions with National Organizations

\section{Organization Name}

Association for Behavioral Health and Wellness

Center for Integrated Health Solutions ${ }^{a}$

National Association of State Alcohol and Drug Abuse Directors

National Association of State Medicaid Directors

National Council for Behavioral Health

NRI

National Association of County Behavioral Health and Developmental Disability Directors

$\operatorname{MCOs}(2)$

SOURCE: Authors' analysis.

${ }^{a}$ Center for Integrated Health Solutions is funded jointly by SAMHSA and the Health Resources and

Services Administration and run by the National Council for Behavioral Health.

\section{Discussions}

Questions for the discussions were developed by the RAND team and shared with ASPE for discussion and editing. A final list of discussion questions was submitted to ASPE on November 12, 2015 (Appendix B). However, the discussions were open ended and were not restricted to specific questions in the guide. Rather, the discussions drew on the questions and content areas in the guide, and we tailored questions to each informant. All discussions were held by phone and conducted by at least two RAND researchers, one leading the discussion and one taking notes. The discussions were audio recorded, with the exception of the discussions with MCOs, because of the informants' company policy.

We targeted and spoke with six national behavioral health organizations, and we were referred to two MCOs to gather more-detailed information about the flow of data between CMHCs, MCOs, and state Medicaid and behavioral health agencies (Table C.1). 


\section{Key Informant Discussions with State Officials}

\section{Selection of States}

States were evaluated based on an assessment of their planning grant proposals with respect to their sophistication in health information technology that could contribute to data collection for evaluation purposes. States were then selected to cover more- and less-sophisticated health information systems. Priority was given to states with more-sophisticated systems. In addition, states that were recommended to us by informants from national organizations were also considered for inclusion. Within each state, efforts were made to hold discussions with representatives from each state's Medicaid office and each state's department of mental health.

\section{Discussions}

Questions were developed following the same process that was used for the discussions with national organizations. The state-level discussion questions differed in that that they were more focused on the local details of data collection and reporting. All discussions were held by phone and conducted by at least two RAND researchers, one leading the discussion and one taking notes. The discussions were audio recorded with the consent of the informants. We completed discussions with representatives from nine states that received planning grants (Table C.2).

Table C.2. Completed Discussions with State Officials

\begin{tabular}{lll}
\hline State & & \multicolumn{2}{c}{ Offices Represented in Discussions } \\
& Medicaid & Mental/Behavioral Health \\
\hline State 1 & $\mathrm{X}$ & - \\
State 2 & $\mathrm{X}$ & $\mathrm{X}$ \\
State 3 & $\mathrm{X}$ & $\mathrm{X}$ \\
State 4 & $\bar{X}$ & $\mathrm{X}$ \\
State 5 & - & - \\
State 6 & - & $\mathrm{X}$ \\
State 7 & - & $\mathrm{X}$ \\
State 8 & $\mathrm{X}$ & - \\
State 9 & &
\end{tabular}

\section{Review of Existing Data and Literature}

Existing information on the status of states' infrastructure and systems to facilitate participation in the demonstration and evaluation was collected. For example, NRI maintains databases about the structure, service systems, emerging policy issues, consumer issues, and research and evaluation activities of state behavioral health systems (NRI, 2015). The State Profiling System data sets as recent as 2015 are available online; we gathered information on the capacity of grantee states to collect and track data. We also examined online resources and literature to clarify which states were currently administering consumer surveys and, of those, which tools are being used. Online sources include the websites for the National Institutes of Health, SAMHSA, and SMHAs. 


\section{Proposal Review and Abstraction}

Proposals from each of the 24 states that were awarded planning grants were obtained from SAMHSA. RAND access to the proposals is covered by a nondisclosure agreement, which restricts access to uses required for this project and publication of potentially identifiable details. We developed a proposal abstraction form based on preliminary exploratory reviews of a sample of proposals. All 24 proposals were then reviewed to abstract information, such as the number of sites proposed, the sources of data, and anticipated challenges in data collection. 


\section{Appendix D. Discussion Questions}

\section{Discussion Questions for Experts on State Systems}

\section{Utilization}

- What is the timeline for release of claims data that could be used for evaluation?

- Are the claims data used for analysis of utilization?

- What is the flow of data from clinic to state? Is there a contractor in place? How might an evaluator gain access to the data?

- What kinds of services can be distinguished in claims?

- Can claims be traced to a specific CCBHC? If not, how will this be addressed?

- Can claims from partner providers be identified?

- Will some portion of CCBHC services be covered by an MCO?

- How can encounter data be accessed? What is the timeline for their availability?

- What is the flow of data from MCOs to the state or other entities?

- What is the quality or granularity of encounter data?

- Are there current information-sharing systems in place in the state?

- How can those systems be used to track services received outside of the CCBHC?

- Can the state detect unbundling of services?

- Are Medicare claims available for Medicare-only and dually eligible consumers?

- Can Medicare be linked to Medicaid?

\section{Access to Care}

- Is access to care currently monitored/evaluated?

- What are the state's plans to monitor access?

- Can the state identify the target population of the CCBHC?

- Can use be connected to population data on the target population?

- Are there specific attempts to engage veterans? Native Americans? Other groups?

- Are there concerns about access across payer groups? MCOs?

- Will clinics use telehealth or mobile in-home services?

- Will clinics use Internet/apps to communicate with consumers?

- Can CCBHC consumers be linked to geographic data to assess access? 
Scope of Services

- What is the current scope of services provided by the clinics that will become CCBHCs?

- Do you anticipate staffing problems for any of the newly added services?

- What services will need to be added to reach certification?

- If SUD treatment is not currently provided, will it be added on site, or will the consumer be referred to a DCO?

- How will scope of services be certified?

- Will certification process be publicly reported?

- What will happen if CCBHCs fail to meet certification criteria?

\section{Quality}

- What are the current quality reporting requirements for CMHCs or similar organizations?

- Are there plans to test new quality reporting requirements for CCBHCs criteria?

- How will measures required for the state be calculated and reported?

- What sources of data will be available on quality of care provided by comparison clinics?

- Will there be information from comparison clinics to risk-adjust the quality measure comparisons?

\section{Cost/Payment}

- What are current cost-reporting requirements for CMHCs?

- What is the content of current CRs?

- How are cost data being collected for rate-setting?

- Are data being collected to update rates? Rebalance payments?

- How are outliers being defined and identified?

- How are managed care payments monitored, and what details are available?

- Will the state pay wrap payments to CCBHCs?

- What will be the challenges associated with implementing a new payment system? 


\section{Discussion Questions for National Experts}

\section{Utilization}

- How do the timeliness and quality of Medicaid claims data very across states? Are there good states?

- Are there strategies for accessing MCO encounter data?

- How well are utilization patterns assessed by EHRs?

- How does the reporting capacity of EHRs vary across states? Across clinics?

- What are the main concerns about negative effects of the payment system?

- Will rate-setting data be publicly available?

- What measures of utilization should be assessed?

\section{Access to Care}

- Are there any standardized reporting requirements related to access to care in behavioral health?

- Historically, what measures or methods have been used to assess improvements in access?

- Are there good benchmarks for assessing access to care that apply to CCBHCs?

- Are there differences across clinics that would affect expectations for access? For example, rural versus urban or hospital affiliated versus freestanding?

- Are there populations more challenging to treat because of implementation of PPS?

\section{Scope of Services}

- Which services in the scope of services are likely to be most challenging to integrate into CCBHCs?

- What models of partnership are likely to work for the CCBHC relationships with DCOs?

- How are workforce shortages likely to impact CCBHCs' ability to provide the full range of services?

- What existing models of care should be used for comparison with the CCBHC's?

- How can the scope of services a CCBHC says it provides be compared with the scope of services consumers actually receive?

- Which services in the scope of services are likely to be most challenging to implement under the PPS?

\section{Quality}

- Are there established measures that will be most useful for assessing quality?

- Do you anticipate that CCBHCs or states will have difficulty reporting required measures?

- What measures are not on the required list would be important to assess in the evaluation? 
- What aspects of quality are likely to be sensitive to changes in the payment system?

- Are there particular quality measures that should be assessed to monitor the impact of the payment system?

- How is the burden of reporting assessed?

- What quality measures are more likely to change during the evaluation time period?

- Are there measures that CCBHCs can more easily impact, for example, process measures or structural measures?

Cost

- How are effects of payment mechanisms assessed?

- Are there specific ways to assess the impact of a daily rate? Monthly rate?

- Are there important externalities that should be considered in assessing the impact of a $\mathrm{CCBHC}$ ?

\section{Discussion Questions for National Policy Advocacy Organizations}

\section{Utilization}

- What should be CCBHC goals for utilization patterns with respect to primary care? Substance use treatment?

- How should patterns of care in a CCBHC differ from previous patterns of care?

- Are there specific utilization patterns that should be core to an evaluation of a CCBHC?

\section{Access to Care}

- Can family members be involved in assessing access to care?

- What populations are of particular concern in extending access to care?

- What are reasonable goals for $\mathrm{CCBHCs}$ to achieve with respect to appointment times?

\section{Scope of Services}

- What role do peer providers play in CCBHC's?

- Are there concerns about the services that must be provided in house?

- Are staff shortages in particular areas of concern?

\section{Quality}

- What are the areas of care in which quality should be carefully addressed? 
- Are there some types of care that should be "easy" for CCBHCs?

- Are some types of care likely to be difficult?

- How is quality of peer support assessed?

- What reporting would provide evidence that clinics are providing culturally competent care?

\section{Cost}

- Do you anticipate changes in costs to caregivers/family members from CCBHC implementation?

- How are costs to caregivers/family members measured currently?

- Are there financial benefits or costs to consumers or families that an evaluation could assess? 


\section{Appendix E. Example of Data Flow}

Figure E.1 illustrates the process through which payment data for Medicaid-covered behavioral health services flow from the clinic in which they are delivered through state agencies and MCOs to the state behavioral health data warehouse in one state. There are different paths for mental health services delivered to individuals covered by FFS Medicaid, substance use treatment delivered to those covered by FFS Medicaid, and any behavioral health services covered by an MCO. Clinics submit mental health FFS claims directly to the state Medicaid office, where they are adjudicated following guidelines from the department of mental health (DMH). Claims paid to the clinic by the Medicaid office are then reported to the DMH, where they are added to the data warehouse. Substance abuse FFS claims follow a more-complicated path because they are submitted to the U.S. Department of Health and Human Services (HHS), which reviews them before they are submitted to the Medicaid office. After adjudication and payment, the claims are resubmitted to the HHS, which then reports them to the DSA, where they are entered into the data warehouse.

The flow of managed care encounter data also is different from that for claims: The initial reports from the clinic go directly to the $\mathrm{MCO}$, where they are adjudicated by the MCO's own rules. Encounters are then reported by the MCO to the state Medicaid office, which reports them to the DHHS, which reports them to DMH/DSA, where they are stored in the data warehouse. According to our informant, the data flow for encounter data does not yet run smoothly. In particular, there are problems with the reporting of encounters from the MCOs to Medicaid, despite the fact that complete reporting of encounter data is required by the MCO contracts with the state. The Medicaid agency is working to solve these reporting issues. Without these improvements, the state data warehouse would be missing a significant amount of data on behavioral health services.

According to our informant, the data initially submitted to the MCO by the clinic include as much information as the Medicaid FFS claims, but she was not certain whether the detail of the $\mathrm{MCO}$ encounter records that ultimately reach the data warehouse contains the same amount of information. However, all the clinics that could become CCBHCs are registered with Medicaid and DMH and have their own identifiers, which appear in both the claims and encounter records. State planners anticipate developing a supplemental identification system to track claims from the CCBHCs. 
Figure E.1 Flow of Medicaid Encounter Data in a Single State with FFS and Managed Care

\section{Mental Health Claims, FFS}
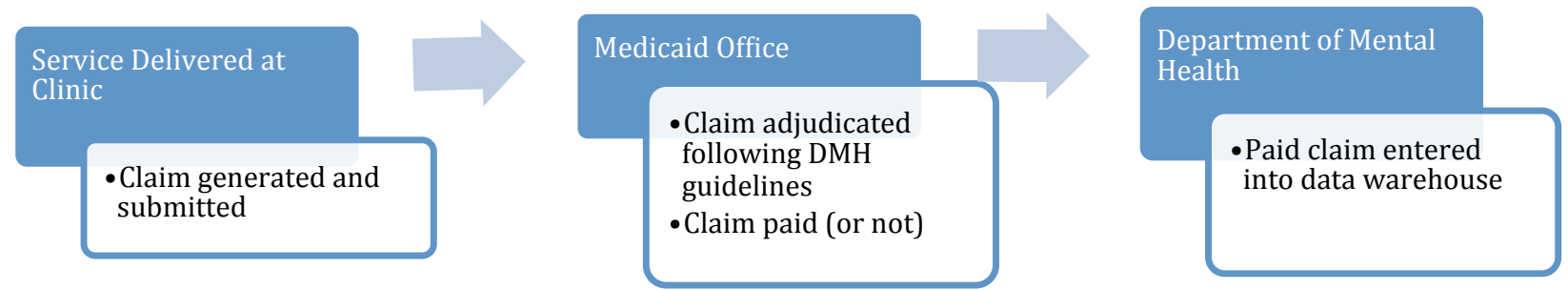

Substance Abuse Claims, FFS
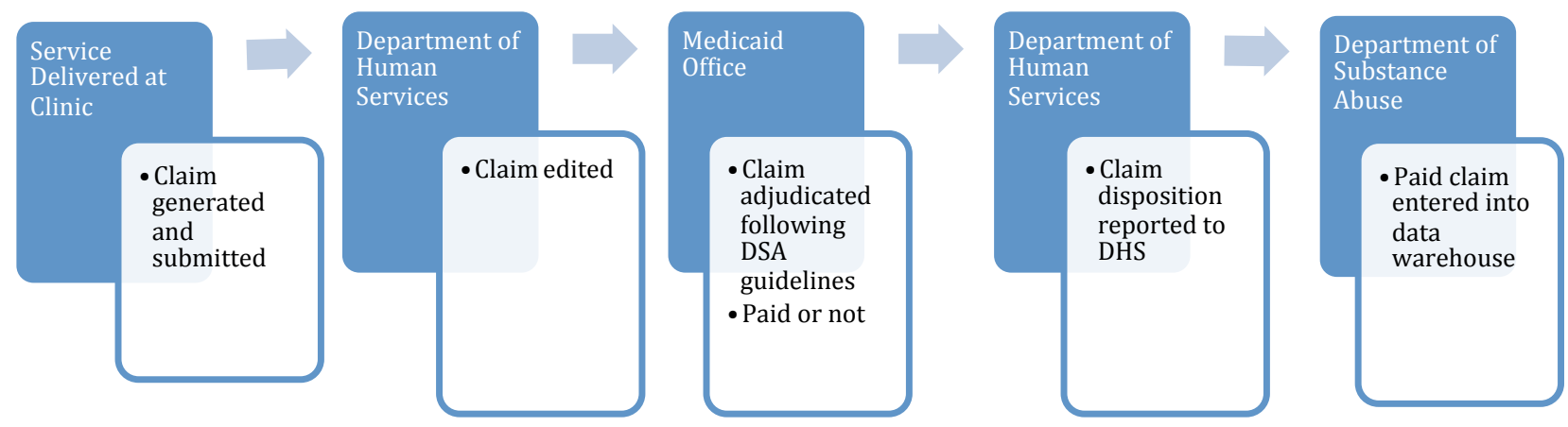

\section{Managed Care Encounters}
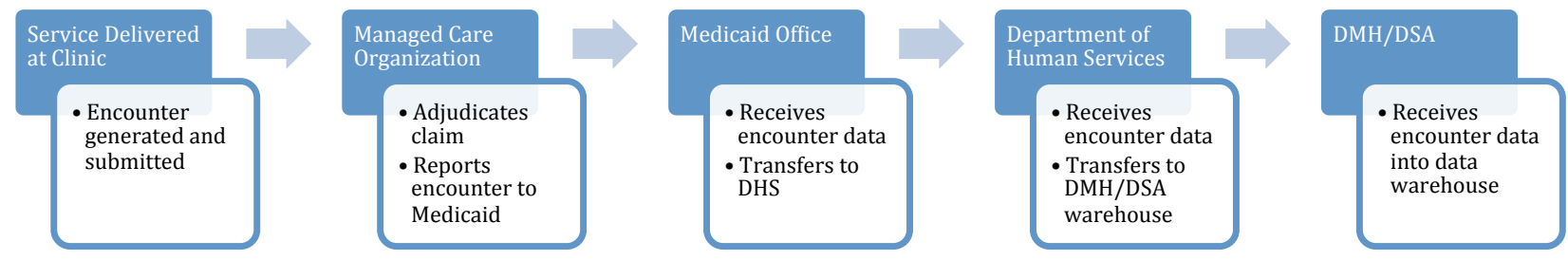

SOURCE: Authors' analysis. 


\section{Appendix F. Estimated Burden of Data Collection}

In this chapter, we provide rough estimates of the burden associated with various potential data sources for the evaluation. More-precise estimates will be possible once the demonstration states have been selected, the number of CCBHC sites has been determined, and the evaluation design has been finalized. For purposes of estimating burden at this point, we make a series of assumptions, including the following:

- number of sites: States have proposed certifying anywhere from two to 30 sites as CCBHCs. The majority of states proposed two to four sites, so we have assumed three sites per state for a total of $24 \mathrm{CCBHC}$ sites.

- evaluation period: We assume that the evaluator will be collecting non-claims-based data from the sites and states during the two-year demonstration period. Some data collection might require Office of Management and Budget clearance, so we assume that the evaluator will have received clearance by the end of the first quarter of the demonstration.

- types of data: Because reporting on quality measures annually is part of the CCBHC certification requirements, we do not include the burden associated with that effort as part of the evaluation. Similarly, CRs are required by CMS, so we do not include the associated burden.

Table F.1. Estimated Burden Hours for Potential New Data Collection

\begin{tabular}{|c|c|c|c|c|c|c|}
\hline Type of Respondent & Instrument Name & $\begin{array}{l}\text { No. of } \\
\text { Respondents }\end{array}$ & \begin{tabular}{|l} 
No. Responses \\
per \\
Respondent
\end{tabular} & \begin{tabular}{|l} 
Average \\
Burden per \\
Response (in \\
hours) \\
\end{tabular} & \begin{tabular}{|l} 
Total \\
Burden \\
Hours \\
\end{tabular} & ] Notes \\
\hline CCBHC Administrator & Quarterly Reports & 24 & 8 & 2 & 384 & Assumes average of $3 \mathrm{CCBHCs} / \mathrm{state}$ \\
\hline CCBHC Key Staff & Web/Mail Survey & 96 & 2 & 1 & 192 & $\begin{array}{l}\text { Assumes } 4 \text { staff @each clinic complete baseline } \\
\text { and f/u surveys }\end{array}$ \\
\hline CCBHC Key Staff & Phone Interviews & 48 & 1 & 1 & 48 & Assumes interviews with 2 staff at 24 CCBHCs \\
\hline Control Site Leaders & Phone Interviews & 24 & 1 & 1 & 24 & $\begin{array}{l}\text { Assumes interviews with } 1 \text { staff at } 24 \text { control } \\
\text { sites }\end{array}$ \\
\hline State Project Directors & Phone Interviews & 16 & 1 & 2 & 32 & Assumes interviews with 2 state officials/state \\
\hline CCBHC Key Staff & Site Visits & 32 & 1 & 1.5 & 48 & $\begin{array}{l}\text { Assumes site visits to } 8 \text { CCBHCs and } 1.5 \text { hour } \\
\text { discussions with } 4 \text { staff at each site }\end{array}$ \\
\hline Total Hours & & & & & 728 & \\
\hline
\end{tabular}

Source: Authors' analysis. 


\section{References}

Alakeson, Vidhya, Richard G. Frank, and Ruth E. Katz, "Specialty Care Medical Homes for People with Severe, Persistent Mental Disorders," Health Affairs, Vol. 29, No. 5, 2010, pp. $867-873$.

Audet, Anne-Marie, David Squires, and Michelle M. Doty, "Where Are We on the Diffusion Curve? Trends and Drivers of Primary Care Physicians' Use of Health Information Technology," Health Services Research, Vol. 49, No. 1, Pt. 2, 2014, pp. 347-360.

Bao, Yuhua, Lawrence P. Casalino, and Harold A. Pincus, "Behavioral Health and Health Care Reform Models: Patient-Centered Medical Home, Health Home, and Accountable Care Organization," Journal of Behavioral Health Services and Research, Vol. 40, No. 1, 2013, pp. 121-132.

Beronio, Kirsten, Sherry Glied, and Richard Frank, "How the Affordable Care Act and Mental Health Parity and Addiction Equity Act Greatly Expand Coverage of Behavioral Health Care," The Journal of Behavioral Health Services and Research, Vol. 41, No. 4, 2014, pp. 410-428.

Brown, Timothy T., Jessica Chung, Sun-Soon Choi, Richard Scheffler, and Neal Adams, "The Impact of California's Full-Service Partnership Program on Mental Health-Related Emergency Department Visits," Psychiatric Services, Vol. 63, No. 8, 2012, pp. 802-807.

Buck, Jeffrey A., "The Looming Expansion and Transformation of Public Substance Abuse Treatment Under the Affordable Care Act," Health Affairs, Vol. 30, No. 8, 2011, pp. 14021410.

Busch, Susan H., Ellen Meara, Haiden A. Huskamp, and Colleen L. Barry, "Characteristics of Adults with Substance Use Disorders Expected to Be Eligible for Medicaid Under the ACA," Psychiatric Services, Vol. 64, No. 6, 2013, pp. 520-526.

Cahoon, Elizabeth K., Emma McGinty, Daniel Ford, and Gail Daumit, "Schizophrenia And Potentially Preventable Hospitalizations In The United States: A Retrospective CrossSectional Study," BMC Psychiatry, Vol. 13, No. 37, 2013.

Centers for Health Care Strategies, "State Approaches for Integrating Behavioral Health into Medicaid Accountable Care Organizations," September 2015. As of April 26, 2016: http://www.chcs.org/resource/state-approaches-for-integrating-behavioral-health-intomedicaid-accountable-care-organizations/

Center for Medicare and Medicaid Innovation, "Financial Alignment Initiative for MedicareMedicaid Enrollees," Centers for Medicare and Medicaid Services, U.S. Department of Health and Human Services, revised January 2016. As of April 26, 2016: https://innovation.cms.gov/initiatives/Financial-Alignment/ 
Centers for Medicare and Medicaid Services, "State-by-State Health Home State Plan Amendment Matrix: Summary Overview," U.S. Department of Health and Human Services, March 2014. As of April 26, 2016:

https://www.medicaid.gov/state-resource-center/medicaid-state-technical-assistance/healthhomes-technical-assistance/downloads/hh-spa-at-a-glance-3-19-14.pdf

- "Medicaid and CHIP Application, Eligibility Determination, and Enrollment Data," web page, U.S. Department of Health and Human Services, 2016. As of April 26, 2016:

https://www.medicaid.gov/medicaid-chip-program-information/programinformation/medicaid-and-chip-enrollment-data/medicaid-and-chip-application-eligibilitydetermination-and-enrollment-data.html

Center for Mental Health Services, Mental Health, United States, 2004, Rockville, Md.:

Substance Abuse and Mental Health Services Administration, U.S. Department of Health and Human Services, Publication (SMA)-06-41952006.

CMHS-See Center for Mental Health Servives.

CMS-See Centers for Medicare and Medicaid Services.

DesRoches, Catherine M., Eric G. Campbell, Sowmya R. Rao, Karen Donelan, Timothy G. Ferris, Ashish Jha, Rainu Kaushal, Douglas E. Levy, Sara Rosenbaum, Alexandra E. Shields, and David Blumenthal, "Electronic Health Records in Ambulatory Care-A National Survey of Physicians," New England Journal of Medicine, Vol. 359, No. 1, 2008, pp. 50-60.

Dimick, Justin B., and Andrew M. Ryan, "Methods for Evaluating Changes in Health Care Policy: The Difference-in-Differences Approach," Journal of the American Medical Association, Vol. 312, No. 22, 2014, pp. 2401-2402.

Donabedian, Avedis, Explorations in Quality Assessment and Monitoring, Vol. 1: The Definition of Quality and Approaches to its Assessment, Ann Arbor, Mich.: Health Administration Press, 1980.

—, Explorations in Quality Assessment and Monitoring, Vol. 2: The Criteria and Standards of Quality, Ann Arbor, Mich.: Health Administration Press, 1982.

- "The Quality of Care: How Can It Be Assessed?" Journal of the American Medical Association, Vol. 260, No. 12, 1988, pp. 1743-1748.

Druss, Benjamin G., Steven Marcus, Jeannie Campbell, Brian Cuffel, James Harnett, Chuck Ingoglia, and Barbara Mauer, "Medical Services For Clients in Community Mental Health Centers: Results from a National Survey." Psychiatric Services, Vol. 59, No. 8, 2008, pp. 917-920.

Eisen, Susan V., James A. Shaul, Brian Clarridge, Deborah Nelson, James Spink, and Paul D. Cleary, "Development of a Consumer Survey for Behavioral Health Services," Psychiatric Services, Vol. 50, No. 6, 1999, pp. 793-798. 
Eisen, Susan V., James A. Shaul, H. Stephen Leff, Vickie Stringfellow, Brian Clarridge, and Paul D. Cleary, "Toward a National Consumer Survey: Evaluation of the CABHS and MHSIP Instruments," Journal of Behavioral Health Services and Research, Vol. 28, No. 3, 2001, pp. 347-369.

Glied, Sherry A., Bradley Stein, Thomas McGuire, Rhonda Robinson Beale, Farifteh Firoozmand Duffy, Samantha Shugarman, and Howard H. Goldman, "Measuring Performance in Psychiatry: A Call to Action," Psychiatric Services, Vol. 66, No. 8, 2015, pp. 872-878.

Goldman, Howard H., Vijay Ganju, Robert E. Drake, Paul Gorman, Michael Hogan, Pamela Hyde, and Oscar Morgan, "Policy Implications for Implementing Evidence-Based Practices," Psychiatric Services, Vol. 52, No. 12, 2001, pp. 1591-1597.

Health IT Buzz, "EHR Certification by the Numbers," web page, Office of the National Coordinator for Health Information Technology, U.S. Department of Health and Human Services, September 13, 2013. As of April 26, 2016: http://www.healthit.gov/buzz-blog/ehr-case-studies/ehr-certification-numbers/

Healthcare IT News, "Behavioral Health's EHR Conundrum," web page, March 12, 2014. As of April 26, 2016:

http://www.healthcareitnews.com/news/behavioral-healths-ehr-conumdrum-0

Healthy People, "Uniform Reporting System," web page, Office of Disease Prevention and Health Promotion, September 2010. As of April 26, 2016:

https://www.healthypeople.gov/2020/data-source/uniform-reporting-system

Henry J. Kaiser Family Foundation, “Medicaid MCO Quality Ratings 2015-2016,” web page, undated. As of April 26, 2016:

$\mathrm{http} / / / \mathrm{kff}$. org/medicaid/state-indicator/medicaid-mco-quality-ratings/

_ , "Medicaid Managed Care Penetration Rates by Eligibility Group," web page, July 1, 2015. As of April 26, 2016:

http://kff.org/medicaid/state-indicator/

managed-care-penetration-rates-by-eligibility-group/

- "Status of State Action on the Medicaid Expansion Decision," web page, March 14, 2016. As of April 26, 2016:

$\mathrm{http} / / \mathrm{kff}$.org/health-reform/state-indicator/state-activity-around-expanding-medicaid-underthe-affordable-care-act/

Hersh, William, "Health Care Information Technology: Progress and Barriers," Journal of the American Medical Association, Vol. 292, No. 18, 2004, pp. 2273-2274.

Howell, Benjamin L., Patrick Conway, and Rahul Rajkumar, "Guiding Principles for Center for Medicare and Medicaid Innovation Model Evaluations," Journal of the American Medical Association, Vol. 313, No. 23, 2015, pp. 2317-2318. 
Kahn, Katherine L., Justin W. Timbie, Mark W. Friedberg, Tara Lavelle, Peter Mendel, J. Scott Ashwood, Liisa Hiatt, Ian Brantley, Beverly A. Weidmer, Afshin Rastegar, Aaron Kofner, Rosalie Malsberger, Mallika Kommareddi, Denise D. Quigley, and Claude Messan Setodji, Evaluation of CMS's Federally Qualified Health Center (FQHC) Advanced Primary Care Practice (APCP) Demonstration: Final Second Annual Report, Santa Monica, Calif.: RAND Corporation, RR-886/1-CMS, 2015. As of April 14, 2016: http://www.rand.org/pubs/research_reports/RR886z1.html

Mark, Tami L., Lauren M. Wier, Kevin Malone, Michael Penne, and Alexander J. Cowell, "National Estimates of Behavioral Health Conditions and Their Treatment Among Adults Newly Insured Under the ACA,” Psychiatric Services, Vol. 66, No. 4, April 2015.

Mechanic, David, "Seizing Opportunities Under the Affordable Care Act for Transforming the Mental and Behavioral Health System," Health Affairs, Vol. 31, No. 2, 2012, pp. 376-382.

National Council for Behavioral Health, "Comments on Model Cost Reporting Instructions for Certified Community Behavioral Health Clinics," letter to Centers for Medicare and Medicaid Services, Office of Strategic Operations and Regulatory Affairs, October 13, 2015.

NRI, "State Mental Health Agency Data Search,” web page, undated(a). As of April 26, 2016: http://www.nri-incdata.org/

_ , "Current and Past Projects," web page, undated(b). As of April 26, 2016: http://www.nri-inc.org/\#!projects/c10ry

- "Uniform Reporting System and Client-Level Data," web page, undated(c). As of April 26, 2016:

http://www.nri-inc.org/\#! urs-client-level-data/cz01

, "State Mental Health Agency Profiling System: 2015," web page, 2015. As of April 26, 2016: http://www.nri-incdata.org/Profiles.cfm?State=All\&Year=15\&Keyword=

__, "2014 State Reporting of Adult MHSIP Survey Results and Survey Methodology/Sample Information,” Excel file, February 2016.

Nutting, Paul A., William L. Miller, Benjamin F. Crabtree, Carlos Roberto Jaen, Elizabeth Stewart, and Kurt C. Stange, "Initial Lessons from the First National Demonstration Project on Practice Transformation to a Patient-Centered Medical Home," Annals of Family Medicine, Vol. 7, No. 3, 2009, pp. 254-260.

Office of Inspector General, Not All States Reported Medicaid Managed Care Encounter Data as Required, U.S. Department of Health and Human Services, OEI-07-13-00120, July 2015. As of April 26, 2016:

http://oig.hhs.gov/oei/reports/oei-07-13-00120.pdf

Office of the National Coordinator of Health Information Technology, "Certified Health IT Product List, Version 4.0," web page, U.S. Department of Health and Human Services, 2014. 
As of April 26, 2016:

http://oncchpl.force.com/ehrcert/Search

- "Interoperability Among U.S. Non-Federal Acute Care Hospitals, 2014," U.S.

Department of Health and Human Services, Data Brief, No. 25, August 2015. As of April 26, 2016:

https://www.healthit.gov/sites/default/files/briefs/

onc databrief 25 interoperabilityv16final 081115.pdf

ONC - See Office of the National Coordinator of Health Information Technology.

Patel, Milesh M., Jonathan D. Brown, Sarah Croake, Rita Lewis, Junqing Liu, Lisa Patton, D. E. B. Potter, and Sarah Hudson Scholle, "The Current State of Behavioral Health Quality Measures: Where Are the Gaps?” Psychiatric Services, Vol. 66, No. 8, 2015, pp. 865-871.

Public Law 104-13, Paperwork Reduction Act of 1995, May 22, 1995. As of June 1, 2016 : https://www.gpo.gov/fdsys/granule/PLAW-104publ13/PLAW-104publ13/content-detail.html

Public Law 110-343, Tax Extenders and Alternative Minimum Tax Relief Act of 2008, October 3, 2008. As of May 31, 2016:

https://www.gpo.gov/fdsys/granule/PLAW-110publ343/PLAW-110publ343/contentdetail.html

Public Law 111-148, Patient Protection and Affordable Care Act, March 23, 2010. As of May 31, 2016:

https://www.gpo.gov/fdsys/granule/PLAW-111publ148/PLAW-111publ148/contentdetail.html

Public Law 113-93, Protecting Access to Medicare Act of 2014, April 1, 2014. As of June 1, 2016:

https://www.gpo.gov/fdsys/granule/PLAW-113pub193/PLAW-113pub193/content-detail.html

Rosenheck, Robert, "Cost-Effectiveness of Services for Mentally Ill Homeless People: The Application of Research to Policy and Practice," American Journal of Psychiatry, Vol. 157, No. 10, 2000, pp. 1563-1570.

Rowe, Michael, Thomas Styron, and Daryn H. David, "Mental Health Outreach to Persons Who Are Homeless: Implications for Practice from a Statewide Study," Community Mental Health Journal, Vol. 52, No. 1, 2016, pp. 56-65.

SAMHSA—See Substance Abuse and Mental Health Services Administration.

Smith, Mary E., and Vijay Ganju, Sampling and the MHSIP Consumer Surveys: Techniques, Models, Issues, NRI State Data Infrastructure Coordinating Center, white paper, 2008. As of April 26, 2016:

http://citeseerx.ist.psu.edu/viewdoc/download?doi=10.1.1.392.4393\&rep=rep1\&type=pdf 
Substance Abuse and Mental Health Services Administration, "Quick Statistics from the Drug and Alcohol Services Information System: Treatment Episode Data Set," web page, undated. As of April 26, 2016:

http://wwwdasis.samhsa.gov/webt/information.htm

, Results from the 2009 National Survey on Drug Use and Health: Mental Health

Findings, Rockville, Md.: Office of Applied Studies, U.S. Department of Health and Human Services, NSDUH Series H-39, HHS Publication SMA 10-46092010, 2010,

, "Criteria for the Demonstration Program to Improve Community Mental Health Centers and to Establish Certified Community Behavioral Health Clinics," U.S. Department of Health and Human Services, 2015a. As of April 26, 2016:

http:/www.samhsa.gov/sites/default/files/programs_campaigns/ccbhc-criteria.pdf

- Funding and Characteristics of Single State Agencies for Substance Abuse Services and State Mental Health Agencies, 2013, Rockville, Md.: U.S. Department of Health and Human Services, Publication (SMA) 15-4926, 2015b. As of April 26, 2016: http://store.samhsa.gov/shin/content//SMA15-4926/SMA15-4926.pdf

Teague, Gregory B., Vijay Ganju, John A. Hornik, J. Rock Johnson, and Jacki McKinney, “The MHSIP Mental Health Report Card: A Consumer-Oriented Approach to Monitoring the Quality of Mental Health Plans," Evaluation Review, Vol. 21, No. 3, 1997, pp. 330-341.

Washington Institute for Mental Health Research and Training, "Quality of Life Measures: Mental Health Services and Consumer Satisfaction Summary,” Mental Health Statistics Improvement Program Surveys project, University of Washington, 2013. As of April 26, 2016:

https://depts.washington.edu/pbhjp/projects-programs/page/ mental-health-statistics-improvement-program-mhsip-surveys 